\title{
Kinematics of galaxies in compact groups
}

\section{Studying the $B$-band Tully-Fischer relation $\star, \star \star$}

\author{
S. Torres-Flores ${ }^{1,2}$, C. Mendes de Oliveira ${ }^{1}$, P. Amram ${ }^{2}$, H. Plana ${ }^{2,3}$, B. Epinat ${ }^{4}$, C. Carignan ${ }^{5,6}$, and C. Balkowski ${ }^{7}$ \\ 1 Departamento de Astronomia, Instituto de Astronomia, Geofísica e Ciências Atmosféricas da USP, Rua do Matão 1226, \\ Cidade Universitária, 05508-090 São Paulo, Brazil \\ e-mail: storres@astro.iag.usp.br \\ 2 Laboratoire d'Astrophysique de Marseille, OAMP, Université de Provence \& CNRS, 38 rue F. Joliot-Curie, \\ 13388 Marseille Cedex 13, France \\ 3 Laboratório de Astrofísica Teórica e Observacional, Universidade Estadual de Santa Cruz, Ilheus, Brazil \\ ${ }^{4}$ Laboratoire d'Astrophysique de Toulouse-Tarbes, Université de Toulouse \& CNRS, 14 avenue Edouard Belin, \\ 31400 Toulouse, France \\ 5 Laboratoire d'Astrophysique Expérimentale (LAE), Observatoire du Mont Mégantic, and Département de Physique, \\ Université de Montréal, CP 6128, Succ. Centre-Ville, H3C 3J7, Montréal, QC, Canada \\ 6 Observatoire d'Astrophysique de l'Université de Ouagadougou (UFR/SEA), 03 BP 7021 Ouagadougou 03, Burkina Faso \\ 7 GEPI, Observatoire de Paris, Paris University Denis Diderot \& CNRS, 5 place Jules Janssen, Meudon, France
}

Received 18 December 2009 / Accepted 26 February 2010

\section{ABSTRACT}

\begin{abstract}
We obtained new Fabry-Perot data cubes and derived velocity fields, monochromatic, and velocity dispersion maps for 28 galaxies in the Hickson compact groups 37, 40, 47, 49, 54, 56, 68, 79, and 93. We also derived rotation curves for 9 of the studied galaxies, 6 of which are strongly asymmetric. Combining these new data with previously published 2D kinematic maps of compact group galaxies, we investigated the differences between the kinematic and morphological position angles for a sample of 46 galaxies. We find that one third of the unbarred compact group galaxies have position angle misalignments between the stellar and gaseous components. This and the asymmetric rotation curves are clear signatures of kinematic perturbations, probably because of interactions among compact group galaxies. A comparison between the $B$-band Tully-Fisher relation for compact group galaxies and for the GHASP field-galaxy sample shows that, despite the high fraction of compact group galaxies with asymmetric rotation curves, these lay on the TF relation defined by galaxies in less dense environments, although with more scatter. This agrees with previous results, but now confirmed for a larger sample of 41 galaxies. We confirm the tendency for compact group galaxies at the low-mass end of the Tully-Fisher relation (HCG 49b, 89d, 96c, 96d, and 100c) to have either a magnitude that is too bright for its mass (suggesting brightening by star formation) and/or a low maximum rotational velocity for its luminosity (suggesting tidal stripping). These galaxies are outside the Tully Fisher relation at the $1 \sigma$ level, even when the minimum acceptable values of inclinations are used to compute their maximum velocities. Including such galaxies with $v<100 \mathrm{~km} \mathrm{~s}^{-1}$ in the determination of the zero point and slope of the compact group $B$-band Tully-Fisher relation would strongly change the fit, making it different from the relation for field galaxies, which has to be kept in mind when studying scaling relations of interacting galaxies, especially at high redshifts.
\end{abstract}

Key words. galaxies: evolution - galaxies: interactions - galaxies: kinematics and dynamics - galaxies: groups: general

\section{Introduction}

Compact groups of galaxies are environments in which tidal encounters are thought to be common. It is, therefore, expected that interactions have stripped or disturbed such systems at some level. Mendes de Oliveira et al. (2003) studied the Tully-Fisher (TF) relation for 25 compact group galaxies and highlighted the importance of having $2 \mathrm{D}$ velocity fields, as derived from the $\mathrm{H} \alpha$ line, in the study of TF of interacting galaxies. They find similar TF relations for compact group and field galaxies and stress that a fine tuning of the kinematic parameters is needed to have meaningful rotation curves for interacting galaxies. This is highly relevant for studying the evolution of the TF relation as a function of redshift, given that at high redshifts the numbers of interacting galaxies raise considerably. We are gathering a large dataset of Fabry-Perot velocity maps for interacting

^ Based on observations collected at the European Southern Obervatory, La Silla, Chile.

$\star \star$ Appendices are only available in electronic form at http://www . aanda. org galaxies at low redshifts which allows the study of the effects of the environment on galaxy evolution in high density structures like compact groups of galaxies ${ }^{1}$. With this goal in mind, we studied the properties of the galaxies in these systems in previous papers, pointing out interaction indicators for individual galaxies (e.g. Mendes de Oliveira et al. 1998), the evolution of the $B$-band TF relation (Mendes de Oliveira et al. 2003), the distribution of luminous and dark mass profiles of compact group galaxies (Plana et al. 2010).

The present study complements the sample of compact group galaxies with measured velocity maps presented by Plana et al. (1998, 2000, 2003), Mendes de Oliveira et al. (1998), Amram et al. (2003, 2004, 2007), and Torres-Flores et al. (2009). We present for the first time velocity maps for galaxies in nine Hickson compact groups (HCGs 37, 40, 47, 49, 54, 56, 68, 79, and 93.) and we revisit the $B$-band TF relation for a sample of 41 Hickson compact group galaxies, including a comparison with the GHASP sample of field galaxies, for which $2 \mathrm{D}$ velocity

\footnotetext{
${ }^{1}$ http://fabryperot.oamp.fr
} 
fields, derived from the $\mathrm{H} \alpha$ line, are also available (Epinat et al. 2008b).

\section{Observation and data reduction}

\subsection{The sample}

We obtained new Fabry-Perot data for galaxies in the following Hickson compact groups (HCG) HCG 37, HCG 40, HCG 47, HCG 49, HCG 54, HCG 56, HCG 68, HCG 79, and HCG 93. This sample is composed of nearby groups from the sample of Hickson et al. (1992), with radial systemic velocities lower than $10500 \mathrm{~km} \mathrm{~s}^{-1}$. To study the relation between kinematic and morphological parameters, we considered the galaxies in this study for which it was possible to determine the kinematic parameters (11 galaxies of a total of 28). In addition, we considered the systems studied in Torres-Flores et al. (2009, 7 galaxies) and those of Mendes de Oliveira et al. (2003, 32 galaxies), for which kinematic and morphological measurements could be made or were already available in the literature. In some cases, there was no information about the kinematic position angle and inclination of the galaxies (HCG 10a, 88c and 2c, 10a, 22c, 40e, 88c, respectively). In other cases, no error bars for the position angle and inclinations were quoted (HCG 7c and 79d). All these objects were excluded from our analysis. Finally, we compared kinematic and morphological position angles for 46 galaxies and kinematic and morphological inclinations for 43 galaxies.

In the case of the $B$-band TF relation, we considered the galaxies of this study ( 9 galaxies with measured rotation curves of a total of 28), 7 galaxies from Torres-Flores et al. (2009) and 25 galaxies (of a total of 32 galaxies) studied by Mendes de Oliveira et al. (2003). For HCG 79d, we did not derive its rotation curve and kinematic parameters, given that they had already been published in Mendes de Oliveira et al. (2003).

\subsection{Observations}

The observations were carried out using a Fabry-Perot instrument mounted either on the Canada France Hawaii telescope (MOSFP, Amram et al. 2003) or on the European Southern Observatory $3.6 \mathrm{~m}$ telescope (CIGALE, Amram et al. 1991), using a CCD or a photon counting system respectively. The observed compact groups, exposure times, and scanning wavelengths are listed in Table 1. A journal of the observations is given in Table 2.

\subsection{Data reduction}

The reduction method we used was the same as the one applied to the GHASP sample in Epinat et al. (2008a,b), who used the reduction package developed by Daigle et al. (2006). The output of this package consists of monochromatic, continuum, dispersion, and radial velocity maps. This procedure includes several improvements with respect to the data reduction and analysis performed to the data presented in Plana et al. (2003) and Amram et al. (2003), listed in the following. First, the present procedure uses an adaptive spatial binning to the data based on the 2D Voronoi tessellation method (see Cappellari \& Copin 2003) applied to the $3 \mathrm{D}$ data cubes, optimizing the determination of the spatial resolution. In this process, the signal-to-noise ratio (SNR) of a bin is computed every time a new pixel is added to the bin. When a required SNR (previously defined by the user) is reached, no more pixels are added to the analyzed bin. Second, the velocity field is automatically cleaned; i.e., all the residual
Table 1. Journal of observations.

\begin{tabular}{cccc}
\hline \hline HCG & $\begin{array}{c}\text { Telescope \& } \\
\text { date of observation }\end{array}$ & $\begin{array}{c}\text { Exp. time } \\
\text { (hours) }\end{array}$ & $\begin{array}{c}\text { Obj. scan } \\
\text { wavelength }(\AA)\end{array}$ \\
\hline 2ab & ESO Sep. 2000 & 1.2 & 6657 \\
2c & ESO Sep. 2000 & 0.9 & 6657 \\
$7 \mathrm{ad}$ & ESO Sep. 2000 & 1.5 & 6655 \\
$7 \mathrm{bd}$ & ESO Sep. 2000 & 0.9 & 6655 \\
22bc & ESO Sep. 2000 & 1.1 & 6621 \\
37a & CFHT March 2000 & 2.1 & 6710 \\
$37 \mathrm{~d}$ & CFHT March 2000 & 2.1 & 6710 \\
40 & CFHT March 2000 & 1.9 & 6709 \\
47 & CFHT March 2000 & 2.3 & 6771 \\
49 & CFHT March 2000 & 2.3 & 6780 \\
54 & CFHT March 2000 & 1.9 & 6594 \\
56 & CFHT March 2000 & 2.3 & 6747 \\
$68 \mathrm{ab}$ & CFHT March 2000 & 1.9 & 6613 \\
$68 \mathrm{c}$ & CFHT March 2000 & 1.9 & 6616 \\
79 & CFHT Aug. 1996 & 1.2 & 6661 \\
$93 \mathrm{ac}$ & CFHT Aug. 1996 & 1.2 & 6675 \\
$93 \mathrm{~b}$ & CFHT Aug. 1996 & 1.2 & 6665 \\
\hline
\end{tabular}

features that are not linked with emission lines in the objects in the groups are removed. Third, we compute the astrometric correction comparing stars in DSS images with the continuum image generated from the cube using KOORDS task in KARMA software. In the present work, the SNR was estimated using the square root of the flux. When the addition of pixels gave an SNR of 6 or 8 (for photon counting system or CCD, respectively), no more pixels were added to the bin. We used Gaussians to achieve spectral smoothing. Wavelength calibrations were obtained by scanning the narrow Ne $6599 \AA$ line under the same conditions as the observations. The $\mathrm{OH}$ subtraction was performed by estimating the sky using the medium spectrum of the data cube.

\section{Data analysis}

\subsection{Morphological and kinematic parameters}

Inclinations, position angles, and galactic centers can be determined either from the morphology (using broad-band imaging) or from the kinematics (using the velocity field). The morphological inclinations have been computed using the axial ratio $\cos (b / a)=i$, where $b$ and $a$ are the optical diameters at the 25 mag $\mathrm{arc}^{-2}$ isophote (Hickson 1993). Because of distorted morphologies of the compact group galaxies, we avoided using the morphological type of the galaxy for computing the inclinations. The morphological centers we estimated using either the center of best ellipse fitting or the flux peak in the continuum image. Due to the asymmetries in the morphology, we used the second method. The morphological PAs were estimated using best ellipse fitting on the continuum image at the isophote of $25 \mathrm{mag} \operatorname{arcsec}^{-2}\left(R_{25}\right)$.

Kinematic centers, inclinations, PAs, and systemic velocities were estimated from the velocity fields using the procedure developed in Epinat et al. (2008a). We list these parameters in Table 3 . The procedure we used to determine these parameters follows three different steps. In a first attempt, all the kinematic parameters were estimated automatically. In a second one, we fixed the center using the morphological center and we allowed the inclination and position angle of the galaxies to be automatically measured in the computation process (from the velocity fields). In a final attempt, we left only the position angle free, to be obtained from the velocity map, and we fixed the center and 
Table 2. Instrumental setup.

\begin{tabular}{|c|c|c|c|}
\hline \multirow{2}{*}{$\begin{array}{l}\text { Parameters } \\
\text { HCG observation: }\end{array}$} & \multicolumn{3}{|c|}{ Values } \\
\hline & & & \\
\hline Telescope & CFHT $3.6 \mathrm{~m}$ & CFHT $3.6 \mathrm{~m}$ & ESO $3.6 \mathrm{~m}$ \\
\hline Equipment & MOS/FP & MOS/FP & CIGALE \\
\hline Date & 1996 Aug. & 2000 Mar. & 2000 Sep. \\
\hline Calibration: & & & \\
\hline Neon light & $\lambda 6598.95 \AA$ & $\lambda 6598.95 \AA$ & $\lambda 6598.95 \AA$ \\
\hline Interferometer order at $\mathrm{H} \alpha$ & 1162 & 1162 & 793 \\
\hline Free spectral range at $\mathrm{H} \alpha\left(\mathrm{km} \mathrm{s}^{-1}\right)$ & 265 & 258 & 378 \\
\hline Sampling: & & & \\
\hline Number of scanning steps & 24 & 28 & 32 \\
\hline Sampling steps $\AA\left(\mathrm{km} \mathrm{s}^{-1}\right)$ & $0.24(11.0)$ & $0.21(9.2)$ & $0.26(11.8)$ \\
\hline Detector: & CCD & CCD & IPCS \\
\hline
\end{tabular}

Table 3. Kinematic properties of the sample

\begin{tabular}{|c|c|c|c|c|c|c|c|c|c|c|c|}
\hline (1) & (2) & (3) & (4) & (5) & (6) & (7) & (8) & (9) & (10) & (11) & (12) \\
\hline HCG & Galaxy & $\begin{array}{c}\mathrm{PA}_{\text {kin }} \\
\mathrm{deg}\end{array}$ & $\begin{array}{c}\mathrm{PA}_{\text {morph }} \\
\text { deg }\end{array}$ & $\begin{array}{c}\mathrm{PA}_{\text {morph }} \\
\text { deg }\end{array}$ & $\begin{array}{l}i_{\text {kin }} \\
\text { deg }\end{array}$ & $\begin{array}{c}i_{\text {morph }} \\
\text { deg }\end{array}$ & $\begin{array}{c}i_{\text {morph }} \\
\text { deg }\end{array}$ & $\begin{array}{l}V_{\text {sysHICK }} \\
\mathrm{km} \mathrm{s}^{-1}\end{array}$ & $\begin{array}{c}V_{\text {sysFP }} \\
\mathrm{km} \mathrm{s}^{-1}\end{array}$ & $\begin{array}{c}\text { vvir } \\
\mathrm{km} \mathrm{s}^{-1}\end{array}$ & $\begin{array}{c}\delta c_{\text {kin-morph }} \\
\operatorname{arcsec}\end{array}$ \\
\hline \multirow[t]{3}{*}{2} & $\mathrm{a}$ & $42 \pm 4$ & 3 & $8 \pm 13$ & $68 \pm 13$ & $61 \pm 2$ & 65 & 4326 & 4347 & 4375 & 42.2 \\
\hline & b & $5 \pm 3$ & 28 & $3 \pm 90$ & $49 \pm 12$ & $30 \pm 21$ & 43 & 4366 & 4357 & 4365 & 1.3 \\
\hline & $\mathrm{c}$ & $168 \pm 4$ & 132 & $158 \pm 18$ & & $57 \pm 3$ & 64 & 4235 & 4266 & 4284 & 2.4 \\
\hline \multirow[t]{2}{*}{7} & $\mathrm{a}$ & $179 \pm 2$ & 153 & $165 \pm 13$ & $67 \pm 3$ & $61 \pm 2$ & 76 & 4210 & 4198 & 4178 & 0.6 \\
\hline & d & $85 \pm 3$ & 58 & $35 \pm 34$ & $31 \pm 12$ & $43 \pm 7$ & 44 & 4116 & 4104 & 4081 & 12.3 \\
\hline 22 & $\mathrm{c}$ & $101 \pm 2$ & 70 & $179 \pm 90$ & $\ldots$ & $25 \pm 14$ & 90 & 2728 & 2572 & 2444 & 6.8 \\
\hline 37 & $\mathrm{~d}$ & $68 \pm 4$ & 58 & $108 \pm 90$ & $60 \pm 15$ & $38 \pm 29$ & 36 & 6207 & 6308 & 6236 & 0.8 \\
\hline \multirow[t]{2}{*}{40} & $\mathrm{c}$ & $120 \pm 2$ & 125 & $134 \pm 8$ & $74 \pm 4$ & $75 \pm 2$ & 90 & 6890 & 6888 & 6341 & 1.6 \\
\hline & $\mathrm{e}$ & $8 \pm 10$ & 72 & $57 \pm 21$ & $\cdots$ & $70 \pm 6$ & 80 & 6625 & $\cdots$ & 6383 & 0.0 \\
\hline \multirow[t]{2}{*}{47} & a & $42 \pm 3$ & 42 & $14 \pm 25$ & $24 \pm 11$ & $47 \pm 5$ & 67 & 9581 & 9507 & 9622 & $\ldots$ \\
\hline & $\mathrm{d}$ & $15 \pm 1$ & 165 & $174 \pm 54$ & $16 \pm 4$ & $39 \pm 12$ & 32 & 9471 & 9325 & 9533 & $\ldots$ \\
\hline \multirow[t]{3}{*}{49} & $\mathrm{a}$ & $42 \pm 8$ & 57 & $49 \pm 90$ & $18 \pm 10$ & $22 \pm 23$ & 43 & 9939 & 9812 & 10196 & 9.1 \\
\hline & b & $91 \pm 3$ & 72 & $85 \pm 31$ & $51 \pm 7$ & $49 \pm 7$ & 59 & 9930 & 9787 & 10190 & 4.5 \\
\hline & $\mathrm{c}$ & $175 \pm 4$ & 98 & $100 \pm 90$ & $11 \pm 6$ & $39 \pm 31$ & 45 & 9926 & 9784 & 10185 & 23.7 \\
\hline 56 & $\mathrm{a}$ & $174 \pm 1$ & 172 & $173 \pm 7$ & $75 \pm 3$ & $75 \pm 1$ & 90 & 8245 & 8374 & 8455 & 1.6 \\
\hline 68 & $\mathrm{c}$ & $31 \pm 1$ & 119 & $34 \pm 25$ & $30 \pm 4$ & $36 \pm 4$ & 54 & 2313 & 2515 & 2550 & 1.0 \\
\hline \multirow[t]{2}{*}{93} & b & $173 \pm 4$ & 156 & $39 \pm 8$ & $79 \pm 6$ & $70 \pm 1$ & 68 & 4672 & 4625 & 4776 & 1.3 \\
\hline & NGC 92 & $146 \pm 2$ & 149 & $149 \pm 12$ & $48 \pm 6$ & $63 / 62 \pm 2$ & 70 & 3219 & 3412 & 3132 & 0.7 \\
\hline
\end{tabular}

Notes. Column (1): group number. Column (2): Galaxy member of the group. Column (3): PA deduced from our velocity field. Column (4): PA taken from Mendes de Oliveira (1992) for HCG. This was determinated for semimajor axis lengths of $2 h^{-1} \mathrm{kpc}$ for all Hickson group galaxies with $z \leq 0.05$. Column (5): optical PA taken from HyperLeda. PA is the position angle of the major axis of the isophote $25 \mathrm{mag}^{-a_{c s e c}-2}$ in the $B$-band. Column (6): inclination deduced from the analysis of our velocity field. Column (7): morphological inclination deduced from the axis ratio of the isophote $25 \mathrm{mag} \operatorname{arcsec}^{-2}$ in the $B$-band for galaxies $(\cos (b / a)=i)$. For NGC 92 given values correspond to HyperLeda/NED. Column (8): morphological inclination taken from HyperLeda. Column (9): systemic velocity taken from Hickson (1993). Column (10): systemic velocity deduced from our velocity field analysis. Column (11): radial velocity corrected by the Virgo infall from HyperLeda. Column (12): difference in arcseconds between the morphologial and kinematic centers.

the inclination, using the morphological values. From these three steps, we concluded that by using the morphological inclination and center and the kinematic PA we obtain more symmetrical rotation curves than in other cases.

In Figs. 1 to 3 we plot comparisons of the kinematicallyand morphologically-derived position angles, inclination, and centers of the compact group galaxies. We included HCG 91c1 and $91 \mathrm{c} 2$ as two differents points in the diagrams, as studied by Mendes de Oliveira et al. (2003). In Fig. 3 we did not plot galaxies HCG $47 \mathrm{a}$ and $47 \mathrm{~d}$, given that the automatic routine was not able to find the correct kinematic centers for these galaxies.

Figure 1 (top panel) shows that there is relatively good agreement between the kinematically and morphologically derived inclinations, except in a few cases. Nevertheless, because the velocity fields are not regular enough, the inclination can't be safely determined from the kinematics. Thus, in the following analysis, we preferred to use the morphological inclination deduced from the optical images, which are usually more symmetric.

In Fig. 1 (bottom panel), the histogram shows 11 galaxies having a difference in inclination between the morphologically and kinematically derived values (delta $i$ ) of more than 15 degrees. These are HCG 2b, 10c, 16d, 19b, 37d, 47a, 47d, $49 \mathrm{c}, 89 \mathrm{~b}$, and $89 \mathrm{c}$.

The position angle for the GHASP galaxies (Epinat et al. 2008a) was determined through an automatic procedure using the velocity fields of the galaxies, which worked well for isolated galaxies. We made similar tests for the compact group sample and concluded that the automatic estimates using the velocity fields are robust. We checked the quality of the kinematic position angle determination by visual inspection. 

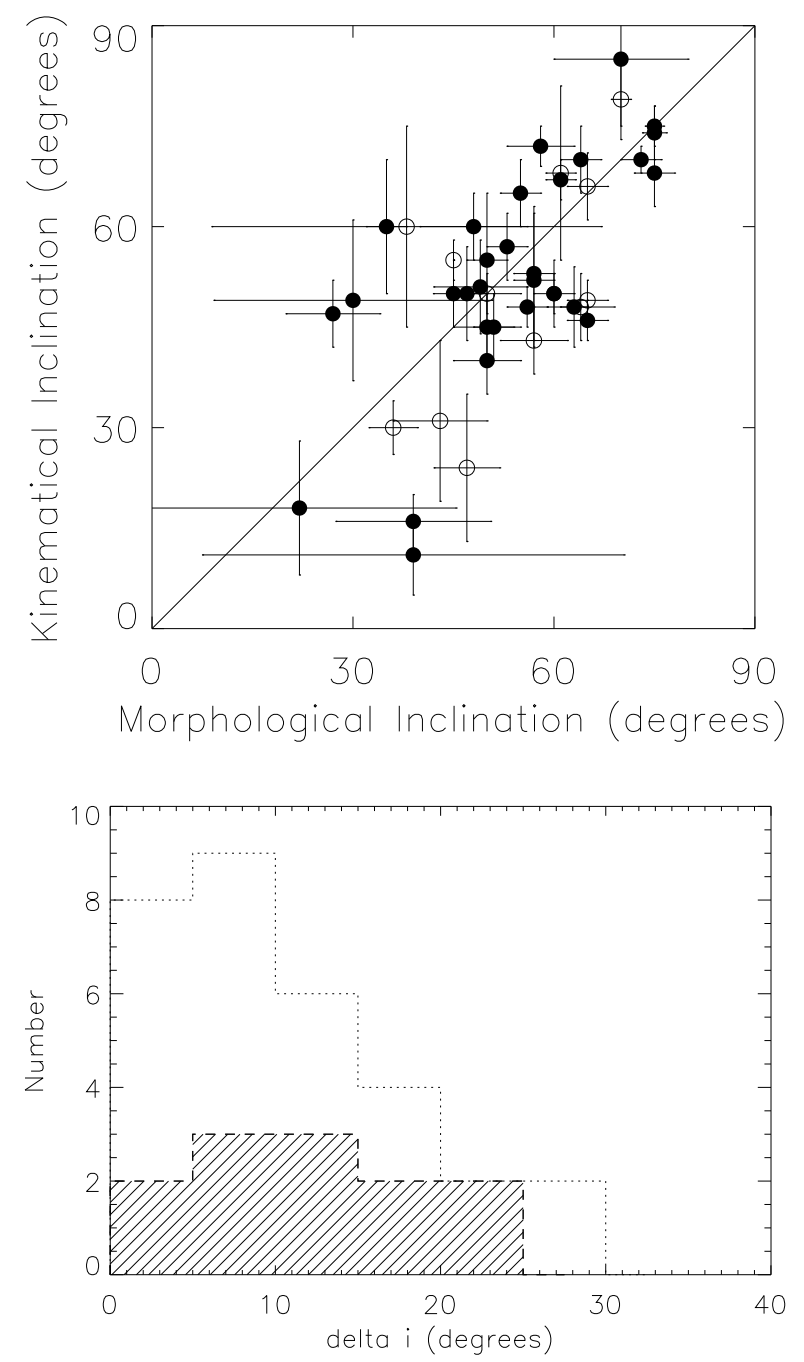

Fig. 1. Top panel: kinematic versus morphological inclination for the 43 HCG galaxies with measured inclinations. Open circles correspond to the barred and filled ones to the unbarred galaxies respectively. Bottom panel: histogram of the differences between the kinematically and morphologically-derived inclinations. Unbarred galaxies are represented by a dotted line (open histogram). Dashed lines represent barred galaxies (filled histogram).

Figure 2 (top panel) shows that optical PAs have large error bars. On the other hand, kinematic PAs present error bars smaller than 10 degrees. This led us to use the kinematic PA in this study.

In Fig. 2 (bottom panel) we show the histogram of the differences between the kinematically- and photometricallydetermined position angles. Most of the unbarred galaxies have delta PA lower than 20 degrees, while the barred galaxies do not show any trend in the plot. The delta PA for barred galaxies span from 0 to 80 degrees with no peak in the distribution. Peirani et al. (2009) find that given specific initial conditions, an interaction between two galaxies having a mass ratio of 1:3 could produce a bar. In view of this result, we can't exclude as interacting objects the barred galaxies that present a misalignment between the optical and kinematic position angles lower than 20 degrees. In the case of galaxies with delta PA higher than 20 degrees, it could be easily associated with galaxy-galaxy interactions.

In Fig. 3, the histogram shows the difference (in arcsec) between the kinematic and morphological center for each galaxy, when all parameters (inclination, position angle and center) are not fixed, i.e., are left for the program to fit. These values are
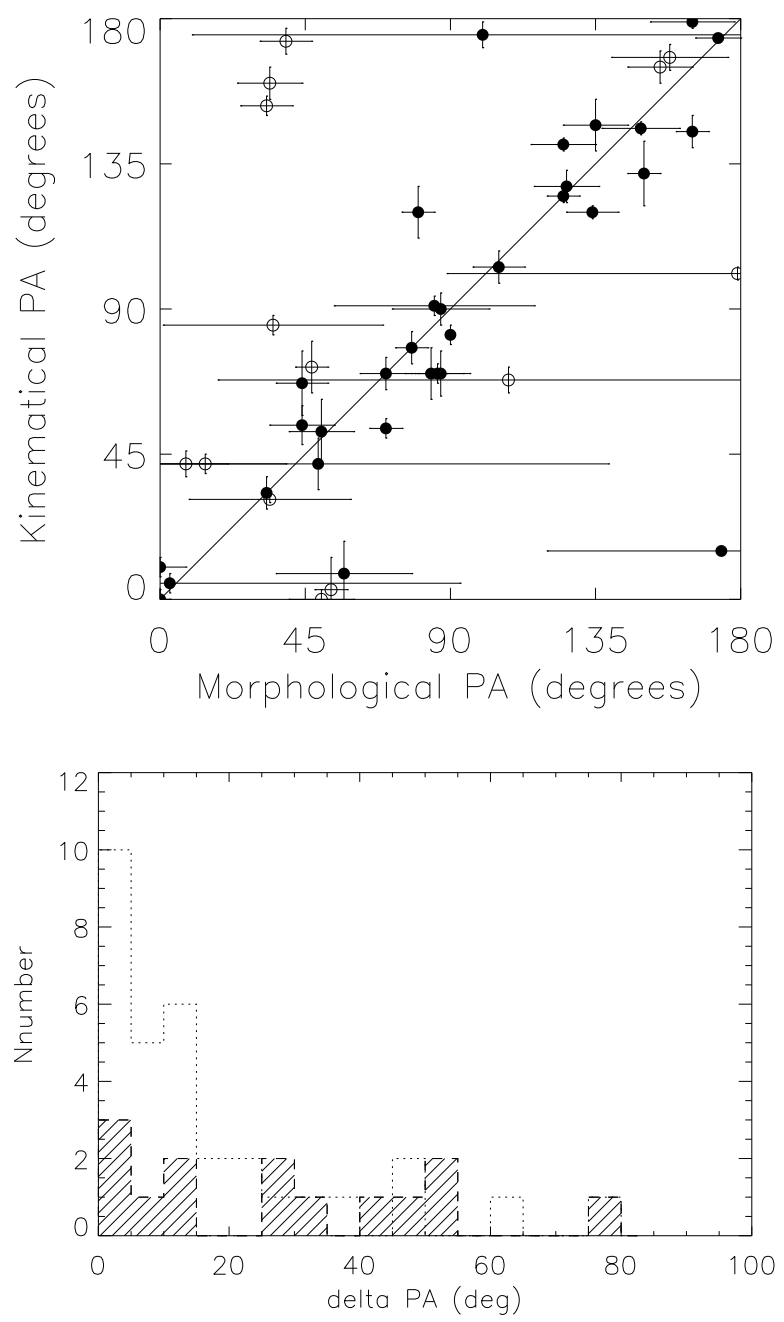

Fig. 2. Top panel: kinematic versus morphological position angle for the $46 \mathrm{HCG}$ galaxies with measured position angles. Open circles correspond to the barred and the filled ones to the unbarred galaxies respectively. Bottom panel: histogram of the differences between the kinematically and morphologically-derived position angles. Unbarred galaxies are represented by a dotted line (open histogram). Dashed lines represent barred galaxies (filled histogram).

listed in Table 3. For HCG 2a, HCG 7d, and HCG 49c, there is a high shift between the kinematic and morphologic center, suggesting the inadequacy of the automatic fit. It can be noted in Fig. 3, that these three galaxies have delta center higher than 10 arcsec. We exclude HCG 47a and 47d from this analysis, given that it was impossible to derive the kinematic center of these objects. As expected, the most symmetrical rotation curves were obtained by fixing the center and inclination (from the morphology) and letting the position angle be determined automatically.

No kinematic analysis was performed for galaxies in HCG 54, owing to their anomalous nature (Verdes-Montenegro et al. 2002).

\subsection{Maximum rotational velocities}

Rotation curves and error bars were computed using the parameters derived in Sect. 3.1 and following the same procedure as in Epinat et al. (2008a). In order to study the TF relation for the compact group galaxies, we estimated the maximum rotational velocity from each rotation curve. To enlarge the statistics, we 


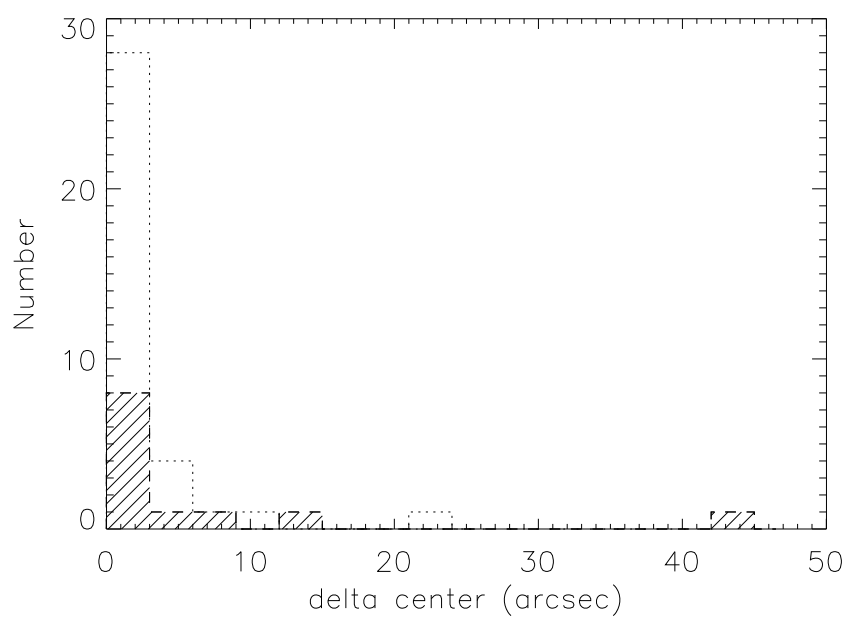

Fig. 3. Histogram of the differences between kinematically- and morphologically-derived centers for $48 \mathrm{HCG}$ galaxies with measured centers. Unbarred galaxies are represented by a dotted line (open histogram). Dashed lines represent barred galaxies (filled histogram).

also included all galaxies studied by Mendes de Oliveira et al. (2003), for which maximum rotational velocities were defined as the maximum values for the average velocities for the approaching and receding sides, similar to Epinat et al. (2008a) for edge-on galaxies.

For several galaxies (HCG 2b, 7a, 7d, 37d, 40c, 40e, 49a, $49 b, 49 c$, NGC 92), the rotation curves do not reach the optical radius $\left(R_{25}\right)$. In these cases we fit an arctan function $\left(V=V_{0} \times\right.$ $(2 / \pi) \times \arctan \left(r / r_{t}\right)$, Courteau 1997) in order to estimate the velocity at $R_{25}$, which will be used as the maximum rotational velocity. Owing to the inner shape of the rotation curve, in two cases (HCG 2b and HCG 40e), this fit gives us extremely overestimated (and clearly erroneous) maximum rotational velocities (see Appendix B). In those cases, we take the average between the velocity at $R_{25}$ from the arctan fit and the maximum velocity measured in the rotation curve. All these values were checked by eye on the rotation curves. At the end, 41 galaxies are available to study the TF relation in compact groups. Table 4 lists the observed and modeled rotational velocities for the unpublished galaxies.

\subsection{Comparison with field galaxies}

To investigate if the TF relation of compact group galaxies is similar to field galaxies, we used the galaxies of the GHASP survey as a control sample. Epinat et al. (2008a,b) find that the galaxies in this sample lie on the $B$-band TF relation, in good agreement with previous determinations of TF for field galaxies (Tully \& Pierce 2000). We exclude from their sample all the galaxies with radial systemic velocities lower than $3000 \mathrm{~km} \mathrm{~s}^{-1}$, for which no other individual measurements of distances were available (the references are indicated in Epinat et al. 2008b). We also removed galaxies with inclinations lower than 25 degrees from the list, because of the large uncertainties in the velocities. Finally, we did not use galaxies for which the maximum velocities were not reached (Epinat et al. 2008b). This left us with 93 galaxies in the GHASP sample.

\subsection{Magnitudes}

The absolute magnitudes were obtained using $M=B_{\text {cor }}-$ $5 \times\left(\log \left(v v i r_{\text {group }} / 75\right)\right)-25$, where $v v i r_{\text {group }}$ corresponds to the heliocentric radial velocity of the group to which the galaxy belongs, corrected for local group infall onto Virgo, from HyperLeda (Paturel et al. 2003) $)^{2}$. $B$-band magnitudes $\left(B_{\text {cor }}\right)$ were taken from $B_{\mathrm{T}}$, from Hickson et al. (1989). For $44 \%$ of the galaxies used in our analysis, the magnitude errors are lower than 0.1 and for $93 \%$ it is lower than 0.2 mag. For HCG 7c, 22c, and $89 \mathrm{a}$, the errors are larger, so, we checked their magnitudes in the Hyperleda database. The magnitude for HCG 22c agrees with the value reported by Hyperleda; however, for 7c and 89a, the difference in magnitudes between Hickson et al. (1989) and Hyperleda is large ( 0.7 and $0.5 \mathrm{mag}$, respectively). These differences are consistent with the errors of 0.7 and 0.5 mag given in Hickson et al. (1989), for both galaxies. The $B_{\mathrm{T}}$ magnitudes were then corrected by Galactic extinction (Schlegel et al. 1998) and by the extinction due to the inclination (Bottinelli et al. 1995). Values for the galactic extinction and extinction due to the inclination were taken directly from HyperLeda. Details on the $B$-band magnitudes for the GHASP sample are given in Epinat et al. $(2008 \mathrm{a}, \mathrm{b})$. Table 4 lists the corrected $B$-band absolute magnitudes for all HCG galaxies.

\subsection{Analysis of individual galaxies}

In the three Appendices $(\mathrm{A}-\mathrm{C})$ to this paper, we present the optical $B$-band images from DSS, velocity fields, monochromatic images, velocity dispersion maps (Figs. B.1 to B.10) and rotation curves (Figs. B.11-B.13, and Appendix C for rotation curves tables) for 11 galaxies in eight Hickson compact groups. Velocity dispersion maps presented are not corrected for instrumental nor thermal broadening. We analyze each individual galaxy using these new data together with literature data as listed in the following. We list in Table 3 the kinematic parameters obtained from the velocity fields (Cols. 3 and 8), the systemic velocities taken from the literature (Cols. 9 and 11) and the systemic velocities resulting from our analysis (Col. 10). In Table 4 we list the different rotational velocities that we obtained, from the observations and from the arctan model (Courteau 1997). In Col. 6, we show the rotational velocties at $R_{25}$. Only $38 \%$ of the galaxies listed in Table 4 reach $R_{25}$ (we noted that no rotation curve was computed for HCG 47a and 47d). Column 8 shows the observed maximum rotational velocity for each galaxy. Column 9 gives the modeled velocity at $R_{25}$. Column 10 corresponds to the rotational velocity used in the TF relation. We noted that for $39 \%$ of the sample $V_{\max }^{\mathrm{RC}}=V_{\max }^{\mathrm{TF}}$. Finally, in Col. 11 we flag the galaxies that reached, probably reached, probably did not reach, or did not reach the maximum rotational velocity. We found that $38 \%$ of the galaxies in the sample did not reach their maximum rotational velocities.

\section{Results and discussion}

\subsection{The Tully-Fisher relation}

In Fig. 4 we show the $B$-band TF relation for the HCG galaxies and the GHASP sample. Maximum rotational velocities were derived as described in Sect. 3.2. The dashed line in Fig. 4 (Eq. (1)) represents the best least-squares bisectors fit on the GHASP data and $1 \sigma$

$M_{\mathrm{B}}=(-3.47 \pm 1.21)-(7.35 \pm 0.53) \times\left[\log \left(V_{\max }\right)\right]$.

The slope of this fit agrees with the value obtained by Epinat et al. (2008b) for the complete GHASP sample. Galaxies with

${ }^{2}$ http://leda.univ-lyon $1 . f r$ 
Table 4. Rotational velocities of the sample.

\begin{tabular}{|c|c|c|c|c|c|c|c|c|c|c|}
\hline \multirow{4}{*}{$\begin{array}{c}\text { (1) } \\
\text { HCG }\end{array}$} & \multirow{4}{*}{$\begin{array}{c}(2) \\
\text { Galaxy }\end{array}$} & \multicolumn{6}{|c|}{ Observed } & \multicolumn{3}{|l|}{ Model } \\
\hline & & (3) & (4) & (5) & (6) & (7) & (8) & (9) & (10) & (11) \\
\hline & & Morph. & $M_{\mathrm{B}}$ & $R_{25}$ & $V_{\mathrm{R}(25)}^{\mathrm{RC}}$ & $R_{\max }$ & $V_{\max }^{\mathrm{RC}}$ & $V_{\mathrm{R}(25)}^{\text {model }}$ & $V_{\max }^{\mathrm{TF}}$ & $V_{\max }$ \\
\hline & & Type & mag & $(\operatorname{arcsec} / \mathrm{kpc})$ & $\mathrm{km} \mathrm{s}^{-1}$ & $(\operatorname{arcsec} / \mathrm{kpc})$ & $\mathrm{km} \mathrm{s}^{-1}$ & $\mathrm{~km} \mathrm{~s}^{-1}$ & $\mathrm{~km} \mathrm{~s}^{-1}$ & \\
\hline \multirow[t]{3}{*}{2} & $\mathrm{a}$ & SBd & -20.75 & $41 / 11.4$ & 212 & $74 / 21.0$ & 264 & 197 & $264 \pm 39$ & 1 \\
\hline & b & $\mathrm{cI}$ & -19.39 & $21 / 6.0$ & $\ldots$ & $7 / 2.0$ & 122 & 270 & $196 \pm 74$ & 4 \\
\hline & $\mathrm{c}$ & SBC & -19.87 & $33 / 9.1$ & 118 & $40 / 11.2$ & 122 & 106 & $122 \pm 13$ & 1 \\
\hline \multirow[t]{2}{*}{7} & $\mathrm{a}$ & $\mathrm{Sb}$ & -20.69 & $57 / 15.3$ & $\ldots$ & $47 / 12.7$ & 226 & 197 & $226 \pm 27$ & 2 \\
\hline & d & SBC & -18.66 & $38 / 10.1$ & $\ldots$ & $16 / 4.3$ & 78 & 85 & $85 \pm 4$ & 2 \\
\hline 22 & $\mathrm{c}$ & SBcd & -19.48 & $52 / 8.3$ & 143 & $52 / 8.3$ & 142 & 142 & $142 \pm 9$ & 1 \\
\hline 37 & d & SBdm & -18.65 & $12 / 4.8$ & $\ldots$ & $5 / 2.0$ & 63 & 76 & $76 \pm 7$ & 4 \\
\hline \multirow[t]{2}{*}{40} & $\mathrm{c}$ & Sbc & -19.91 & $37 / 15.1$ & $\ldots$ & $24 / 9.9$ & 197 & 203 & $203 \pm 3$ & 2 \\
\hline & e & $\mathrm{Sc}$ & -18.02 & $18 / 7.3$ & $\ldots$ & $7 / 2.9$ & 146 & 226 & $186 \pm 40$ & 4 \\
\hline \multirow[t]{2}{*}{47} & $\mathrm{a}$ & $\mathrm{SBb}$ & -21.23 & $\ldots$ & $\ldots$ & $\ldots$ & $\ldots$ & $\ldots$ & $\ldots$ & $\ldots$ \\
\hline & $\mathrm{d}$ & $\mathrm{Sd}$ & -19.33 & & $\ldots$ & & & . & $\ldots$ & $\ldots$ \\
\hline \multirow[t]{3}{*}{49} & $\mathrm{a}$ & Scd & -19.76 & $14 / 9.4$ & $\ldots$ & $10 / 6.4$ & 126 & 182 & $154 \pm 28$ & 4 \\
\hline & b & $\mathrm{Sd}$ & -19.47 & $13 / 8.7$ & $\ldots$ & $4 / 2.5$ & 69 & 58 & $58 \pm 6$ & 3 \\
\hline & $\mathrm{c}$ & Im & -18.36 & $10 / 6.6$ & $\ldots$ & $7 / 4.3$ & 123 & 133 & $133 \pm 5$ & 4 \\
\hline 56 & $\mathrm{a}$ & $\mathrm{Sc}$ & -20.52 & $28 / 15.2$ & 200 & $22 / 12.0$ & 205 & 228 & $205 \pm 14$ & 1 \\
\hline 68 & $\mathrm{c}$ & SBbc & -20.83 & $77 / 12.6$ & 244 & $115 / 18.9$ & 244 & 234 & $244 \pm 8$ & 1 \\
\hline \multirow[t]{2}{*}{93} & b & SBd & -21.44 & $57 / 17.7$ & 191 & $28 / 8.5$ & 235 & 220 & $235 \pm 22$ & 2 \\
\hline & NGC 92 & $\mathrm{Sa}$ & -19.55 & $49 / 10.0$ & $\ldots$ & $7 / 1.5$ & 207 & 229 & $229 \pm 11$ & 4 \\
\hline
\end{tabular}

Notes. Column (1): group number. Column (2): Galaxy member of the group. Column (3): morphological type taken from Hickson (1993). Column (4): $B$-band absolute magnitude. Column (5): isophotal radius at the limiting surface brightness of $25 \mathrm{~B} \mathrm{mag}^{\mathrm{arcsec}}{ }^{-2}$, Column (6): observed rotational velocity at $R_{25}$. Column (7): maximum radius reached by the rotation curve. Column (8): observed maximum rotational velocity. Column (9): rotational velocity at $R_{25}$ derived from the arctan model. Column (10): rotational velocity used in the TF relation. Column (11): quality flag on $V_{\max }$ (1: reached; 2: probably reached; 3: probably did not reach; 4: did not reach).

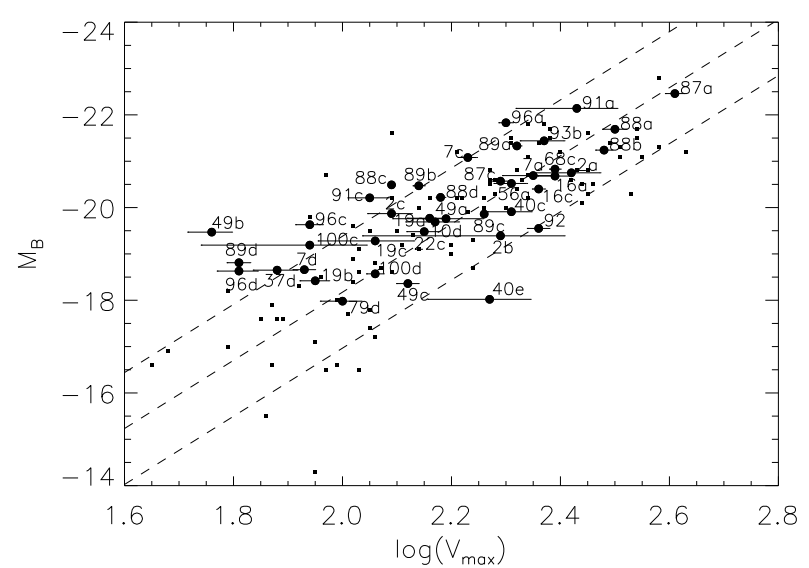

Fig. 4. $B$-band Tully-Fisher relation for galaxies in compact groups (Mendes de Oliveira et al. 2003, and this work, filled circles) and a field galaxy sample (Epinat et al. 2008b, small squares). For each rotation curve, we derived the PA automatically, from the velocity field, using IDL routines. We fixed the center using the morphological center and we fixed the inclination using the morphological inclination.

radial velocities lower than $3000 \mathrm{~km} \mathrm{~s}^{-1}$ (and no independent distance measurement) were removed from our analysis. The TF relation derived here for the GHASP sample is in agrees with the results from Tully \& Pierce (2000), who found a slope of -7.27. To compare our results with other ones from the literature, an inverse least-square fit was applied to the GHASP sample. We find a slope of $-9.11 \pm 0.85$. Kannappan et al. (2002) and Verheijen (2001) find slopes of $-10.09 \pm 0.39$ (using an unweighted inverse fit) and $-9.0 \pm 0.4$ (RC/FD sample, excluding NGC 3992), respectively. These agree with the ones found in this paper.
Figure 4 does not exhibit large differences in the $\mathrm{TF}$ of HCG galaxies and the GHASP sample. Only one galaxy is off by more than $2 \sigma$ from the TF relation (HCG $49 \mathrm{~b}$ ). Only one galaxy (HCG 40e) is more than $1 \sigma$ lower than the TF relation. Several cases are possible: it could have a high rotational velocity for its magnitude or a faint magnitude for its velocity or both. In the first case, the high maximum velocity we computed may be overestimated. Indeed, the maximum rotational velocity is only observed at $\sim R_{25} / 3\left(146 \mathrm{~km} \mathrm{~s}^{-1}\right)$, and we extrapolated to $186 \mathrm{~km} \mathrm{~s}^{-1}$ at $R_{25}$ (see Sect. 3.2). If the actual velocity is $146 \mathrm{~km} \mathrm{~s}^{-1}$, this galaxy falls on the $1 \sigma \mathrm{TF}$ relation. On the other hand, if the maximum rotational velocity is $186 \mathrm{~km} \mathrm{~s}^{-1}$ no inclination could push the galaxy on the $1 \sigma$ relation. In the second case, the problem is linked to the extinction. We can't rule out the possibility that the extinction of this galaxy may have been underestimated, given the difficulty in making such measurements in an edge-on galaxy. That underestimated value would lead to pushing the galaxy out of the TF relation. The galaxy has a $B$-band internal extinction of 0.41 (determined using Bottinelli et al. 1995). To lie on the $1 \sigma$ relation, this galaxy should have an internal extinction of $\sim 1.3 \mathrm{mag}$, which is a very unlikely value. In conclusion, it is most likely that the maximum rotational velocity was overestimated for HCG 40e, owing to the extrapolation in the rotation curve.

In the low-mass regime, galaxy HCG $49 \mathrm{~b}$ appears to have lower rotational velocity than the value expected from the TF relation, or alternatively it appears to have a higher B luminosity than that expected from its observed maximum rotational velocity. This galaxy should have a velocity of $151 \mathrm{~km} \mathrm{~s}^{-1}$ to lie on the TF relation. An inclination of 17 degrees could give us that rotational velocity. However, this value is too low considering the kinematic and morphological inclinations given in Table 3. This effect was also noted by Mendes de Oliveira et al. (2003), for other galaxies at the low-mass end of the relation, e.g. HCG 96d and HCG 89d. 


\subsection{Outliers from the TF relation}

Compact groups of galaxies are environments where interactions between galaxies take place frequently. This is confirmed by a number of studies that have shown distorted kinematics and morphologies of compact group galaxies (e.g. Presotto et al. 2010; Amram et al. 2007; Coziol \& Plauchu-Frayn 2007; Amram et al. 2003; Plana et al. 2003, 1998; and Mendes de Oliveira et al. 1998), also by studies of groups containing HI tidal debris (Verdes-Montenegro et al. 2001) and newly formed stars forming systems outside the luminous member galaxies (e.g. de Mello et al. 2008), as well as studies of diffuse light presumably originated from stripped material from the outskirts of galaxies in compact groups (e.g. da Rocha et al. 2008). From these studies, it is clear that galaxy interactions represent an effective mechanism to remove some of the stars and neutral gas from the member galaxies. However, another important question arises: can interactions remove some of the dark halo of the compact groups galaxies? Mendes de Oliveira et al. (2003) found a few low-mass galaxies that had a lower maximum velocity than expected from the TF relation. In this paper we find one more galaxy, HCG 49b. Given that these studies focus on the the $B$-band TF relation, we can't tell whether these galaxies have been brightened by star formation or if they have truncated profiles. In the latter case, if HCG $49 \mathrm{~b}$ sometime in the past lay on the TF relation sometime in the past (defined by the best fit to the GHASP data), this object would have had to lose $85 \%$ of its possible initial mass to move to its observed position on the TF relation. The $K$-band TF relation and mass profile decomposition into luminous and halo components are necessary to address this issue (Torres-Flores et al. 2010a,b, in prep.).

To quantify the possible similarities/differences between the HCG and the GHASP samples, we applied a least square bisector fit to the HCG sample. In this case we obtain $M_{\mathrm{B}}=$ $(-8.40 \pm 1.20)-(5.30 \pm 0.53) \times\left[\log \left(V_{\max }\right)\right]$. From these values and from inspecting Fig. 4, it is clear that low-mass galaxies strongly influence this result for the TF relation of compact groups. To confirm that, we removed galaxies with rotational velocities lower than $100 \mathrm{~km} \mathrm{~s}^{-1}$. In this case, the TF relation for HCG galaxies is $M_{\mathrm{B}}=(-4.26 \pm 1.73)-(7.07 \pm 0.74) \times$ $\left[\log \left(V_{\max }\right)\right]$, and for GHASP it is $M_{\mathrm{B}}=(-4.28 \pm 1.39)-(6.98 \pm$ $0.60) \times\left[\log \left(V_{\max }\right)\right]$. We also fitted an ordinary least square fit and a least square bisector fit to the HCG and GHASP samples, excluding objects fainter than $M_{\mathrm{B}}=-18$, and again we obtain very similar results; i.e., there are no significative differences in the slopes and zero points of the TF for the two samples. If we add GHASP and HCG galaxies (excluding HCG galaxies with rotational velocities lower than $\left.100 \mathrm{~km} \mathrm{~s}^{-1}\right)$, we obtain: $M_{\mathrm{B}}=(-3.44 \pm 1.09)-(7.38 \pm 0.48) \times\left[\log \left(V_{\max }\right)\right]$. This result fully agrees with the fit obtained for the GHASP sample. From this analysis we concluded that low-mass galaxies in compact groups lie off the $B$-band TF relation while for galaxies with rotational velocities higher than $100 \mathrm{~km} \mathrm{~s}^{-1}$, the TF relations for HCGs and GHASP galaxies have very similar slopes and zero points. If we take the error bars into account in the inclination and we remove galaxies for which no error bars were quoted or having extremely large error bars that produced errors in the computation (HCG 7c, 47d, 49a, 79d, and 87a), we found that $75 \%$ of the HCG sample is inside $1 \sigma$ of the relation defined by GHASP (Eq. (1)). A fraction of $25 \%$ of the compact group sample could not reach the TF relation inside $1 \sigma$ (HCG 40e, 49b, 88c, 89d, 91c, 96c, 96d, 100c, and NGC 92). Interestingly, HCG 49b, 89d, 96c, 96d, and 100c have rotational velocities lower than $100 \mathrm{~km} \mathrm{~s}^{-1}$.
Table 5. Interaction indicators.

\begin{tabular}{ccccccc}
\hline \hline Interaction & \multicolumn{7}{c}{ Galaxy (HCG) } \\
indicator & $37 \mathrm{~d}$ & $40 \mathrm{c}$ & $40 \mathrm{e}$ & $47 \mathrm{a}$ & $47 \mathrm{~d}$ & $49 \mathrm{a}$ \\
\hline$(1)$ & - & - & - & - & - & - \\
$(2)$ & + & - & + & $\ldots$ & $\ldots$ & + \\
$(3)$ & - & - & + & + & + & - \\
$(4)$ & - & - & - & - & - & + \\
$(5)$ & - & - & & - & - & + \\
$(6)$ & - & - & + & + & - & $\ldots$ \\
$(7)$ & - & - & - & - & $\ldots$ & $\ldots$ \\
\hline & $49 \mathrm{~b}$ & $49 \mathrm{c}$ & $56 \mathrm{a}$ & $68 \mathrm{c}$ & $93 \mathrm{~b}$ & \\
$(1)$ & + & - & - & - & + & \\
$(2)$ & + & + & - & - & + & \\
$(3)$ & + & + & - & - & + & \\
$(4)$ & + & - & - & - & - & \\
$(5)$ & - & - & - & - & - & \\
$(6)$ & $\ldots$ & $\ldots$ & - & $\ldots$ & $\ldots$ & \\
$(7)$ & $\ldots$ & $\ldots$ & - & + & - & \\
\hline
\end{tabular}

Notes. Interaction indicators for the new sample presented in this paper. (1) Highly disturbed velocity field. (2) Disagreement between both sides of the rotation curve. (3) Gaseous versus stellar major-axis misalignment. (4) Changing position angle along major axis. (5) Tidal Tails. (6) High IR luminosity. (7) Central activity. The symbol "+" means that the indicator is "on" otherwise the symbol is " - ".

We study the dispersion that our samples present in the TF relation with respect to the fit derived from GHASP and HCG together (without the galaxies with $v<100 \mathrm{~km} \mathrm{~s}^{-1}$, in the case of HCG galaxies). We found that a total of $32 \%$ of the HCG and $25 \%$ of the GHASP galaxies are outside the $1 \sigma$ TF relation. This suggests a higher dispersion presented by the HCG galaxies, although the main result here is that $98 \%$ and $97 \%$ of the HCG and GHASP samples are within the same relation at the $2 \sigma$ level, showing complete agreement at this level. The higher dispersion for HCGs could stem from the frequent interactions in this environment. Puech et al. (2008) find that galaxies at $z \sim 0.6$ having a complex kinematics produced a high dispersion in the TF relation. This result agrees with the results of compact groups of galaxies.

In the low-mass regime, a few field galaxies producing high dispersion in the TF relation display lower $B$-band luminosities than expected, and therefore, low stellar masses, because the gaseous component is not negligible for low-mass galaxies in the field. If the gas mass is included, field low-mass galaxies are shifted towards the TF relation (as already shown in McGaugh et al. 2000). For HCG galaxies, however, adding the gas component moves their positions upwards, off the TF relation. The compact groups outliers have enhanced luminosities (probably due to star formation), which is not the case for field galaxies. In this sense, it could be dangerous to quantify and compare the dispersions in the TF relation for HCG and GHASP galaxies in the low-mass regime, given that the physical reason for such dispersion may be different.

\subsection{Interaction indicators}

Mendes de Oliveira et al. (1998), Amram et al. (2003), and Plana et al. (2003) have devised a scheme to classify galaxies as interacting or not, based on analysis of 2D velocity fields and other indicators. Using this same scheme, Torres-Flores et al. (2009) classified HCG 2, HCG 7, HCG 22, and NGC 92 in different evolutionary stages. In a similar way, we classified the galaxies studied here as interacting or not. In Table 5 we show the main 
interaction indicators. Of all 11 galaxies studied in this new sample (from which we have derived rotation curves for 9 of them), 6 present at least two interaction indicators and can be classified as interacting.

One of the interaction parameters listed in Table 5 is the difference between the kinematically and morphological-derived position angles. We plot this difference for 46 compact group galaxies in Fig. 2 (bottom panel). This difference is an indicator of interactions only for unbarred galaxies given that it is common to find bars that are not aligned with kinematic major axes of galaxies. If we discard the barred galaxies we still find that almost one third of the sample of 32 galaxies studied in detail so far (this paper, Mendes de Oliveira et al. 2003; Torres-Flores et al. 2009) has a misalignment greater than 20 degrees between the kinematic and the morphological position angle, yielding even more pieces of evidence for the high incidence of interactions among galaxies in compact groups. Only one galaxy (HCG 49a) has a kinematic and morphological inclination lower than 25 degrees. This object has a small misalignment between kinematic and morphological PA (7 degrees), therefore its low inclination does not affect the determination of the position angles of this galaxy.

A new interaction indicator for the whole sample of compact groups could be associated with the number of galaxies for which it is possible to obtain the rotation curves versus the total number of observed galaxies. If we gather all the HCG galaxies that have Fabry-Perot observations, discarding elliptical and S0, we found that rotation curves could be obtained for $68 \%$ of the observed galaxies. In the case of the GHASP sample, it is possible to derive the rotation curves for $85 \%$ of the observed galaxies. This fact could be associated with the complex kinematics shown by HCG galaxies. Moreover, HCG presents a deficiency in the content of HI gas (Verdes-Montenegro et al. 2001), so we can't exclude the lack of gas in the HCG galaxies as an important bias in this comparison.

\section{Summary and conclusions}

We have presented new velocity fields, monochromatic $\mathrm{H} \alpha$ images and velocity dispersion maps for galaxies in nine compact groups. We explored the $B$-band TF relation for a sample of 41 galaxies in compact groups and compared it with the reanalyzed TF relation for the GHASP sample. We found that galaxies in dense environments lie on the TF relation defined by field galaxies; however, some of the low-mass galaxies have either a high luminosity for their mass or a high rotational velocity for their luminosities (e.g. HCG 49b). We also found that one third of the unbarred galaxies in compact groups have a misalignment between the kinematic and morphological position angle higher than 20 degrees.

Acknowledgements. We would like to thank the anonymous referee for very useful comments and suggestions, which were very important in improving this paper. S.T.-F. acknowledges the financial support of FAPESP through a Ph.D. fellowship (2007/07973-3). S.T.-F. also acknowledges the financial support of Egide through a Eiffel scholarship. C.M.d.O. acknowledgs support from FAPESP (2006/56213-9), and CNPq. H.P. acknowledges financial support from CAPES (3656/08-0). S.T.-F., C.M.d.O., and H.P. would like to thank the staff members of the Laboratoire d'Astrophysique de Marseille for their hospitality when part of this work was developed. This research made use of the NASA/IPAC Extragalactic Database (NED) which is operated by the Jet Propulsion Laboratory, California Institute of Technology, under contract with the National Aeronautics and Space Administration. We also acknowledge the use of the HyperLeda database (http: //leda.univ-lyon 1. fr).

\section{References}

Amram, P., Boulesteix, J., Georgelin, Y. M., et al. 1991, Msngr, 64, 44 Amram, P., Balkowski, C., Boulesteix, J., et al. 1996, A\&A, 310, 737 Amram, P., Plana, H., Mendes de Oliveira, C., Balkowski, C., \& Boulesteix, J. 2003, A\&A, 402, 865

Amram, P., Mendes de Oliveira, C., Plana, H., et al. 2004, ApJ, 612, L5

Amram, P., Mendes de Oliveira, C., Plana, H., Balkowski, C., \& Hernandez, O. 2007, A\&A, 471, 753

Bottinelli, L., Gouguenheim, L., Paturel, G., \& Teerikorpi, P. 1995, A\&A, 296, 64

Cappellari, M., \& Copin, Y. 2003, MNRAS, 342, 345

Courteau, S. 1997, AJ, 114, 2402

Coziol, R., \& Plauchu-Frayn, I. 2007, AJ, 133, 2630

Coziol, R., de Carvalho, R. R., Capelato, H. V., \& Ribeiro, A. L. B. 1998, ApJ, 506,545

Coziol, R., Iovino, A., \& de Carvalho, R. R. 2000, AJ, 120, 47

Coziol, R., Brinks, E., \& Bravo-Alfaro, H. 2004, AJ, 128, 68

Daigle, O., Carignan, C., Hernandez, O., Chemin, L., \& Amram, P. 2006, MNRAS, 368, 1016

Da Rocha, C., Ziegler, B. L., \& Mendes de Oliveira, C. 2008, MNRAS, 388, 1433

de Mello, D. F., Torres-Flores, S., \& Mendes de Oliveira, C. 2008a, AJ, 135, 319 Durbala, A., del Olmo, A., Yun, M. S., et al. 2008, AJ, 135, 130

Epinat, B., Amram, P., Marcelin, M., et al. 2008a, MNRAS, 388, 500

Epinat, B., Amram, P., \& Marcelin, M. 2008b, MNRAS, 390, 466

Fasano, G. \& Bettoni, D. 1994, AJ, 107, 1649

Hickson, P. 1982, ApJ, 255, 382

Hickson, P. 1993, Atlas of Compact Groups of Galaxies (New York: Gordon and Breach Science Publishers)

Hickson, P., Kindl, E., \& Auman, J. R. 1989, ApJS, 7, 687

Hickson, P., Mendes de Oliveira, C., Huchra, J. P., \& Palumbo, G. G. 1992, ApJ, 399, 353

Kannappan, S. J., Fabricant, D. G., \& Franx, M. 2002, AJ, 123, 2358

McGaugh, S. S., Schombert, J. M., Bothun, G. D., \& de Blok, W. J. G. 2000, ApJ, 533, L99

Mendes de Oliveira, C. 1992, Ph.D. Thesis, British Columbia Univ.

Mendes de Oliveira, C., Plana, H., Amram, P., Balkowski, C., \& Boulesteix, J. 1998, ApJ, 507, 691

Mendes de Oliveira, C., Amram, P., Plana, H., \& Balkowski, C. 2003, AJ, 126, 2635

Paturel, G., Petit, C., Prugniel, P., et al. 2003, A\&A, 412, 45

Phillips, A. C. 1996, ASPC, 91, 44

Pisano, D. J., Wilcots, E. M., \& Elmegreen, B. G. 2000, AJ, 120, 763

Peirani, S., Hammer, F., Flores, H., Yang, Y., \& Athanassoula, E. 2009, A\&A, 496, 51

Plana, H., Mendes de Oliveira, C., Amram, P., \& Boulesteix, J. 1998, AJ, 116, 2123

Plana, H., Amram, P., Mendes de Oliveira, C., \& Balkowski, C. 2000, AJ, 120, 621

Plana, H., Amram, P., Mendes de Oliveira, C., Balkowski, C., \& Boulesteix, J. 2003, AJ, 125, 1736

Plana, H., Amram, P., Mendes de Oliveira, C., \& Balkowski, C. 2010, AJ, 139, 1 Presotto, V., Iovino, A., Pompei, E., \& Temporin, S. 2010, A\&A, 510, A31

Puech, M., Flores, H., Hammer, F., et al. 2008, A\&A, 484, 173

Schelegel, D. J., Finkbeiner, D. P., \& Davis, M. 1998, ApJ, 500, 525

Shimada, M., Ohyama, Y., Nishiura, S., Murayama, T., \& Taniguchi, Y. 2000, AJ, 119, 2664

Torres-Flores, S., Mendes de Oliveira, C., de Mello, D. F., et al. 2009, A\&A, 507,723

Tully, R. B., \& Pierce, M. J. 2000, ApJ, 533, 744

Verdes-Montenegro, L., Yun, M. S., Williams, B. A., et al. 2001, A\&A, 377, 812

Verdes-Montenegro, L., Del Olmo, A., Iglesias-Páramo, J. I., et al. 2002, A\&A, 396, 815

Verheijen, M. A. W. 2001, ApJ, 563, 694

Vilchez, J. M., \& Iglesias-Páramo, J. 1998, ApJS, 117, 1

Pages 9 to 39 are available in the electronic edition of the journal at http: //www . aanda.org 


\section{Appendix A: Individual galaxy properties}

\section{A.1. HCG 37}

This group is formed by five galaxies. The brighter member, HCG 37a, has a morphological type E7 (Hickson 1992). Coziol et al. (2004) classified galaxies HCG 37a, HCG 37b, HCG 37c, and HCG 37d as a dwarf LINER (dLINER), LINER, low luminosity AGN, and a star forming galaxy (SFG), respectively. HCG 37b is a near IR source (Allam et al. 1996). Verdes-Montenegro et al. (2001) report that $87 \%$ of the expected $\mathrm{HI}$ is missing in HCG 37. Four of the five galaxies of HCG 37 were observed (thanks to the field of view of the observations) and we detect $\mathrm{H} \alpha$ emission only in two of them. HCG 37a shows a central $\mathrm{H} \alpha$ emission, as was reported in Vilchez et al. (1998), however, the $\mathrm{H} \alpha$ profiles have a low signal-to-noise ratios. For this galaxy it was impossible to perform a rotation curve.

The monochromatic map of HCG $37 \mathrm{~d}$ shows an extension of $13 \operatorname{arcsec}(5.2 \mathrm{kpc})$. It has two peaks in the emission, as was found in Vilchez et al. (1998), the peak located in the northwest side of the galaxy being stronger. The continuum image shows the same peaks as the monochromatic image. The velocity field of this object is regular. The kinematic position angle is aligned with the optical one (as derived by Mendes de Oliveira 1992, at $2 h^{-1} \mathrm{kpc}$ ), differing by only $2^{\circ}$. The rotation curve of HCG $37 \mathrm{~d}$ is not symmetric, and both sides do not match. The receding and approaching sides reach velocities of $60 \mathrm{~km} \mathrm{~s}^{-1}$ and $53 \mathrm{~km} \mathrm{~s}^{-1}$, respectively. The rotation curve does not reach the optical radius of the galaxy $\left(R_{25}\right)$.

\section{A.2. $\mathrm{HCG} 40$}

This quintet is composed by two early-type and three late-type galaxies. HCG 40a, HCG 40d, and HCG 40e were classified as radio sources (dLNR, LNR, and Sy2, respectively) in Coziol et al. (1998) and re-classified as no-emission galaxy, SFG and SFG in Coziol et al. (2004). HCG 40b is a no-emission galaxies and HCG 40c is an SFG (Coziol et al. 2004). HCG 40e is an FIR source (Allam et al. 1996). In the evolutive scenario of Verdes-Montenegro et al. (2001), HCG 40 is a type 3a group, where $89 \%$ of the expected $\mathrm{HI}$ mass is missing, which converts this group into a very evolved group.

The strongest $\mathrm{H} \alpha$ emission of the group is detected in two peaks, in the barred early-type spiral HCG 40d. This emission is very concentrated in the central region, probably associated with star formation at the end of the bar. We could not derive the rotation curve for this object.

We also detected $\mathrm{H} \alpha$ emission in the central regions of HCG 40a, and HCG 40b. Both galaxies were classified as early-type galaxies by Hickson (1992), E3 and S0, respectively. Interestingly, no emission was detected in Coziol et al. (2000) for these objects. As for HCG 40d, we could not obtain the rotation curve for these objects.

HCG 40c displays an extended monochromatic map. We detected a peak in the $\mathrm{H} \alpha$ emission in the southeast side of HCG 40c, coincident with the peak in the HI distribution shown in Verdes-Montenegro et al. (2001). Its velocity field is regular. The kinematic position angle does not change with radius. The rotation curve is symmetric, reaching a plateau at $6 \mathrm{kpc}$; however, this curve does not reach the optical radius $R_{25}$. At radii greater than $10 \mathrm{kpc}$, there is no more $\mathrm{H} \alpha$ emission, can be noted from the monochromatic image. HCG 40e shows a weak $\mathrm{H} \alpha$ emission on its disk. Both sides of the rotation curve do not match.

\section{A.3. HCG 47}

This quartet is formed by two pairs of galaxies. HCG 47a is an $\mathrm{SBb}$ (Hickson 1993) galaxy, showing a ring-shape structure on its southwest side (Fasano et al. 1994). Shimada et al. (2000) classify HCG 47a as an absorption-line galaxy. Hickson classify HCG 47b, HCG 47c and, HCG 47d as E3, Sc and Sd galaxies. HCG 47a, and HCG 47b are radio and FIR sources (Allam et al. 1996).

We detected a strong $\mathrm{H} \alpha$ emission in the ring of HCG 47a. On the other hand, HCG $47 \mathrm{~b}$ shows weak intensity on its monochromatic map. The north side of HCG $47 \mathrm{~d}$ shows the strongest $\mathrm{H} \alpha$ emission in this galaxy. However, we also note an extended emission in its disk. HCG 47c only shows a central knot in its monochromatic image, at the same position as for the continuum peak.

The velocity field shows higher velocities in the eastern part of the approaching side than in the western region, probably due to the presence of the ring. The kinematic position angle differs from the optical one, at $2 \mathrm{~h}^{-1} \mathrm{kpc}$ and at $R_{25}$, in $14^{\circ}$ in both cases.

HCG $47 \mathrm{~d}$ shows a regular velocity field. However, there is an offset between the kinematic and optical position angles of $32^{\circ}$ and $23^{\circ}$ (Mendes de Oliveira 1992, and HyperLeda, respectively). For HCG $47 \mathrm{a}$ and $47 \mathrm{~d}$ it was impossible to obtain the rotation curves. The procedure developed by Epinat et al. (2008a) does not converge for these galaxies.

\section{A.4. HCG 49}

This small and compact quartet of galaxies shows an angular diameter of 0.9 arcmin (Hickson et al. 1982) (36 kpc) and is the most distant group in this sample $(140 \mathrm{Mpc})$. HCG $49 \mathrm{a}$ and HCG 49 b are late-type spiral galaxies, HCG 49c is an Im and HCG 49d is a E5 (Hickson 1993). In the scenario proposed in Verdes-Montenegro et al. (2001), HCG 49 is a well developed group, in the $3 \mathrm{~b}$ phase, where the HI gas forms a large cloud containing all galaxies, with a single velocity gradient.

Fasano et al. (1996) note that HCG 49a seems to be a superposition of two galaxies, but our monochromatic map shows that the emission is coming from only one object. We analyzed the $\mathrm{H} \alpha$ profile in the region where the superposition appears, and we do not detect a defined profile. The monochromatic map of HCG 49a shows $\mathrm{H} \alpha$ emission across the disk of this object. This emission peaks at the same place in the monochromatic and the continuum map. This object shows a regular velocity field. The kinematic position angle differs only in $7^{\circ}$ from the optical position angle at $2 h^{-1} \mathrm{kpc}$. However, the difference is greater if we take the optical position angle at $R_{25}\left(16^{\circ}\right)$. The rotation curve is symmetric, and both sides match relatively well.

HCG 49b shows two strong peaks in the monochromatic map. One of them is located at the same position of the continuum maximum. The other bright knot is placed to the east of the galaxy. This knot shows an amplitude of $\sim 40 \mathrm{~km} \mathrm{~s}^{-1}$. HCG $49 \mathrm{~b}$ shows a perturbed velocity field. The kinematic position angle changes along the radius and it differs from the optical one at $2 h^{-1} \mathrm{kpc}$ in $17^{\circ}$. However, at $R_{25}$ the optical and kinematic position angles reach a similar value (Table 3 ). The rotation curve of HCG $49 \mathrm{~b}$ extended out to $12.5 \operatorname{arcsec}(\sim 8.5 \mathrm{kpc})$. Both sides do not match. The receding side reaches values of $70 \mathrm{~km} \mathrm{~s}^{-1}$ and the approaching side reaches values of $75 \mathrm{~km} \mathrm{~s}^{-1}$.

The monochromatic map of HCG 49c shows a much lower intensity than HCG 49a, and b. We detected a bridge in the $\mathrm{H} \alpha$ emission between members $\mathrm{b}$ and $\mathrm{c}$. The velocity field seems regular. However, a disagreement of $64^{\circ}$ is observed between the 
kinematic, and optical position angles. Both sides of the rotation curve match from the center out to $2.5 \mathrm{kpc}$. Beyond this radius, no $\mathrm{H} \alpha$ emission is detected on the approaching side.

\section{A.5. HCG 54}

Hickson et al. (1989) classified this group as formed by three irregular galaxies and one Sdm galaxy. Verdes-Montenegro et al. (2002) found HI tidal tails and shells in the environment of HCG 54. They concluded that this group is a merger remnant.

From our monochromatic map, we note that HCG 54b shows the strongest $\mathrm{H} \alpha$ emission and its velocity field shows an amplitude of $30 \mathrm{~km} \mathrm{~s}^{-1}$. HCG 54b and 54d also appear in the monochromatic map; however, it is difficult to get some information from the velocity field. HCG 54a is detected in the continuum image. Our data supports the scenario that HCG 54 is in fact one single galaxy and not a group. The nature of this object (Verdes-Montenegro et al. 2002) made us decide not to obtain any kinematic parameter of its members.

\section{A.6. $H C G 56$}

This quintet if formed by the late-type spiral HCG 56a, the SB0 HCG 56b, and three SO galaxies (c-e). Coziol et al. (2004) classified members a, d and e as star forming galaxies, HCG 56b as a Seyfert galaxy and HCG 56c as a no-emission line galaxy. Allam et al. (1996) detected members b-d at 25, 60, and $100 \mu \mathrm{m}$. This group only shows $19 \%$ of its expected HI mass (Verdes-Montenegro et al. 2001). We present Fabry-Perot data for members $\mathrm{a}-\mathrm{d}$ of this group. The monochromatic map of HCG 56a shows an extended emission along the disk. Peaks in the $\mathrm{H} \alpha$ emission are detected in the southern and northern side of this galaxy. Both peaks are located at the same distance with respect to the peak in the continuum image. The velocity field of HCG 56a seems to be regular. We noted that the approaching side is more extended than the receding side. We do not detect any misalignment between the kinematic and optical position angles for this galaxy. The rotation curve of HCG 56a is symmetric. The approaching and receding sides match from 3 to $18^{\prime \prime}$ ( 2 to $10 \mathrm{kpc}$ ), where the approaching side reaches a plateau. At radii larger than $18^{\prime \prime}$, there is no data for the receding side; however, the approaching side reaches $35^{\prime \prime}$.

We detected $\mathrm{H} \alpha$ emission at the center of the S0 galaxies HCG 56b, HCG 56c, and HCG 56d. Given that we only detected $\mathrm{H} \alpha$ emission at the center of these objects, it was not possible to obtain their rotation curves. No emission was detected in the bridge between members $b$, and $c$. Members b-d show a shift of $0.88^{\prime \prime}$ (one pixel) between their monochromatic and continuum peaks.

\section{A.7. HCG 68}

This group is formed by four early-type galaxies (HCG 68a, b, d, and e) and one barred spiral galaxy (HCG 68c) (Hikcson 1993). Shimada et al. (2000) classified members a-c as AGN; however, Coziol et al. (2004) classified HCG 68a as a no-emission galaxy. Verdes-Montenegro et al. (2001) detected only $33 \%$ of the expected HI mass for this group. We detected $\mathrm{H} \alpha$ emission in the monochromatic map of HCG $68 \mathrm{a}$ and $\mathrm{b}$. However, the $\mathrm{H} \alpha$ profile is not well defined in either galaxies.
We detected several bright HII regions on the well-defined arms of HCG $68 \mathrm{c}$. In the nuclear region, we detected a peak in $\mathrm{H} \alpha$; nevertheless, no emission was detected across the bar of this object, as also reported by Vilchez et al. (1998). The maximum intensity in the monochromatic map of HCG $68 \mathrm{c}$ corresponds to an HII region located $60^{\prime \prime}$ from its center (northwest side of the galaxy). The velocity field of HCG $68 \mathrm{c}$ is quite regular. The kinematic and optical $\left(R_{25}\right)$ position angles are aligned. The difference between the kinematic and optical position angles at $2 h^{-1}$ is caused by the influence of the bar at this radius. The rotation curve of HCG $68 \mathrm{c}$ reaches $115^{\prime \prime}$ (19 kpc). In the first $10^{\prime \prime}$, both sides of the rotation curve do not match, and we detected a bump in the approaching side, reaching $250 \mathrm{~km} \mathrm{~s}^{-1}$. Both sides of the rotation curve match from 15 to $105^{\prime \prime}$. At $40^{\prime \prime}$, the approaching side shows higher velocities than the receding side, showing some bumps, probably produced by the crossing of spiral arms.

\section{A.8. HCG 79}

Mendes de Oliveira et al. (2003) presented the rotation curve of HCG 79d. Inclinations for HCG 79d are $64^{\circ}$ and $78^{\circ}$ (depending on whether is taken from the axis ratio given in Hickson 1993, or if it is taken from HyperLeda database). Durbala et al. (2008) showed continuum-subtracted $\mathrm{H} \alpha$ images of HCG 79 (for this group, see details in Durbala et al. 2008).

\section{A.9. HCG 93}

This quartet is formed by two barred spiral galaxies, HCG 93b, and HCG 93c, one E1 galaxy (HCG 93a), and the SB0 galaxy HCG 93d (Hickson 1993). Members a and c were classified as AGN by Shimada et al. (2000) and Coziol et al. (2004). HCG 93b is classified as an AGN by Shimada et al. (2004) but Coziol et al. (2004) classified it as a star forming galaxy. About $84 \%$ of the expected HI mass in HCG 93 is missing (Verdes-Montenegro et al. 2001). We presented Fabry-Perot data only for the barred spiral HCG 93b. Its monochromatic map shows $\mathrm{H} \alpha$ emission across the bar and two bright knots at the end of it, produced by star formation resulting from the compression of gas in this place, in agreement with its morphological type (Phillips 1996; Pisano et al. 2000). In the arms, we detected a few HII regions. The velocity field of HCG 93b shows a twist. We detected a disagreement between optical and kinematic position angles of $17^{\circ}$ and $134^{\circ}$ (Mendes de Oliveira et al. 2003, and HyperLeda, respectively). Both sides of the rotation curve of HCG 93b do not match. From 20" (7 kpc), the approaching side falls, reaching values of $\sim 120 \mathrm{~km} \mathrm{~s}^{-1}$. The approaching side has an extension of $95^{\prime \prime}(30 \mathrm{kpc})$.

\section{Appendix B: Individual maps and rotation curves}


S. Torres-Flores et al.: Kinematics of galaxies in compact groups
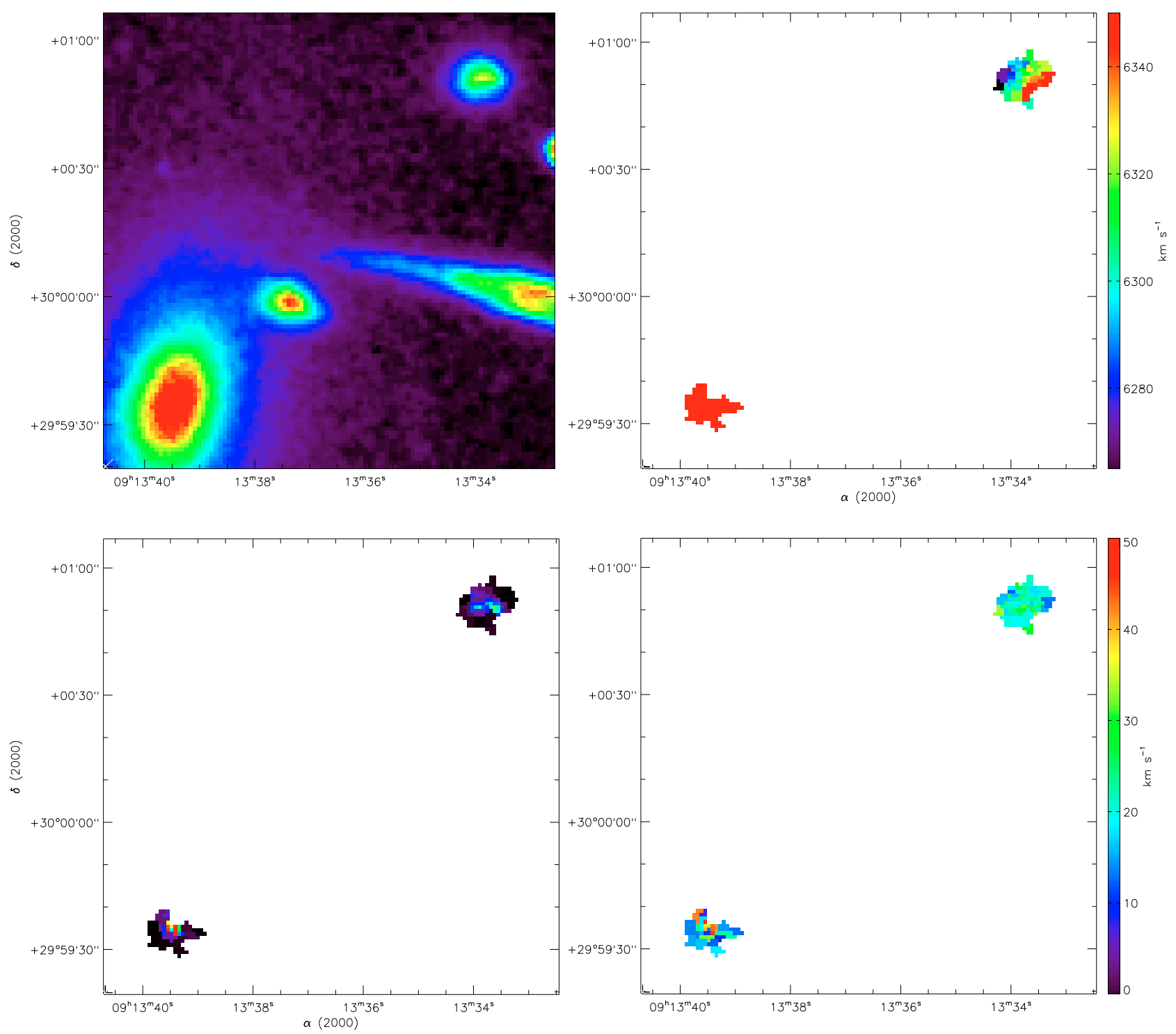

Fig. B.1. Maps for HCG 37. North is at the top and east to the left for all images in Figs. B.1 to B.10. HCG 37a is located to the southeast of HCG 37d. Top left: B band image from DSS. Top right: velocity field. Bottom left: monochromatic image. Bottom right: velocity dispersion map. 

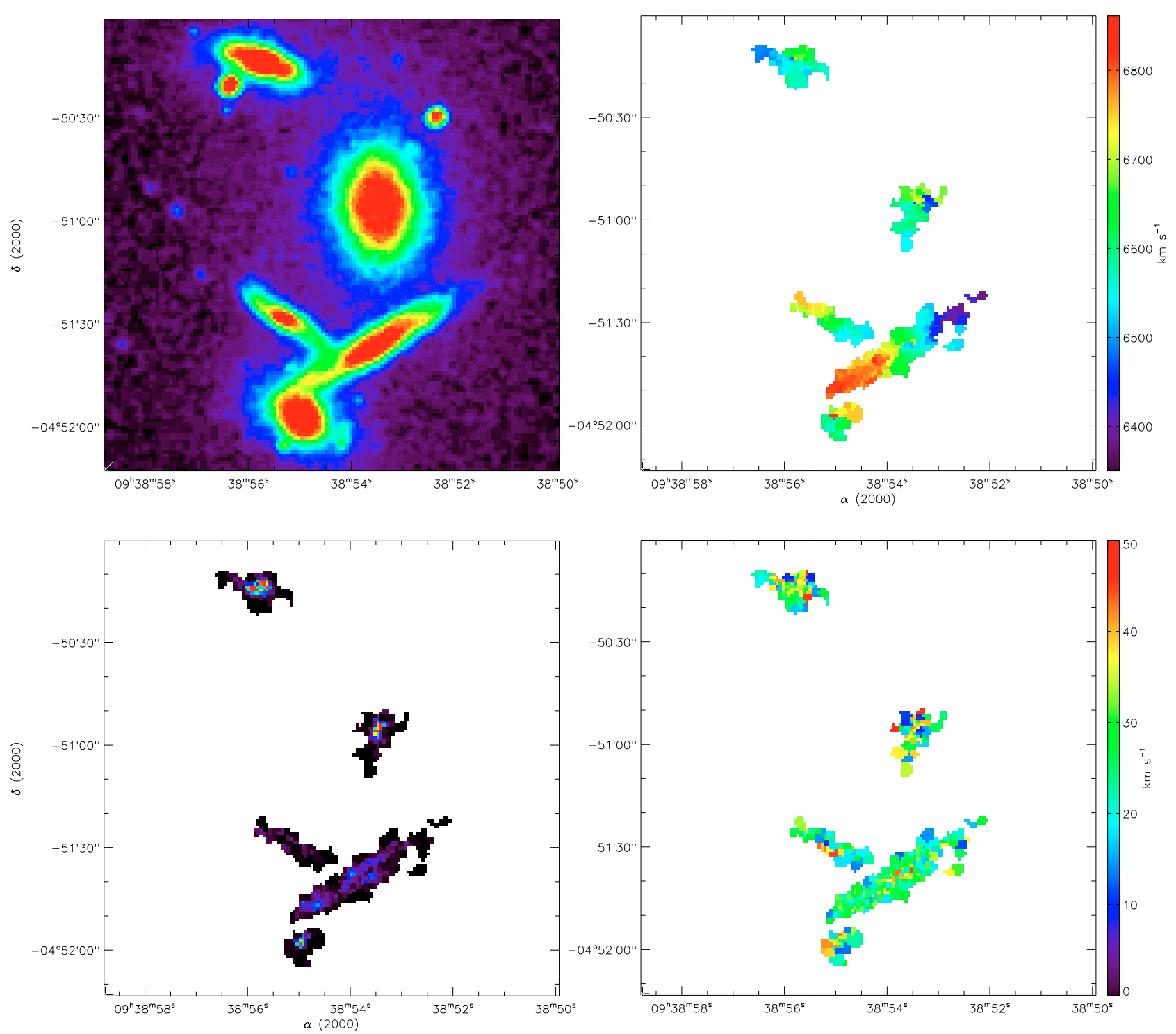

Fig. B.2. Maps for HCG 40. HCG 40a is located close to the center of the field and to the south west of HCG 40d. HCG 40e, b and c are located to the southeast of HCG 40a. Top left: B band image from DSS. Top right: velocity field. Bottom left: monochromatic image. Bottom right: velocity dispersion map. 
S. Torres-Flores et al.: Kinematics of galaxies in compact groups
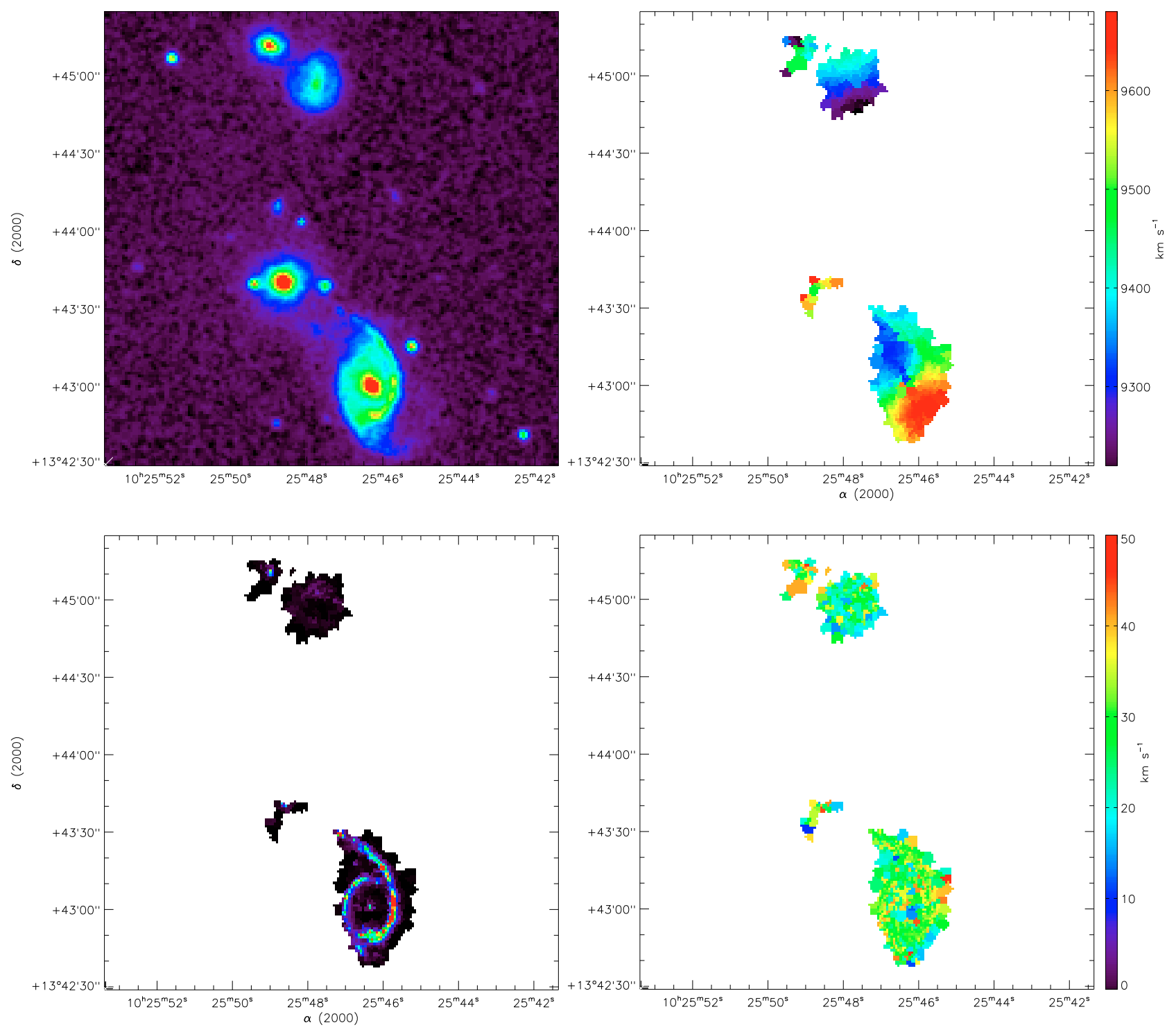

Fig. B.3. Maps for HCG 47. HCG 47b and 47a are located at the bottom of the field. HCG 47c and 47d are located at the north of the field. Top left: $B$ band image from DSS. Top right: velocity field. Bottom left: monochromatic image. Bottom right: velocity dispersion map. 
A\&A 521, A59 (2010)
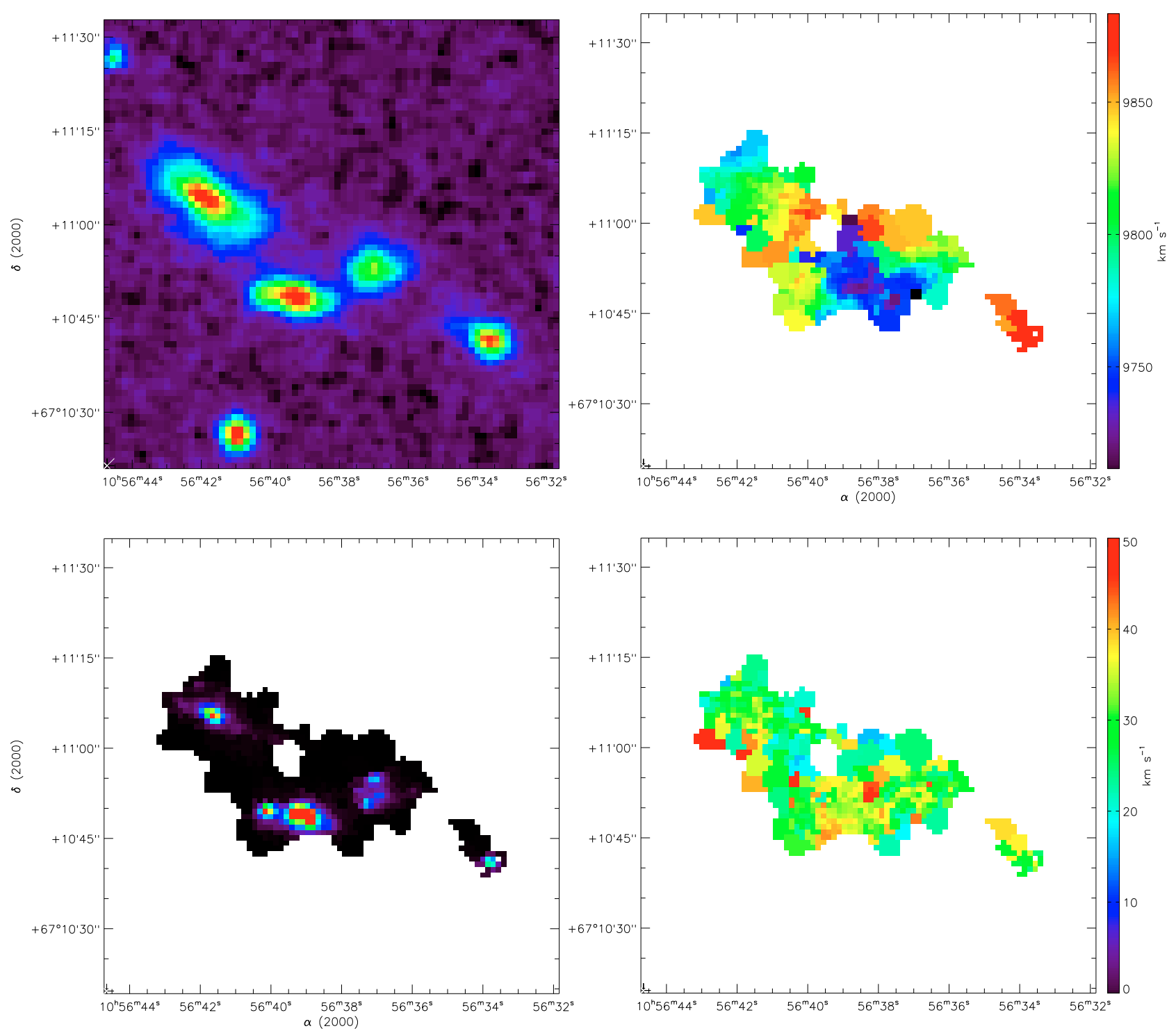

Fig. B.4. Maps for HCG 49. From east to west: HCG 49a, 49b, 49c and 49d. Top left: B band image from DSS. Top right: velocity field. Bottom left: monochromatic image. Bottom right: velocity dispersion map. 
S. Torres-Flores et al.: Kinematics of galaxies in compact groups
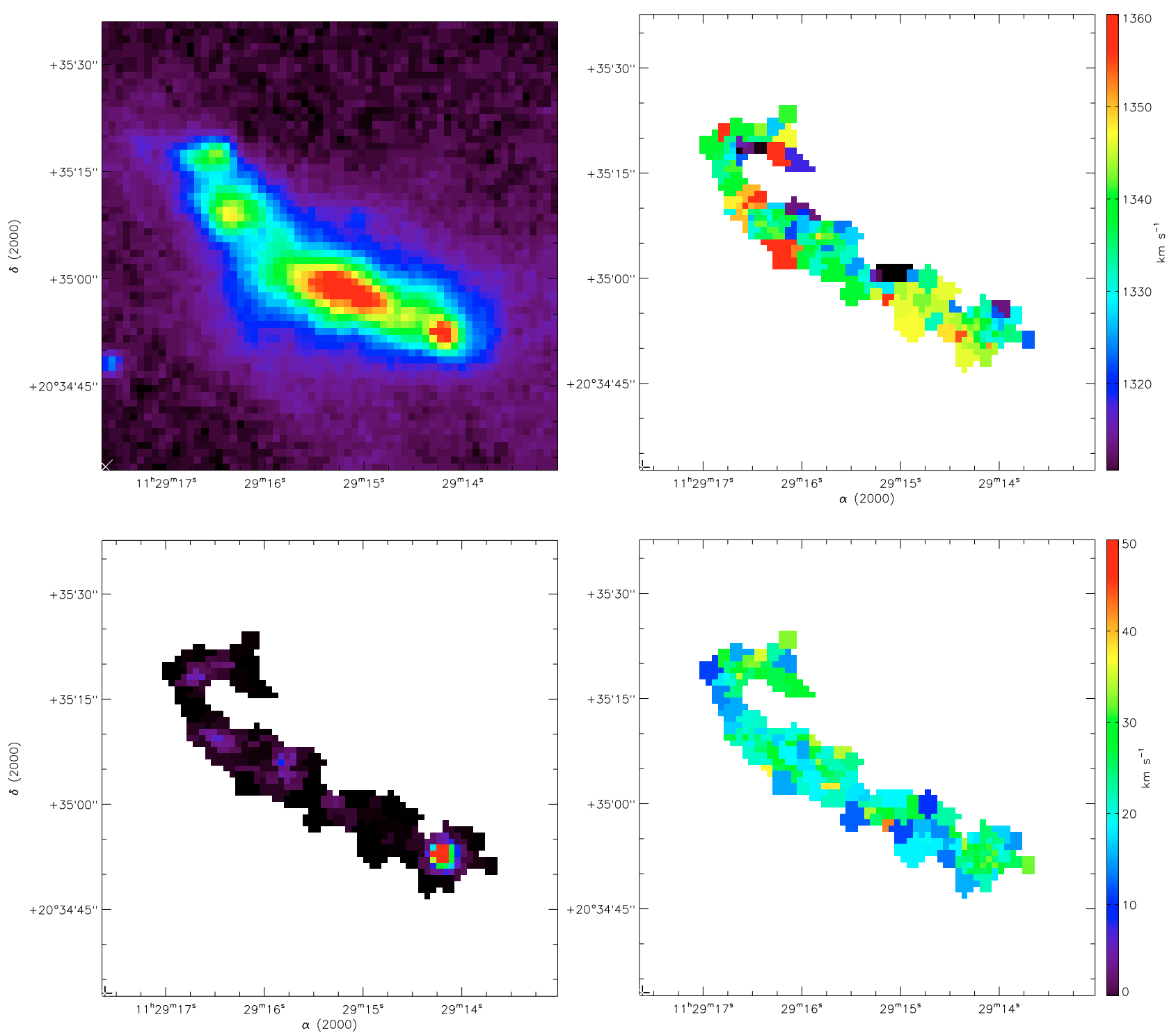

Fig. B.5. Maps for HCG 54. Top left: B band image from DSS. Top right: velocity field. Bottom left: monochromatic image. Bottom right: velocity dispersion map. 
A\&A 521, A59 (2010)
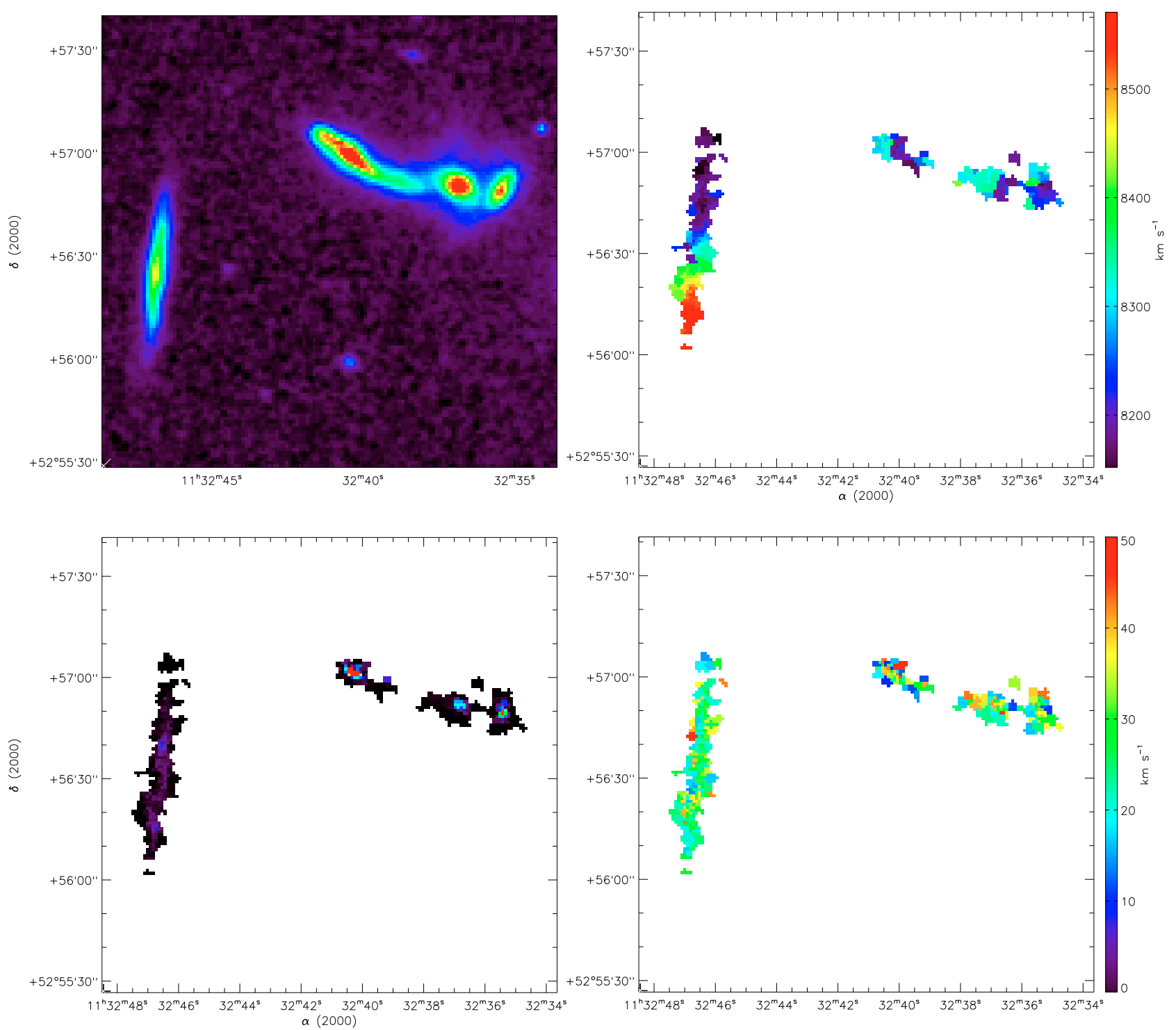

Fig. B.6. Maps for HCG 56. From east to west: HCG 56a, 56b, 56c, and 56d. Top left: B band image from DSS. Top right: velocity field. Bottom left: monochromatic image. Bottom right: velocity dispersion map. 
S. Torres-Flores et al.: Kinematics of galaxies in compact groups
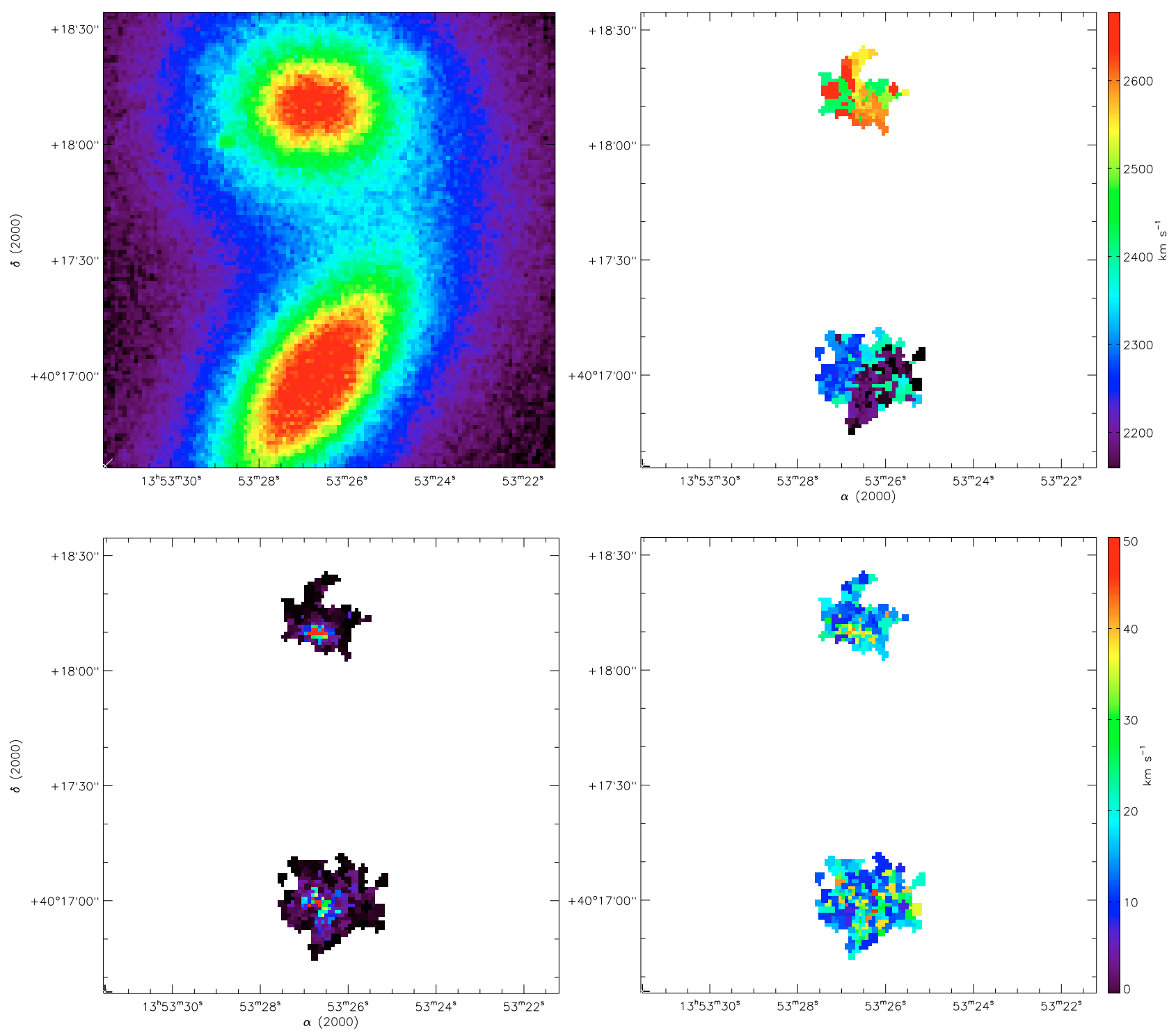

Fig. B.7. Maps for HCG 68. HCG 68a is located to the south of HCG 68b. Top left: B band image from DSS. Top right: velocity field. Bottom left: monochromatic image. Bottom right: velocity dispersion map. 
A\&A 521, A59 (2010)
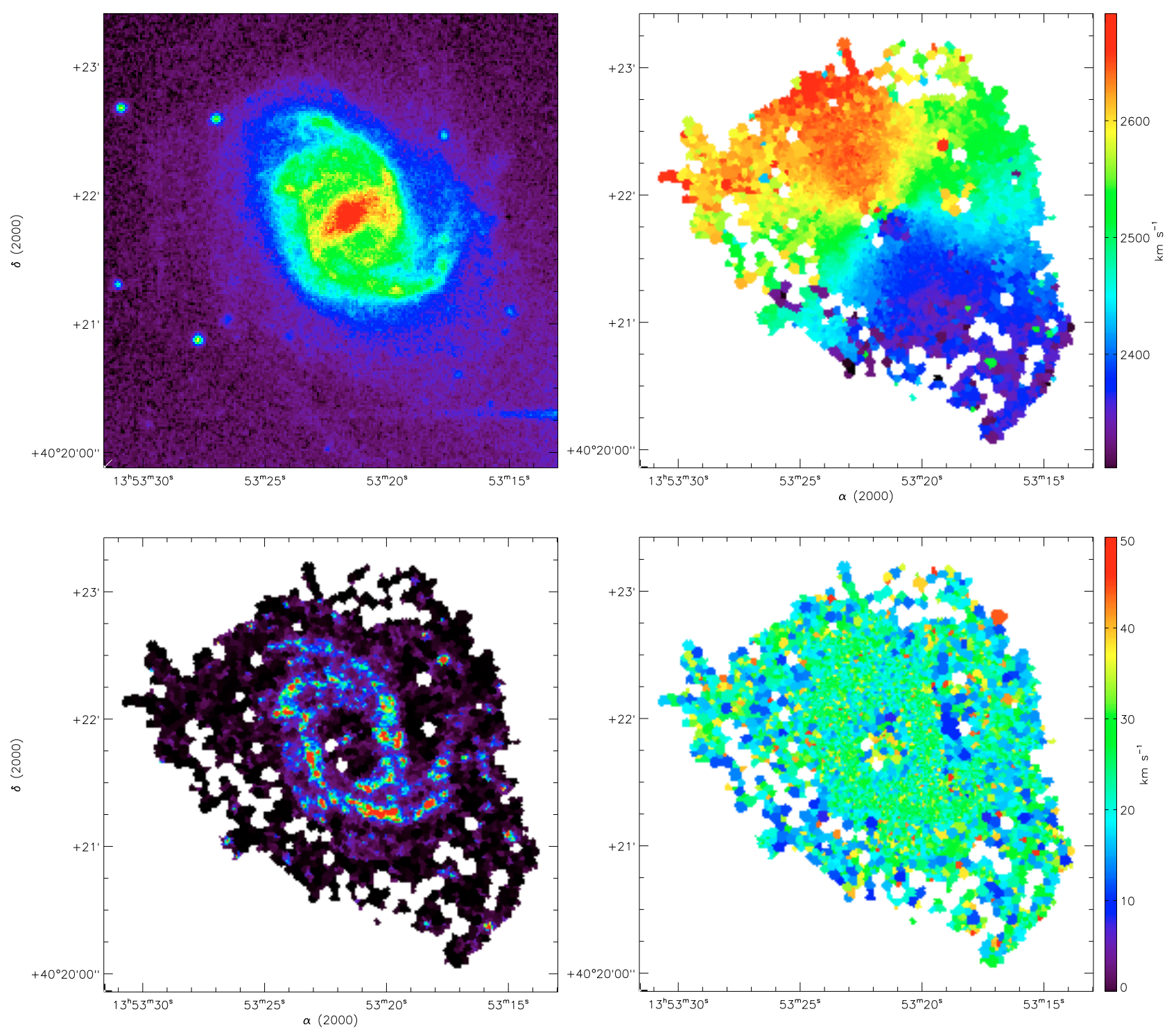

Fig. B.8. Maps for HCG 68c. Top left: B band image from DSS. Top right: velocity field. Bottom left: monochromatic image. Bottom right: velocity dispersion map. 
S. Torres-Flores et al.: Kinematics of galaxies in compact groups
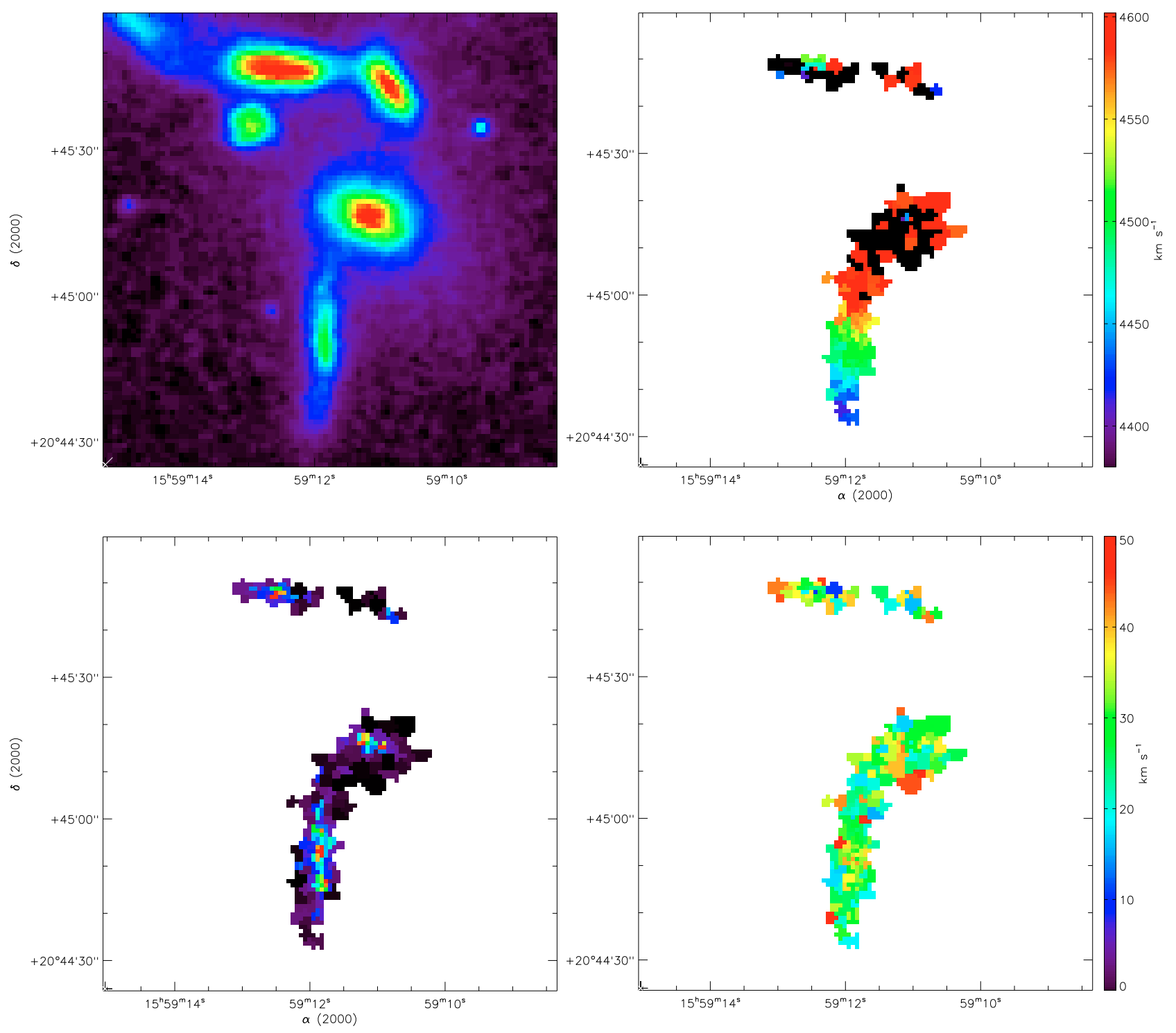

Fig. B.9. Maps for HCG 79. HCG 79b and 79c are located in the north of the field, from east to west. HCG 79a is in the center of the field and HCG 79d placed at the south of 79a. Top left: B band image from DSS. Top right: velocity field. Bottom left: monochromatic image. Bottom right: velocity dispersion map. 
A\&A 521, A59 (2010)
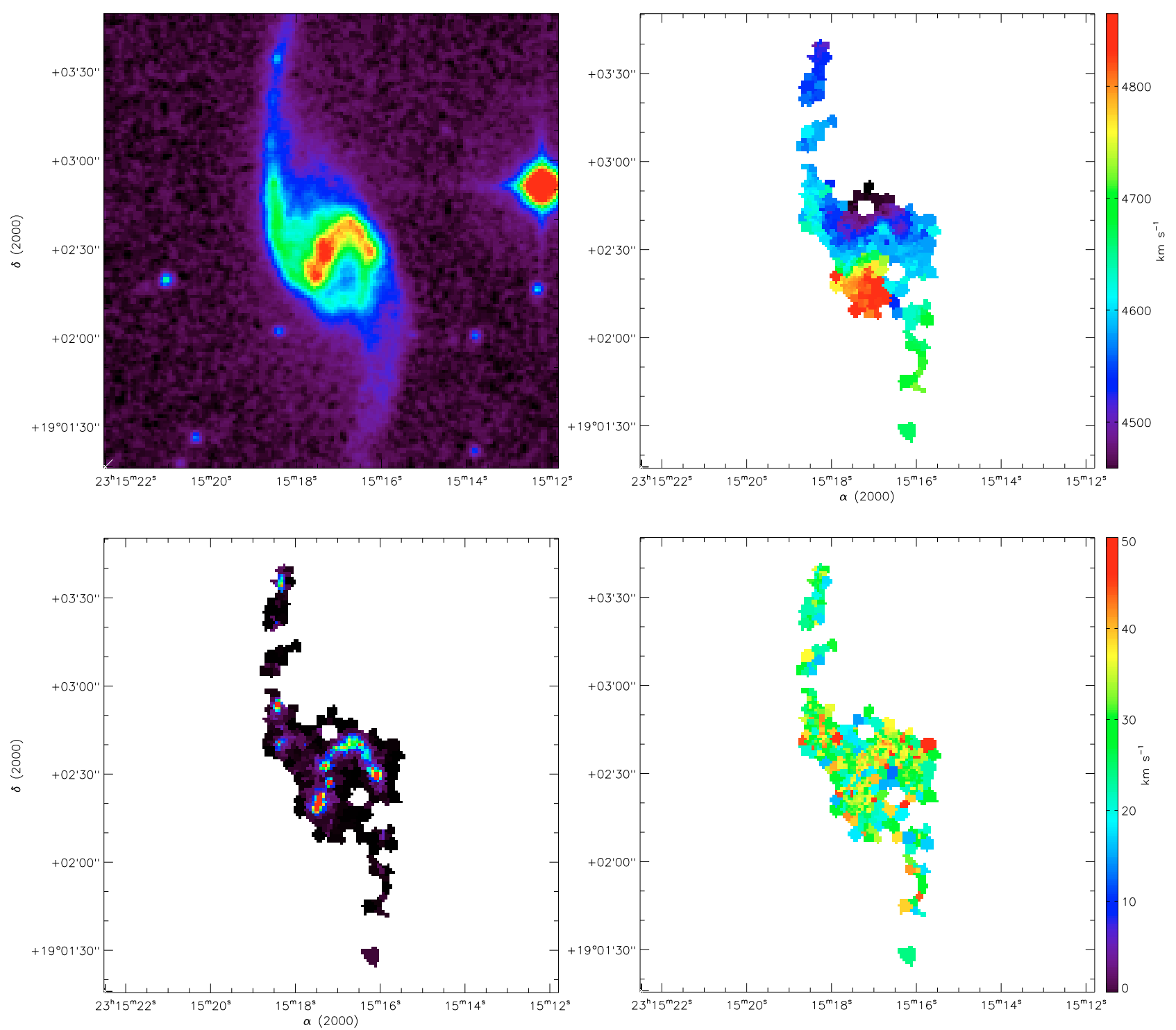

Fig. B.10. Maps for HCG 93b. Top left: B band image from DSS. Top right: velocity field. Bottom left: monochromatic image. Bottom right: velocity dispersion map. 
S. Torres-Flores et al.: Kinematics of galaxies in compact groups
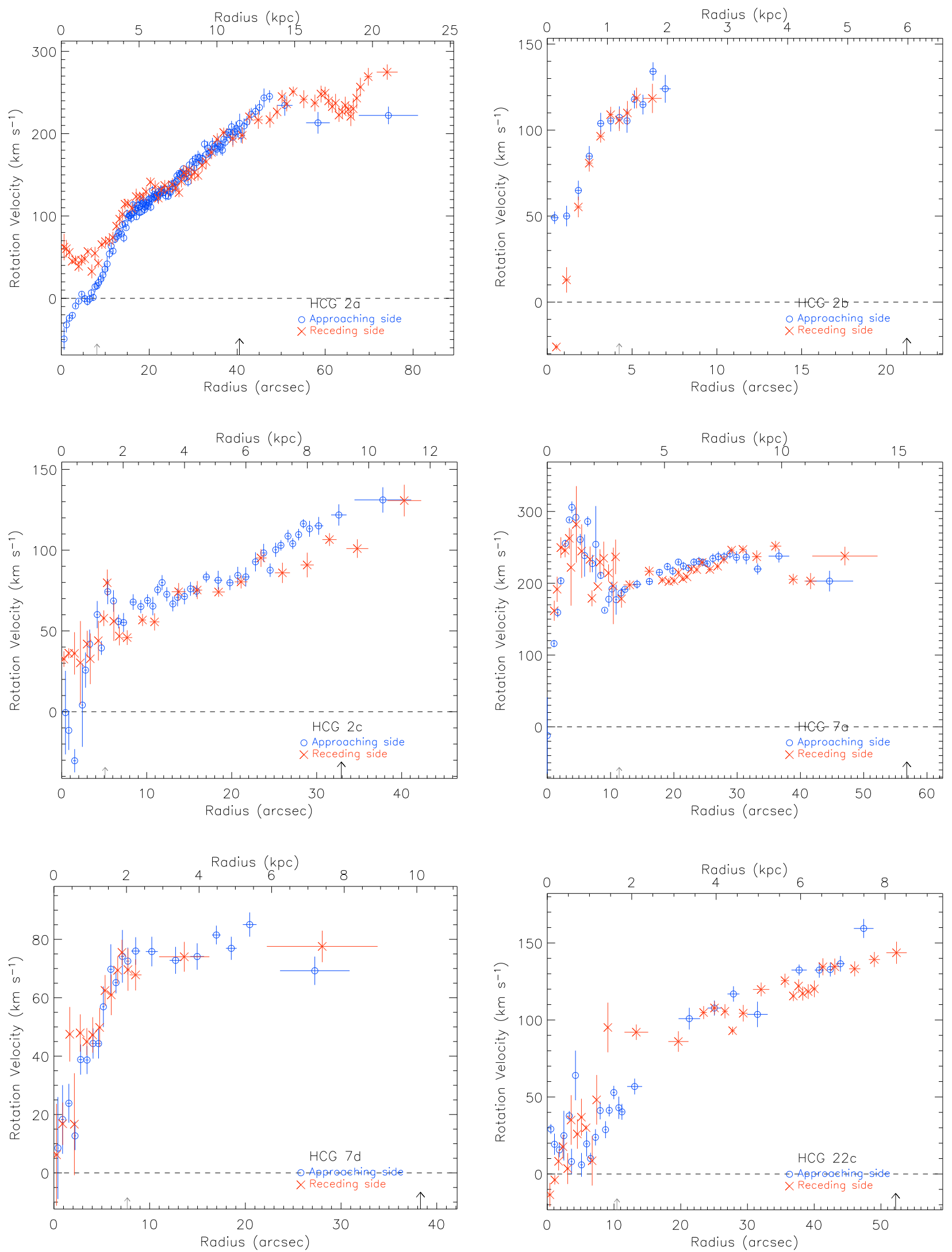

Fig. B.11. Rotation curves in this sample. The PA was determinated automatically from the model. The center and inclination were fixed (mophological center and photometic inclination, respectively). The black vertical arrow in the $x$-axis represents the radius $R_{25}$ while the smaller grey arrow in the $x$-axis represents the transition radius that is defined by the first ring that contains more than 25 uncorrelated bins in the velocity field (see Epinat et al. 2008a). 
A\&A 521, A59 (2010)
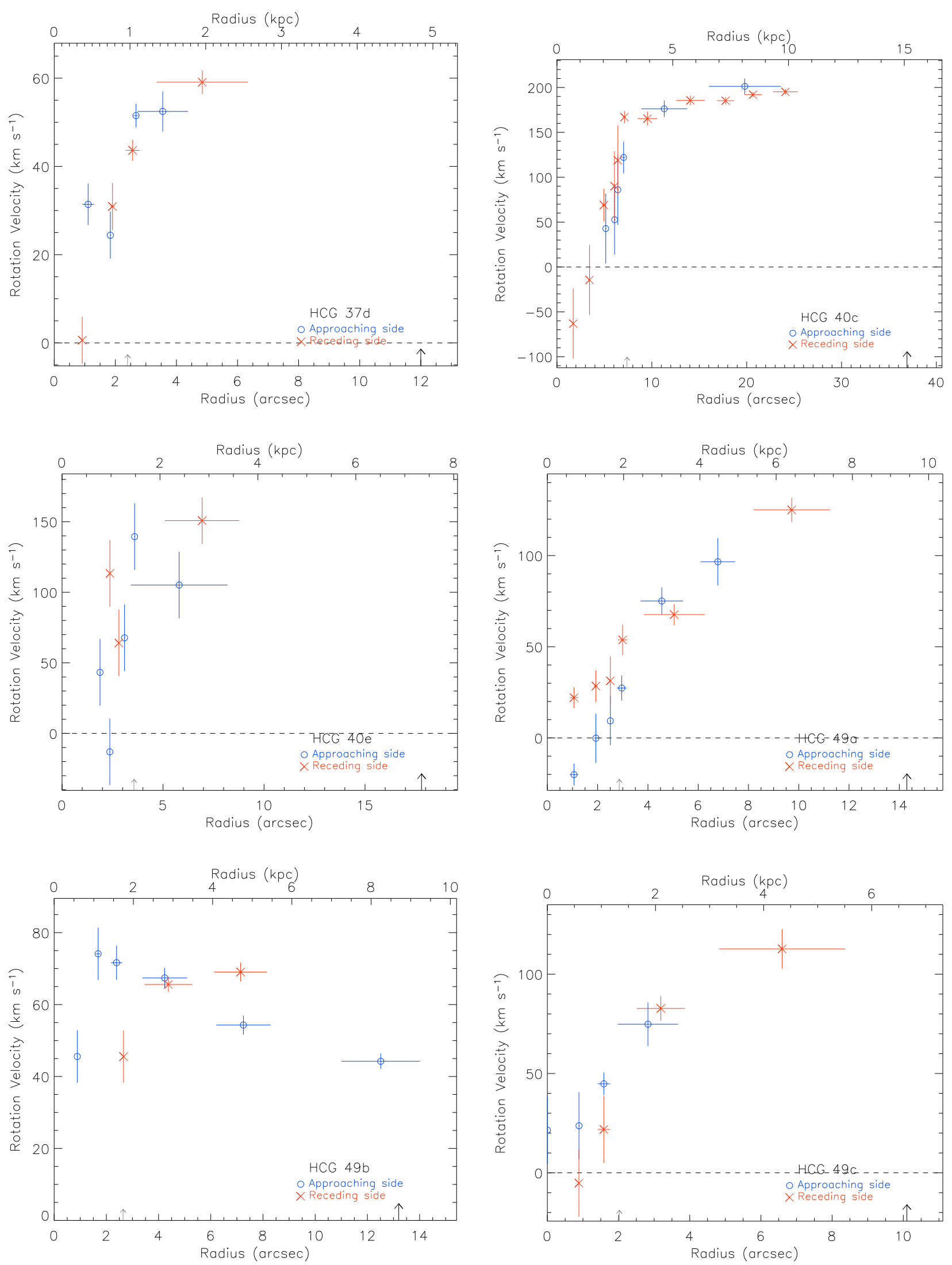

Fig. B.12. See caption of Fig. B.11. 
S. Torres-Flores et al.: Kinematics of galaxies in compact groups
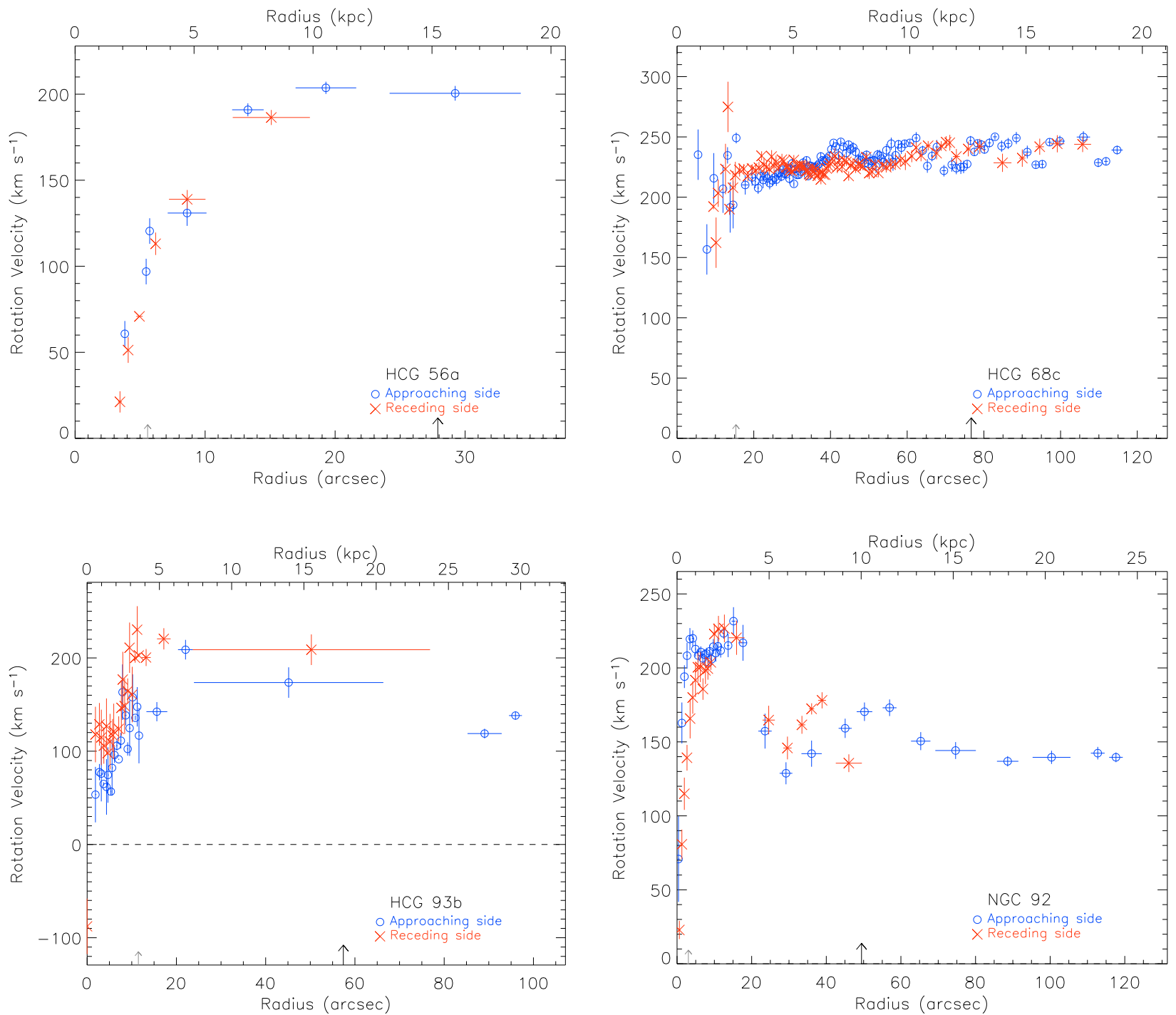

Fig. B.13. See caption of Fig. B.11. 
Appendix C: Rotation curve tables (long tables are placed at the end of this Appendix)

Table C.1. HCG 2b rotation curve.

\begin{tabular}{|c|c|c|c|c|c|c|c|}
\hline $\begin{array}{c}r \\
(\mathrm{kpc}) \\
(1)\end{array}$ & $\begin{array}{c}\sigma_{r} \\
(\mathrm{kpc}) \\
(2)\end{array}$ & $\begin{array}{c}r \\
\left({ }^{\prime \prime}\right) \\
(3)\end{array}$ & $\begin{array}{l}\sigma_{r} \\
\left({ }^{\prime \prime}\right) \\
(4)\end{array}$ & $\begin{array}{c}v \\
\left(\mathrm{~km} \mathrm{~s}^{-1}\right) \\
(5)\end{array}$ & $\begin{array}{c}\sigma_{v} \\
\left(\mathrm{~km} \mathrm{~s}^{-1}\right) \\
(6)\end{array}$ & $\begin{array}{c}N \\
\text { bins } \\
\text { (7) }\end{array}$ & Side \\
\hline 0.12 & 0.07 & 0.4 & 0.2 & 49 & 3 & 4 & $a$ \\
\hline 0.15 & 0.03 & 0.5 & 0.1 & -26 & 1 & 3 & $r$ \\
\hline 0.32 & 0.05 & 1.1 & 0.2 & 12 & 7 & 9 & $\mathrm{r}$ \\
\hline 0.32 & 0.05 & 1.1 & 0.2 & 50 & 5 & 9 & $\mathrm{a}$ \\
\hline 0.52 & 0.05 & 1.8 & 0.2 & 55 & 5 & 14 & $r$ \\
\hline 0.52 & 0.05 & 1.8 & 0.2 & 64 & 5 & 14 & $\mathrm{a}$ \\
\hline 0.70 & 0.05 & 2.5 & 0.2 & 80 & 4 & 20 & $\mathrm{r}$ \\
\hline 0.70 & 0.05 & 2.5 & 0.2 & 84 & 5 & 20 & $\mathrm{a}$ \\
\hline 0.89 & 0.05 & 3.1 & 0.2 & 96 & 3 & 24 & $\mathrm{r}$ \\
\hline 0.89 & 0.05 & 3.1 & 0.2 & 103 & 6 & 24 & $\mathrm{a}$ \\
\hline 1.06 & 0.04 & 3.7 & 0.2 & 108 & 4 & 24 & $\mathrm{r}$ \\
\hline 1.06 & 0.04 & 3.7 & 0.2 & 105 & 6 & 24 & $\mathrm{a}$ \\
\hline 1.20 & 0.04 & 4.3 & 0.1 & 105 & 6 & 24 & $r$ \\
\hline 1.20 & 0.04 & 4.3 & 0.1 & 107 & 6 & 24 & $\mathrm{a}$ \\
\hline 1.33 & 0.03 & 4.7 & 0.1 & 105 & 6 & 24 & $\mathrm{a}$ \\
\hline 1.33 & 0.04 & 4.7 & 0.1 & 109 & 6 & 24 & $r$ \\
\hline 1.45 & 0.03 & 5.1 & 0.1 & 117 & 5 & 24 & $\mathrm{a}$ \\
\hline 1.49 & 0.05 & 5.3 & 0.2 & 118 & 6 & 24 & $r$ \\
\hline 1.59 & 0.05 & 5.6 & 0.2 & 114 & 5 & 24 & $\mathrm{a}$ \\
\hline 1.75 & 0.15 & 6.2 & 0.5 & 118 & 8 & 21 & $r$ \\
\hline 1.76 & 0.06 & 6.2 & 0.2 & 134 & 5 & 24 & $\mathrm{a}$ \\
\hline 1.96 & 0.09 & 7.0 & 0.3 & 123 & 8 & 20 & $\mathrm{a}$ \\
\hline
\end{tabular}

Notes. (1), (3) Galactic radius. (2), (4) Dispersion around the galactic radius. (5) Rotation velocity. (6) Dispersion on the rotation velocity. (7) Number of velocity bins. (8) Receding $-\mathrm{r}-$ or approaching $-\mathrm{a}-$ side.
Table C.2. HCG 7d rotation curve.

\begin{tabular}{|c|c|c|c|c|c|c|c|}
\hline $\begin{array}{c}r \\
(\mathrm{kpc}) \\
(1)\end{array}$ & $\begin{array}{c}\sigma_{r} \\
(\mathrm{kpc}) \\
(2)\end{array}$ & $\begin{array}{c}r \\
(") \\
(3)\end{array}$ & $\begin{array}{l}\sigma_{r} \\
(") \\
(4)\end{array}$ & $\begin{array}{c}v \\
\left(\mathrm{~km} \mathrm{~s}^{-1}\right) \\
(5)\end{array}$ & $\begin{array}{c}\sigma_{v} \\
\left(\mathrm{~km} \mathrm{~s}^{-1}\right) \\
(6)\end{array}$ & $\begin{array}{c}N \\
\text { bins } \\
\text { (7) }\end{array}$ & $\begin{array}{r}\text { Side } \\
(8)\end{array}$ \\
\hline 0.07 & 0.05 & 0.3 & 0.2 & 6 & 17 & 2 & $r$ \\
\hline 0.11 & 0.00 & 0.4 & 0.0 & 8 & 17 & 1 & $\mathrm{a}$ \\
\hline 0.24 & 0.04 & 0.9 & 0.2 & 18 & 11 & 6 & $\mathrm{a}$ \\
\hline 0.24 & 0.04 & 0.9 & 0.1 & 16 & 7 & 4 & $\mathrm{r}$ \\
\hline 0.41 & 0.05 & 1.6 & 0.2 & 23 & 6 & 9 & $\mathrm{a}$ \\
\hline 0.44 & 0.04 & 1.7 & 0.2 & 47 & 9 & 4 & $r$ \\
\hline 0.56 & 0.00 & 2.1 & 0.0 & 16 & 17 & 1 & $r$ \\
\hline 0.58 & 0.03 & 2.2 & 0.1 & 12 & 4 & 7 & $\mathrm{a}$ \\
\hline 0.73 & 0.05 & 2.8 & 0.2 & 47 & 6 & 9 & $\mathrm{r}$ \\
\hline 0.74 & 0.05 & 2.8 & 0.2 & 38 & 5 & 12 & $\mathrm{a}$ \\
\hline 0.91 & 0.04 & 3.4 & 0.2 & 44 & 4 & 6 & $\mathrm{r}$ \\
\hline 0.91 & 0.05 & 3.5 & 0.2 & 38 & 4 & 12 & $\mathrm{a}$ \\
\hline 1.07 & 0.04 & 4.1 & 0.2 & 47 & 6 & 8 & $\mathrm{r}$ \\
\hline 1.08 & 0.05 & 4.1 & 0.2 & 44 & 5 & 14 & $\mathrm{a}$ \\
\hline 1.23 & 0.06 & 4.7 & 0.2 & 44 & 5 & 9 & $\mathrm{a}$ \\
\hline 1.26 & 0.04 & 4.8 & 0.2 & 49 & 6 & 9 & $r$ \\
\hline 1.36 & 0.03 & 5.2 & 0.1 & 56 & 6 & 11 & $\mathrm{a}$ \\
\hline 1.41 & 0.04 & 5.3 & 0.1 & 62 & 5 & 7 & $\mathrm{r}$ \\
\hline 1.57 & 0.05 & 5.9 & 0.2 & 69 & 8 & 8 & $\mathrm{a}$ \\
\hline 1.58 & 0.05 & 6.0 & 0.2 & 60 & 6 & 9 & $\mathrm{r}$ \\
\hline 1.71 & 0.04 & 6.5 & 0.2 & 65 & 3 & 7 & $\mathrm{a}$ \\
\hline 1.76 & 0.04 & 6.7 & 0.1 & 69 & 4 & 12 & $r$ \\
\hline 1.88 & 0.04 & 7.1 & 0.1 & 75 & 4 & 11 & $\mathrm{r}$ \\
\hline 1.89 & 0.05 & 7.2 & 0.2 & 74 & 9 & 5 & $\mathrm{a}$ \\
\hline 2.04 & 0.05 & 7.7 & 0.2 & 72 & 4 & 9 & $\mathrm{a}$ \\
\hline 2.04 & 0.05 & 7.7 & 0.2 & 69 & 7 & 11 & $\mathrm{r}$ \\
\hline 2.25 & 0.16 & 8.5 & 0.6 & 67 & 5 & 23 & $r$ \\
\hline 2.25 & 0.12 & 8.5 & 0.5 & 75 & 4 & 23 & $\mathrm{a}$ \\
\hline 2.70 & 0.17 & 10.2 & 0.6 & 75 & 5 & 23 & $\mathrm{a}$ \\
\hline 3.35 & 0.16 & 12.7 & 0.6 & 72 & 4 & 23 & $\mathrm{a}$ \\
\hline 3.59 & 0.69 & 13.6 & 2.6 & 74 & 5 & 23 & $\mathrm{r}$ \\
\hline 3.95 & 0.19 & 15.0 & 0.7 & 74 & 4 & 23 & $\mathrm{a}$ \\
\hline 4.48 & 0.12 & 17.0 & 0.4 & 81 & 3 & 23 & $\mathrm{a}$ \\
\hline 4.89 & 0.15 & 18.5 & 0.6 & 76 & 3 & 23 & $\mathrm{a}$ \\
\hline 5.40 & 0.19 & 20.5 & 0.7 & 85 & 4 & 23 & $\mathrm{a}$ \\
\hline 7.19 & 0.96 & 27.3 & 3.6 & 69 & 4 & 22 & $\mathrm{a}$ \\
\hline 7.39 & 1.53 & 28.0 & 5.8 & 77 & 5 & 15 & $\mathrm{r}$ \\
\hline
\end{tabular}

Notes. (1), (3) Galactic radius. (2), (4) Dispersion around the galactic radius. (5) Rotation velocity. (6) Dispersion on the rotation velocity. (7) Number of velocity bins. (8) Receding $-\mathrm{r}-$ or approaching $-\mathrm{a}-$ side. 
Table C.3. HCG 22c rotation curve.

\begin{tabular}{|c|c|c|c|c|c|c|c|}
\hline $\begin{array}{c}r \\
(\mathrm{kpc}) \\
(1)\end{array}$ & $\begin{array}{c}\sigma_{r} \\
(\mathrm{kpc}) \\
(2)\end{array}$ & $\begin{array}{c}r \\
\left({ }^{\prime \prime}\right) \\
(3)\end{array}$ & $\begin{array}{l}\sigma_{r} \\
\left({ }^{\prime \prime}\right) \\
(4)\end{array}$ & $\begin{array}{c}v \\
\left(\mathrm{~km} \mathrm{~s}^{-1}\right) \\
(5)\end{array}$ & $\begin{array}{c}\sigma_{v} \\
\left(\mathrm{~km} \mathrm{~s}^{-1}\right) \\
(6)\end{array}$ & $\begin{array}{c}N \\
\text { bins } \\
\text { (7) }\end{array}$ & Side \\
\hline 0.06 & 0.04 & 0.4 & 0.2 & -13 & 7 & 4 & $\mathrm{r}$ \\
\hline 0.08 & 0.02 & 0.5 & 0.1 & 29 & 3 & 3 & $\mathrm{a}$ \\
\hline 0.17 & 0.03 & 1.1 & 0.2 & 19 & 6 & 7 & $\mathrm{a}$ \\
\hline 0.18 & 0.03 & 1.1 & 0.2 & -3 & 3 & 9 & $r$ \\
\hline 0.27 & 0.02 & 1.7 & 0.1 & 8 & 5 & 10 & $\mathrm{r}$ \\
\hline 0.29 & 0.02 & 1.8 & 0.1 & 15 & 4 & 6 & $\mathrm{a}$ \\
\hline 0.37 & 0.04 & 2.4 & 0.2 & 17 & 7 & 9 & $\mathrm{r}$ \\
\hline 0.39 & 0.03 & 2.5 & 0.2 & 24 & 16 & 4 & $\mathrm{a}$ \\
\hline 0.48 & 0.03 & 3.1 & 0.2 & 3 & 10 & 6 & $\mathrm{r}$ \\
\hline 0.52 & 0.02 & 3.3 & 0.1 & 37 & 3 & 2 & $\mathrm{a}$ \\
\hline 0.57 & 0.00 & 3.6 & 0.0 & 35 & 16 & 1 & $r$ \\
\hline 0.57 & 0.02 & 3.6 & 0.1 & 8 & 8 & 2 & $\mathrm{a}$ \\
\hline 0.67 & 0.00 & 4.2 & 0.0 & 64 & 16 & 1 & $\mathrm{a}$ \\
\hline 0.71 & 0.04 & 4.5 & 0.3 & 25 & 9 & 4 & $\mathrm{r}$ \\
\hline 0.81 & 0.04 & 5.1 & 0.2 & 36 & 12 & 4 & $\mathrm{r}$ \\
\hline 0.81 & 0.03 & 5.1 & 0.2 & 5 & 7 & 5 & $\mathrm{a}$ \\
\hline 0.92 & 0.02 & 5.8 & 0.1 & 30 & 1 & 2 & $\mathrm{r}$ \\
\hline 0.93 & 0.04 & 5.9 & 0.2 & 19 & 8 & 7 & $\mathrm{a}$ \\
\hline 1.03 & 0.04 & 6.5 & 0.2 & 10 & 3 & 3 & $\mathrm{a}$ \\
\hline 1.06 & 0.00 & 6.7 & 0.0 & 8 & 16 & 1 & $\mathrm{r}$ \\
\hline 1.14 & 0.03 & 7.2 & 0.2 & 23 & 5 & 10 & $\mathrm{a}$ \\
\hline 1.17 & 0.00 & 7.4 & 0.0 & 48 & 16 & 1 & $\mathrm{r}$ \\
\hline 1.25 & 0.02 & 7.9 & 0.1 & 41 & 5 & 8 & $\mathrm{a}$ \\
\hline 1.38 & 0.03 & 8.7 & 0.2 & 28 & 5 & 10 & $\mathrm{a}$ \\
\hline 1.44 & 0.00 & 9.1 & 0.0 & 95 & 16 & 1 & $\mathrm{r}$ \\
\hline 1.47 & 0.03 & 9.3 & 0.2 & 41 & 3 & 8 & $\mathrm{a}$ \\
\hline 1.58 & 0.03 & 10.0 & 0.2 & 52 & 4 & 11 & $\mathrm{a}$ \\
\hline 1.69 & 0.04 & 10.7 & 0.2 & 42 & 7 & 9 & $\mathrm{a}$ \\
\hline 1.77 & 0.06 & 11.2 & 0.4 & 40 & 5 & 21 & $\mathrm{a}$ \\
\hline 2.07 & 0.18 & 13.1 & 1.1 & 56 & 5 & 21 & $\mathrm{a}$ \\
\hline 2.11 & 0.28 & 13.3 & 1.8 & 92 & 5 & 21 & $\mathrm{r}$ \\
\hline 3.11 & 0.24 & 19.7 & 1.5 & 85 & 6 & 21 & $\mathrm{r}$ \\
\hline 3.36 & 0.25 & 21.3 & 1.6 & 100 & 7 & 21 & $\mathrm{a}$ \\
\hline 3.70 & 0.07 & 23.4 & 0.5 & 104 & 4 & 21 & $\mathrm{r}$ \\
\hline 3.96 & 0.16 & 25.0 & 1.0 & 107 & 4 & 21 & $\mathrm{a}$ \\
\hline 3.96 & 0.09 & 25.1 & 0.6 & 107 & 4 & 21 & $\mathrm{r}$ \\
\hline 4.21 & 0.06 & 26.6 & 0.4 & 105 & 4 & 21 & $\mathrm{r}$ \\
\hline 4.39 & 0.05 & 27.8 & 0.3 & 93 & 2 & 21 & $\mathrm{r}$ \\
\hline 4.41 & 0.14 & 27.9 & 0.9 & 116 & 5 & 21 & $\mathrm{a}$ \\
\hline 4.64 & 0.10 & 29.4 & 0.6 & 104 & 5 & 21 & $\mathrm{r}$ \\
\hline 4.98 & 0.24 & 31.5 & 1.5 & 103 & 8 & 21 & $\mathrm{a}$ \\
\hline 5.07 & 0.19 & 32.1 & 1.2 & 119 & 4 & 21 & $\mathrm{r}$ \\
\hline 5.63 & 0.09 & 35.6 & 0.6 & 125 & 4 & 21 & $\mathrm{r}$ \\
\hline 5.83 & 0.03 & 36.9 & 0.2 & 115 & 3 & 21 & $\mathrm{r}$ \\
\hline 5.95 & 0.03 & 37.7 & 0.2 & 122 & 4 & 21 & $\mathrm{r}$ \\
\hline 5.97 & 0.18 & 37.7 & 1.1 & 132 & 3 & 21 & $\mathrm{a}$ \\
\hline 6.05 & 0.03 & 38.3 & 0.2 & 117 & 4 & 21 & $\mathrm{r}$ \\
\hline 6.18 & 0.04 & 39.1 & 0.3 & 118 & 4 & 21 & $\mathrm{r}$ \\
\hline 6.33 & 0.05 & 40.0 & 0.3 & 120 & 5 & 21 & $\mathrm{r}$ \\
\hline 6.44 & 0.11 & 40.8 & 0.7 & 132 & 4 & 21 & $\mathrm{a}$ \\
\hline 6.53 & 0.07 & 41.3 & 0.4 & 134 & 5 & 21 & $\mathrm{r}$ \\
\hline 6.70 & 0.05 & 42.4 & 0.3 & 132 & 4 & 21 & $\mathrm{a}$ \\
\hline 6.81 & 0.10 & 43.1 & 0.6 & 134 & 5 & 21 & $\mathrm{r}$ \\
\hline 6.94 & 0.10 & 43.9 & 0.6 & 136 & 5 & 21 & $\mathrm{a}$ \\
\hline 7.28 & 0.13 & 46.1 & 0.8 & 133 & 4 & 21 & $\mathrm{r}$ \\
\hline 7.49 & 0.23 & 47.4 & 1.5 & 159 & 6 & 21 & $\mathrm{a}$ \\
\hline 7.75 & 0.13 & 49.0 & 0.8 & 139 & 4 & 21 & $\mathrm{r}$ \\
\hline 8.27 & 0.24 & 52.3 & 1.5 & 143 & 7 & 18 & $\mathrm{r}$ \\
\hline
\end{tabular}

Notes. (1), (3) Galactic radius. (2), (4) Dispersion around the galactic radius. (5) Rotation velocity. (6) Dispersion on the rotation velocity. (7) Number of velocity bins. (8) Receding $-r-$ or approaching $-a-$ side.
Table C.4. HCG 37d rotation curve.

\begin{tabular}{|c|c|c|c|c|c|c|c|}
\hline $\begin{array}{c}r \\
(\mathrm{kpc}) \\
(1)\end{array}$ & $\begin{array}{c}\sigma_{r} \\
(\mathrm{kpc}) \\
(2)\end{array}$ & $\begin{array}{c}r \\
(") \\
(3)\end{array}$ & $\begin{array}{l}\sigma_{r} \\
\left({ }^{\prime \prime}\right) \\
(4)\end{array}$ & $\begin{array}{c}v \\
\left(\mathrm{~km} \mathrm{~s}^{-1}\right) \\
(5)\end{array}$ & $\begin{array}{c}\sigma_{v} \\
\left(\mathrm{~km} \mathrm{~s}^{-1}\right) \\
(6)\end{array}$ & $\begin{array}{c}N \\
\text { bins } \\
\text { (7) }\end{array}$ & Side \\
\hline 0.37 & 0.00 & 0.9 & 0.0 & 0 & 5 & 1 & $\mathrm{r}$ \\
\hline 0.45 & 0.08 & 1.1 & 0.2 & 31 & 4 & 2 & a \\
\hline 0.74 & 0.00 & 1.8 & 0.0 & 24 & 5 & 1 & a \\
\hline 0.77 & 0.03 & 1.9 & 0.1 & 30 & 5 & 2 & $\mathrm{r}$ \\
\hline 1.04 & 0.09 & 2.6 & 0.2 & 43 & 2 & 2 & $\mathrm{r}$ \\
\hline 1.08 & 0.03 & 2.7 & 0.1 & 51 & 2 & 2 & $\mathrm{a}$ \\
\hline 1.43 & 0.33 & 3.6 & 0.8 & 52 & 4 & 7 & $\mathrm{a}$ \\
\hline 1.96 & 0.60 & 4.8 & 1.5 & 59 & 2 & 19 & $\mathrm{r}$ \\
\hline
\end{tabular}

Notes. (1), (3) Galactic radius. (2), (4) Dispersion around the galactic radius. (5) Rotation velocity. (6) Dispersion on the rotation velocity. (7) Number of velocity bins. (8) Receding $-\mathrm{r}-$ or approaching $-\mathrm{a}-$ side.

Table C.5. HCG 40c rotation curve.

\begin{tabular}{|c|c|c|c|c|c|c|c|}
\hline $\begin{array}{c}r \\
(\mathrm{kpc}) \\
(1)\end{array}$ & $\begin{array}{c}\sigma_{r} \\
(\mathrm{kpc}) \\
(2)\end{array}$ & $\begin{array}{c}r \\
\left({ }^{\prime \prime}\right) \\
(3)\end{array}$ & $\begin{array}{l}\sigma_{r} \\
\left({ }^{\prime \prime}\right) \\
(4)\end{array}$ & $\begin{array}{c}v \\
\left(\mathrm{~km} \mathrm{~s}^{-1}\right) \\
(5)\end{array}$ & $\begin{array}{c}\sigma_{v} \\
\left(\mathrm{~km} \mathrm{~s}^{-1}\right) \\
(6)\end{array}$ & $\begin{array}{c}N \\
\text { bins } \\
(7)\end{array}$ & Side \\
\hline 0.70 & 0.00 & 1.7 & 0.0 & -63 & 38 & 1 & $\mathrm{r}$ \\
\hline 1.41 & 0.00 & 3.4 & 0.0 & -14 & 38 & 1 & $\mathrm{r}$ \\
\hline 2.03 & 0.07 & 4.9 & 0.2 & 68 & 18 & 2 & $\mathrm{r}$ \\
\hline 2.11 & 0.00 & 5.1 & 0.0 & 42 & 38 & 1 & $\mathrm{a}$ \\
\hline 2.49 & 0.00 & 6.1 & 0.0 & 90 & 38 & 2 & $\mathrm{r}$ \\
\hline 2.49 & 0.00 & 6.1 & 0.0 & 52 & 38 & 1 & $\mathrm{a}$ \\
\hline 2.63 & 0.00 & 6.4 & 0.0 & 86 & 38 & 1 & $\mathrm{a}$ \\
\hline 2.63 & 0.00 & 6.4 & 0.0 & 118 & 38 & 1 & $\mathrm{r}$ \\
\hline 2.88 & 0.08 & 7.0 & 0.2 & 122 & 17 & 4 & $\mathrm{a}$ \\
\hline 2.92 & 0.06 & 7.1 & 0.1 & 166 & 6 & 4 & $\mathrm{r}$ \\
\hline 3.91 & 0.42 & 9.5 & 1.0 & 165 & 7 & 23 & $\mathrm{r}$ \\
\hline 4.63 & 0.99 & 11.3 & 2.4 & 176 & 9 & 23 & $\mathrm{a}$ \\
\hline 5.77 & 0.61 & 14.1 & 1.5 & 185 & 5 & 23 & $\mathrm{r}$ \\
\hline 7.28 & 0.37 & 17.8 & 0.9 & 185 & 3 & 23 & $\mathrm{r}$ \\
\hline 8.11 & 1.55 & 19.8 & 3.8 & 201 & 8 & 17 & $\mathrm{a}$ \\
\hline 8.47 & 0.37 & 20.7 & 0.9 & 191 & 2 & 23 & $\mathrm{r}$ \\
\hline 9.87 & 0.53 & 24.1 & 1.3 & 195 & 2 & 22 & $\mathrm{r}$ \\
\hline
\end{tabular}

Notes. (1), (3) Galactic radius. (2), (4) Dispersion around the galactic radius. (5) Rotation velocity. (6) Dispersion on the rotation velocity. (7) Number of velocity bins. (8) Receding $-\mathrm{r}-$ or approaching $-\mathrm{a}-$ side.

Table C.6. HCG 40e rotation curve.

\begin{tabular}{|c|c|c|c|c|c|c|c|}
\hline $\begin{array}{c}r \\
(\mathrm{kpc}) \\
(1)\end{array}$ & $\begin{array}{c}\sigma_{r} \\
(\mathrm{kpc}) \\
(2)\end{array}$ & $\begin{array}{l}r \\
\left({ }^{\prime \prime}\right) \\
(3)\end{array}$ & $\begin{array}{l}\sigma_{r} \\
\left({ }^{\prime \prime}\right) \\
(4)\end{array}$ & $\begin{array}{c}v \\
\left(\mathrm{~km} \mathrm{~s}^{-1}\right) \\
(5)\end{array}$ & $\begin{array}{c}\sigma_{v} \\
\left(\mathrm{~km} \mathrm{~s}^{-1}\right) \\
(6)\end{array}$ & $\begin{array}{c}N \\
\text { bins } \\
(7)\end{array}$ & Side \\
\hline 0.78 & 0.00 & 1.9 & 0.0 & 43 & 23 & 1 & $a$ \\
\hline 0.98 & 0.00 & 2.4 & 0.0 & -13 & 23 & 1 & a \\
\hline 0.98 & 0.00 & 2.4 & 0.0 & 113 & 23 & 1 & $\mathrm{r}$ \\
\hline 1.16 & 0.00 & 2.8 & 0.0 & 64 & 23 & 1 & $\mathrm{r}$ \\
\hline 1.28 & 0.00 & 3.1 & 0.0 & 67 & 23 & 1 & a \\
\hline 1.48 & 0.00 & 3.6 & 0.0 & 139 & 23 & 1 & a \\
\hline 2.39 & 0.99 & 5.8 & 2.4 & 105 & 23 & 3 & $\mathrm{a}$ \\
\hline 2.86 & 0.76 & 6.9 & 1.8 & 150 & 16 & 3 & $\mathrm{r}$ \\
\hline
\end{tabular}

Notes. (1), (3) Galactic radius. (2), (4) Dispersion around the galactic radius. (5) Rotation velocity. (6) Dispersion on the rotation velocity. (7) Number of velocity bins. (8) Receding $-\mathrm{r}-$ or approaching - a side. 
Table C.7. HCG 49a rotation curve.

\begin{tabular}{|c|c|c|c|c|c|c|c|}
\hline $\begin{array}{c}r \\
(\mathrm{kpc}) \\
(1)\end{array}$ & $\begin{array}{c}\sigma_{r} \\
(\mathrm{kpc}) \\
(2)\end{array}$ & $\begin{array}{c}r \\
\left({ }^{\prime \prime}\right) \\
(3)\end{array}$ & $\begin{array}{l}\sigma_{r} \\
\left({ }^{\prime \prime}\right) \\
(4)\end{array}$ & $\begin{array}{c}v \\
\left(\mathrm{~km} \mathrm{~s}^{-1}\right) \\
(5)\end{array}$ & $\begin{array}{c}\sigma_{v} \\
\left(\mathrm{~km} \mathrm{~s}^{-1}\right) \\
(6)\end{array}$ & $\begin{array}{c}N \\
\text { bins } \\
(7)\end{array}$ & Side \\
\hline 0.70 & 0.11 & 1.1 & 0.2 & -20 & 6 & 3 & $\mathrm{a}$ \\
\hline 0.70 & 0.11 & 1.1 & 0.2 & 22 & 5 & 3 & $\mathrm{r}$ \\
\hline 1.27 & 0.05 & 1.9 & 0.1 & 0 & 13 & 4 & a \\
\hline 1.27 & 0.05 & 1.9 & 0.1 & 28 & 8 & 4 & $\mathrm{r}$ \\
\hline 1.65 & 0.00 & 2.5 & 0.0 & 31 & 13 & 1 & $r$ \\
\hline 1.65 & 0.00 & 2.5 & 0.0 & 9 & 13 & 1 & $\mathrm{a}$ \\
\hline 1.95 & 0.12 & 3.0 & 0.2 & 27 & 6 & 7 & a \\
\hline 1.97 & 0.13 & 3.0 & 0.2 & 53 & 8 & 5 & $\mathrm{r}$ \\
\hline 3.00 & 0.56 & 4.6 & 0.8 & 75 & 7 & 24 & $\mathrm{a}$ \\
\hline 3.33 & 0.80 & 5.0 & 1.2 & 67 & 5 & 24 & $\mathrm{r}$ \\
\hline 4.47 & 0.46 & 6.8 & 0.7 & 96 & 12 & 13 & a \\
\hline 6.41 & 1.00 & 9.7 & 1.5 & 125 & 6 & 24 & $r$ \\
\hline
\end{tabular}

Notes. (1), (3) Galactic radius. (2), (4) Dispersion around the galactic radius. (5) Rotation velocity. (6) Dispersion on the rotation velocity. (7) Number of velocity bins. (8) Receding $-\mathrm{r}-$ or approaching $-\mathrm{a}-$ side.

Table C.8. HCG 49b rotation curve.

\begin{tabular}{|c|c|c|c|c|c|c|c|}
\hline $\begin{array}{c}r \\
(\mathrm{kpc}) \\
(1)\end{array}$ & $\begin{array}{c}\sigma_{r} \\
(\mathrm{kpc}) \\
(2)\end{array}$ & $\begin{array}{l}r \\
(") \\
(3)\end{array}$ & $\begin{array}{l}\sigma_{r} \\
(") \\
(4)\end{array}$ & $\begin{array}{c}v \\
\left(\mathrm{~km} \mathrm{~s}^{-1}\right) \\
(5)\end{array}$ & $\begin{array}{c}\sigma_{v} \\
\left(\mathrm{~km} \mathrm{~s}^{-1}\right) \\
(6)\end{array}$ & $\begin{array}{c}N \\
\text { bins } \\
(7)\end{array}$ & $\begin{array}{l}\text { Side } \\
(8)\end{array}$ \\
\hline 0.58 & 0.00 & 0.9 & 0.0 & 45 & 7 & 1 & $\mathrm{a}$ \\
\hline 1.11 & 0.05 & 1.7 & 0.1 & 74 & 7 & 3 & $\mathrm{a}$ \\
\hline 1.57 & 0.14 & 2.4 & 0.2 & 71 & 4 & 3 & $\mathrm{a}$ \\
\hline 1.75 & 0.00 & 2.7 & 0.0 & 45 & 7 & 1 & $\mathrm{r}$ \\
\hline 2.79 & 0.57 & 4.2 & 0.9 & 67 & 2 & 24 & $\mathrm{a}$ \\
\hline 2.88 & 0.60 & 4.4 & 0.9 & 65 & 2 & 24 & $\mathrm{r}$ \\
\hline 4.71 & 0.67 & 7.1 & 1.0 & 69 & 2 & 19 & $\mathrm{r}$ \\
\hline 4.78 & 0.69 & 7.3 & 1.0 & 54 & 2 & 24 & $\mathrm{a}$ \\
\hline 8.24 & 0.99 & 12.5 & 1.5 & 44 & 2 & 24 & a \\
\hline
\end{tabular}

Notes. (1), (3) Galactic radius. (2), (4) Dispersion around the galactic radius. (5) Rotation velocity. (6) Dispersion on the rotation velocity. (7) Number of velocity bins. (8) Receding $-\mathrm{r}-$ or approaching $-\mathrm{a}-$ side.

Table C.9. HCG 49c rotation curve.

\begin{tabular}{|c|c|c|c|c|c|c|c|}
\hline $\begin{array}{c}r \\
(\mathrm{kpc}) \\
(1)\end{array}$ & $\begin{array}{c}\sigma_{r} \\
(\mathrm{kpc}) \\
(2)\end{array}$ & $\begin{array}{c}r \\
\left({ }^{\prime \prime}\right) \\
(3)\end{array}$ & $\begin{array}{l}\sigma_{r} \\
\left({ }^{\prime \prime}\right) \\
(4)\end{array}$ & $\begin{array}{c}v \\
\left(\mathrm{~km} \mathrm{~s}^{-1}\right) \\
(5)\end{array}$ & $\begin{array}{c}\sigma_{v} \\
\left(\mathrm{~km} \mathrm{~s}^{-1}\right) \\
(6)\end{array}$ & $\begin{array}{c}N \\
\text { bins } \\
(7)\end{array}$ & Side \\
\hline 0.00 & 0.00 & 0.0 & 0.0 & 21 & 16 & 1 & $a$ \\
\hline 0.58 & 0.00 & 0.9 & 0.0 & -5 & 16 & 1 & $r$ \\
\hline 0.59 & 0.00 & 0.9 & 0.0 & 23 & 16 & 1 & $\mathrm{a}$ \\
\hline 1.04 & 0.11 & 1.6 & 0.2 & 21 & 16 & 3 & $\mathrm{r}$ \\
\hline 1.05 & 0.11 & 1.6 & 0.2 & 44 & 5 & 3 & $\mathrm{a}$ \\
\hline 1.86 & 0.56 & 2.8 & 0.8 & 74 & 11 & 7 & $\mathrm{a}$ \\
\hline 2.10 & 0.45 & 3.2 & 0.7 & 82 & 6 & 16 & $\mathrm{r}$ \\
\hline 4.34 & 1.16 & 6.6 & 1.8 & 112 & 9 & 10 & $\mathrm{r}$ \\
\hline
\end{tabular}

Notes. (1), (3) Galactic radius. (2), (4) Dispersion around the galactic radius. (5) Rotation velocity. (6) Dispersion on the rotation velocity. (7) Number of velocity bins. (8) Receding $-\mathrm{r}-$ or approaching $-\mathrm{a}-$ side.
Table C.10. HCG 56a rotation curve.

\begin{tabular}{cccccccc}
\hline \hline $\begin{array}{c}r \\
(\mathrm{kpc})\end{array}$ & $\begin{array}{c}\sigma_{r} \\
(\mathrm{kpc})\end{array}$ & $\begin{array}{c}r \\
\left({ }^{\prime \prime}\right)\end{array}$ & $\begin{array}{c}\sigma_{r} \\
\left({ }^{\prime \prime}\right)\end{array}$ & $\begin{array}{c}v \\
\left(\mathrm{~km} \mathrm{~s}^{-1}\right)\end{array}$ & $\begin{array}{c}\sigma_{v} \\
\left(\mathrm{~km} \mathrm{~s}^{-1}\right) \\
(6)\end{array}$ & $\begin{array}{c}N \\
\text { bins } \\
(4)\end{array}$ & $\begin{array}{c}\text { Side } \\
(5)\end{array}$ \\
\hline 1.89 & 0.08 & 3.5 & 0.1 & 21 & 6 & 2 & $\mathrm{r}$ \\
2.09 & 0.00 & 3.8 & 0.0 & 60 & 7 & 1 & $\mathrm{a}$ \\
2.23 & 0.00 & 4.1 & 0.0 & 51 & 7 & 1 & $\mathrm{r}$ \\
2.71 & 0.13 & 5.0 & 0.2 & 70 & 0 & 2 & $\mathrm{r}$ \\
2.99 & 0.00 & 5.5 & 0.0 & 96 & 7 & 1 & $\mathrm{a}$ \\
3.13 & 0.00 & 5.7 & 0.0 & 120 & 7 & 1 & $\mathrm{a}$ \\
3.39 & 0.05 & 6.2 & 0.1 & 113 & 6 & 2 & $\mathrm{r}$ \\
4.71 & 0.82 & 8.6 & 1.5 & 130 & 7 & 22 & $\mathrm{a}$ \\
4.71 & 0.77 & 8.6 & 1.4 & 138 & 5 & 22 & $\mathrm{r}$ \\
7.26 & 0.66 & 13.3 & 1.2 & 190 & 3 & 22 & $\mathrm{a}$ \\
8.25 & 1.62 & 15.1 & 3.0 & 186 & 4 & 22 & $\mathrm{r}$ \\
10.54 & 1.27 & 19.3 & 2.3 & 203 & 3 & 22 & $\mathrm{a}$ \\
15.98 & 2.76 & 29.2 & 5.0 & 200 & 4 & 17 & $\mathrm{a}$ \\
\hline
\end{tabular}

Notes. (1), (3) Galactic radius. (2), (4) Dispersion around the galactic radius. (5) Rotation velocity. (6) Dispersion on the rotation velocity. (7) Number of velocity bins. (8) Receding $-\mathrm{r}-$ or approaching $-\mathrm{a}-$ side.

Table C.11. HCG 79d rotation curve.

\begin{tabular}{cccccccc}
\hline \hline$r$ & $\begin{array}{c}\sigma_{r} \\
(\mathrm{kpc})\end{array}$ & $\begin{array}{c}r \\
\left({ }^{\prime \prime}\right)\end{array}$ & $\begin{array}{c}\sigma_{r} \\
\left({ }^{\prime \prime}\right)\end{array}$ & $\begin{array}{c}v \\
\left(\mathrm{~km} \mathrm{~s}^{-1}\right)\end{array}$ & $\begin{array}{c}\sigma_{v} \\
\left(\mathrm{~km} \mathrm{~s}^{-1}\right)\end{array}$ & $\begin{array}{c}N \\
\text { bins }\end{array}$ & Side \\
$(1)$ & $(2)$ & $(3)$ & $(4)$ & $(5)$ & $(6)$ & $(7)$ & $(8)$ \\
\hline 0.00 & 0.00 & 0.0 & 0.0 & -35 & 14 & 1 & $\mathrm{a}$ \\
0.33 & 0.00 & 1.1 & 0.0 & 38 & 14 & 1 & $\mathrm{r}$ \\
0.33 & 0.00 & 1.1 & 0.0 & 3 & 14 & 1 & $\mathrm{a}$ \\
0.51 & 0.00 & 1.7 & 0.0 & 26 & 14 & 1 & $\mathrm{a}$ \\
0.63 & 0.00 & 2.0 & 0.0 & 20 & 14 & 1 & $\mathrm{r}$ \\
0.63 & 0.00 & 2.0 & 0.0 & 4 & 14 & 1 & $\mathrm{a}$ \\
0.65 & 0.00 & 2.1 & 0.0 & 32 & 14 & 1 & $\mathrm{r}$ \\
0.65 & 0.00 & 2.1 & 0.0 & 1 & 14 & 1 & $\mathrm{a}$ \\
0.86 & 0.00 & 2.8 & 0.0 & 34 & 14 & 1 & $\mathrm{r}$ \\
1.00 & 0.02 & 3.3 & 0.1 & 17 & 14 & 2 & $\mathrm{a}$ \\
1.03 & 0.00 & 3.3 & 0.0 & 32 & 14 & 1 & $\mathrm{r}$ \\
1.07 & 0.01 & 3.5 & 0.0 & 54 & 13 & 2 & $\mathrm{r}$ \\
1.12 & 0.02 & 3.6 & 0.1 & 27 & 0 & 2 & $\mathrm{a}$ \\
1.30 & 0.00 & 4.2 & 0.0 & 66 & 14 & 1 & $\mathrm{r}$ \\
1.46 & 0.00 & 4.8 & 0.0 & 35 & 14 & 1 & $\mathrm{a}$ \\
1.49 & 0.04 & 4.9 & 0.1 & 40 & 0 & 2 & $\mathrm{r}$ \\
1.63 & 0.00 & 5.3 & 0.0 & 37 & 14 & 1 & $\mathrm{a}$ \\
1.65 & 0.02 & 5.4 & 0.1 & 74 & 4 & 2 & $\mathrm{r}$ \\
1.74 & 0.00 & 5.7 & 0.0 & 46 & 14 & 1 & $\mathrm{r}$ \\
2.56 & 0.38 & 8.4 & 1.3 & 58 & 4 & 20 & $\mathrm{a}$ \\
3.40 & 0.93 & 11.1 & 3.0 & 69 & 4 & 20 & $\mathrm{r}$ \\
4.15 & 0.60 & 13.5 & 2.0 & 101 & 4 & 15 & $\mathrm{a}$ \\
\hline
\end{tabular}

Notes. (1), (3) Galactic radius. (2), (4) Dispersion around the galactic radius. (5) Rotation velocity. (6) Dispersion on the rotation velocity. (7) Number of velocity bins. (8) Receding $-\mathrm{r}-$ or approaching $-\mathrm{a}-$ side. 
Table C.12. HCG 93b rotation curve.

\begin{tabular}{|c|c|c|c|c|c|c|c|}
\hline $\begin{array}{c}r \\
(\mathrm{kpc}) \\
(1)\end{array}$ & $\begin{array}{c}\sigma_{r} \\
(\mathrm{kpc}) \\
(2)\end{array}$ & $\begin{array}{l}r \\
(") \\
(3)\end{array}$ & $\begin{array}{l}\sigma_{r} \\
\left({ }^{\prime \prime}\right) \\
(4)\end{array}$ & $\begin{array}{c}v \\
\left(\mathrm{~km} \mathrm{~s}^{-1}\right) \\
(5)\end{array}$ & $\begin{array}{c}\sigma_{v} \\
\left(\mathrm{~km} \mathrm{~s}^{-1}\right) \\
(6)\end{array}$ & $\begin{array}{c}N \\
\text { bins } \\
\text { (7) }\end{array}$ & Side \\
\hline 0.00 & 0.00 & 0.0 & 0.0 & -87 & 29 & 1 & $\mathrm{r}$ \\
\hline 0.58 & 0.00 & 1.9 & 0.0 & 53 & 29 & 1 & $\mathrm{a}$ \\
\hline 0.58 & 0.00 & 1.9 & 0.0 & 117 & 29 & 1 & $\mathrm{r}$ \\
\hline 0.85 & 0.02 & 2.7 & 0.1 & 77 & 8 & 2 & $\mathrm{a}$ \\
\hline 0.85 & 0.02 & 2.7 & 0.1 & 128 & 22 & 2 & $\mathrm{r}$ \\
\hline 0.98 & 0.00 & 3.2 & 0.0 & 75 & 29 & 1 & $\mathrm{a}$ \\
\hline 0.98 & 0.00 & 3.2 & 0.0 & 114 & 29 & 1 & $\mathrm{r}$ \\
\hline 1.14 & 0.02 & 3.7 & 0.1 & 64 & 1 & 2 & $\mathrm{a}$ \\
\hline 1.16 & 0.03 & 3.7 & 0.1 & 105 & 19 & 3 & $\mathrm{r}$ \\
\hline 1.34 & 0.00 & 4.3 & 0.0 & 126 & 29 & 1 & $\mathrm{r}$ \\
\hline 1.34 & 0.00 & 4.3 & 0.0 & 61 & 29 & 1 & $\mathrm{a}$ \\
\hline 1.43 & 0.01 & 4.6 & 0.0 & 98 & 2 & 2 & $\mathrm{r}$ \\
\hline 1.44 & 0.00 & 4.7 & 0.0 & 74 & 29 & 1 & $\mathrm{a}$ \\
\hline 1.58 & 0.00 & 5.1 & 0.0 & 110 & 29 & 1 & $\mathrm{r}$ \\
\hline 1.64 & 0.04 & 5.3 & 0.1 & 56 & 3 & 3 & $\mathrm{a}$ \\
\hline 1.73 & 0.00 & 5.6 & 0.0 & 82 & 29 & 1 & $\mathrm{a}$ \\
\hline 1.76 & 0.03 & 5.7 & 0.1 & 116 & 17 & 2 & $\mathrm{r}$ \\
\hline 1.84 & 0.00 & 6.0 & 0.0 & 121 & 29 & 1 & $\mathrm{r}$ \\
\hline 1.89 & 0.04 & 6.1 & 0.1 & 95 & 8 & 2 & $\mathrm{a}$ \\
\hline 2.06 & 0.05 & 6.7 & 0.2 & 105 & 5 & 2 & $\mathrm{a}$ \\
\hline 2.19 & 0.03 & 7.1 & 0.1 & 91 & 0 & 3 & $\mathrm{a}$ \\
\hline 2.19 & 0.03 & 7.1 & 0.1 & 123 & 13 & 3 & $\mathrm{r}$ \\
\hline 2.33 & 0.03 & 7.6 & 0.1 & 111 & 8 & 2 & $\mathrm{a}$ \\
\hline 2.37 & 0.00 & 7.7 & 0.0 & 146 & 29 & 1 & $\mathrm{r}$ \\
\hline 2.45 & 0.00 & 7.9 & 0.0 & 163 & 29 & 1 & $\mathrm{a}$ \\
\hline 2.47 & 0.00 & 8.0 & 0.0 & 176 & 29 & 1 & $\mathrm{r}$ \\
\hline 2.60 & 0.00 & 8.4 & 0.0 & 148 & 29 & 1 & $\mathrm{r}$ \\
\hline 2.67 & 0.06 & 8.6 & 0.2 & 138 & 10 & 4 & $\mathrm{a}$ \\
\hline 2.80 & 0.03 & 9.1 & 0.1 & 102 & 7 & 2 & $\mathrm{a}$ \\
\hline 2.81 & 0.03 & 9.1 & 0.1 & 164 & 13 & 2 & $\mathrm{r}$ \\
\hline 2.94 & 0.01 & 9.5 & 0.0 & 210 & 26 & 2 & $\mathrm{r}$ \\
\hline 2.94 & 0.00 & 9.5 & 0.0 & 124 & 29 & 1 & $\mathrm{a}$ \\
\hline 3.12 & 0.03 & 10.1 & 0.1 & 160 & 29 & 5 & $\mathrm{r}$ \\
\hline 3.15 & 0.02 & 10.2 & 0.1 & 157 & 24 & 2 & $\mathrm{a}$ \\
\hline 3.32 & 0.02 & 10.8 & 0.1 & 200 & 5 & 4 & $\mathrm{r}$ \\
\hline 3.34 & 0.00 & 10.8 & 0.0 & 135 & 2 & 2 & $\mathrm{a}$ \\
\hline 3.47 & 0.02 & 11.2 & 0.1 & 147 & 21 & 2 & $\mathrm{a}$ \\
\hline 3.47 & 0.02 & 11.2 & 0.1 & 230 & 25 & 2 & $\mathrm{r}$ \\
\hline 3.58 & 0.02 & 11.6 & 0.1 & 202 & 1 & 3 & $\mathrm{r}$ \\
\hline 3.59 & 0.00 & 11.6 & 0.0 & 116 & 29 & 1 & $\mathrm{a}$ \\
\hline 4.08 & 0.32 & 13.2 & 1.0 & 200 & 9 & 25 & $\mathrm{r}$ \\
\hline 4.82 & 0.72 & 15.6 & 2.3 & 142 & 10 & 25 & $\mathrm{a}$ \\
\hline 5.31 & 0.47 & 17.2 & 1.5 & 220 & 11 & 25 & $\mathrm{r}$ \\
\hline 6.81 & 0.52 & 22.0 & 1.7 & 208 & 10 & 25 & $\mathrm{a}$ \\
\hline 13.94 & 6.55 & 45.2 & 21.2 & 173 & 16 & 25 & $\mathrm{a}$ \\
\hline 15.52 & 8.21 & 50.2 & 26.6 & 208 & 16 & 23 & $\mathrm{r}$ \\
\hline 27.50 & 1.18 & 89.1 & 3.8 & 118 & 5 & 25 & $\mathrm{a}$ \\
\hline 29.64 & 0.45 & 96.0 & 1.5 & 138 & 4 & 15 & $\mathrm{a}$ \\
\hline
\end{tabular}

Notes. (1), (3) Galactic radius. (2), (4) Dispersion around the galactic radius. (5) Rotation velocity. (6) Dispersion on the rotation velocity. (7) Number of velocity bins. (8) Receding $-\mathrm{r}-$ or approaching $-\mathrm{a}-$ side.
Table C.13. NGC 92 rotation curve.

\begin{tabular}{|c|c|c|c|c|c|c|c|}
\hline $\begin{array}{c}r \\
(\mathrm{kpc}) \\
(1)\end{array}$ & $\begin{array}{c}\sigma_{r} \\
(\mathrm{kpc}) \\
(2)\end{array}$ & $\begin{array}{c}r \\
(") \\
(3)\end{array}$ & $\begin{array}{l}\sigma_{r} \\
\left({ }^{\prime \prime}\right) \\
(4)\end{array}$ & $\begin{array}{c}v \\
\left(\mathrm{~km} \mathrm{~s}^{-1}\right) \\
(5)\end{array}$ & $\begin{array}{c}\sigma_{v} \\
\left(\mathrm{~km} \mathrm{~s}^{-1}\right) \\
(6)\end{array}$ & $\begin{array}{c}N \\
\text { bins } \\
(7)\end{array}$ & Side \\
\hline 0.08 & 0.06 & 0.4 & 0.3 & 70 & 28 & 3 & $a$ \\
\hline 0.13 & 0.00 & 0.6 & 0.0 & 22 & 6 & 2 & $\mathrm{r}$ \\
\hline 0.26 & 0.04 & 1.3 & 0.2 & 80 & 9 & 6 & $\mathrm{r}$ \\
\hline 0.26 & 0.04 & 1.3 & 0.2 & 162 & 13 & 6 & $\mathrm{a}$ \\
\hline 0.40 & 0.02 & 2.0 & 0.1 & 114 & 10 & 6 & $r$ \\
\hline 0.40 & 0.02 & 2.0 & 0.1 & 194 & 7 & 5 & $\mathrm{a}$ \\
\hline 0.54 & 0.05 & 2.7 & 0.2 & 139 & 8 & 7 & $r$ \\
\hline 0.54 & 0.04 & 2.7 & 0.2 & 208 & 8 & 11 & $\mathrm{a}$ \\
\hline 0.70 & 0.04 & 3.4 & 0.2 & 219 & 7 & 12 & $\mathrm{a}$ \\
\hline 0.71 & 0.03 & 3.5 & 0.1 & 165 & 13 & 9 & $r$ \\
\hline 0.85 & 0.05 & 4.2 & 0.2 & 179 & 10 & 20 & $r$ \\
\hline 0.85 & 0.05 & 4.2 & 0.2 & 220 & 5 & 17 & $\mathrm{a}$ \\
\hline 1.00 & 0.03 & 4.9 & 0.2 & 191 & 11 & 19 & $\mathrm{r}$ \\
\hline 1.00 & 0.03 & 4.9 & 0.2 & 212 & 5 & 15 & $\mathrm{a}$ \\
\hline 1.13 & 0.04 & 5.6 & 0.2 & 200 & 9 & 22 & $\mathrm{r}$ \\
\hline 1.15 & 0.04 & 5.7 & 0.2 & 208 & 4 & 22 & $\mathrm{a}$ \\
\hline 1.27 & 0.03 & 6.3 & 0.2 & 200 & 10 & 22 & $\mathrm{r}$ \\
\hline 1.29 & 0.03 & 6.4 & 0.2 & 210 & 3 & 22 & $\mathrm{a}$ \\
\hline 1.40 & 0.03 & 6.9 & 0.1 & 206 & 3 & 22 & $\mathrm{a}$ \\
\hline 1.41 & 0.04 & 6.9 & 0.2 & 185 & 7 & 22 & $r$ \\
\hline 1.50 & 0.02 & 7.4 & 0.1 & 209 & 3 & 22 & $\mathrm{a}$ \\
\hline 1.54 & 0.04 & 7.6 & 0.2 & 198 & 9 & 22 & $\mathrm{r}$ \\
\hline 1.60 & 0.03 & 7.9 & 0.1 & 209 & 3 & 22 & $\mathrm{a}$ \\
\hline 1.68 & 0.04 & 8.3 & 0.2 & 199 & 7 & 22 & $\mathrm{r}$ \\
\hline 1.68 & 0.03 & 8.3 & 0.2 & 203 & 3 & 22 & $\mathrm{a}$ \\
\hline 1.77 & 0.02 & 8.7 & 0.1 & 211 & 4 & 22 & $\mathrm{a}$ \\
\hline 1.84 & 0.05 & 9.1 & 0.2 & 203 & 5 & 22 & $r$ \\
\hline 1.87 & 0.02 & 9.2 & 0.1 & 205 & 4 & 22 & $\mathrm{a}$ \\
\hline 1.97 & 0.03 & 9.7 & 0.2 & 214 & 5 & 22 & $\mathrm{a}$ \\
\hline 2.02 & 0.07 & 10.0 & 0.4 & 222 & 6 & 22 & $\mathrm{r}$ \\
\hline 2.10 & 0.03 & 10.4 & 0.1 & 209 & 5 & 22 & $\mathrm{a}$ \\
\hline 2.22 & 0.04 & 10.9 & 0.2 & 214 & 6 & 22 & $\mathrm{a}$ \\
\hline 2.25 & 0.09 & 11.1 & 0.4 & 226 & 8 & 22 & $\mathrm{r}$ \\
\hline 2.37 & 0.05 & 11.7 & 0.2 & 211 & 4 & 22 & $\mathrm{a}$ \\
\hline 2.53 & 0.06 & 12.5 & 0.3 & 223 & 3 & 22 & $\mathrm{a}$ \\
\hline 2.57 & 0.10 & 12.7 & 0.5 & 226 & 9 & 22 & $\mathrm{r}$ \\
\hline 2.77 & 0.07 & 13.7 & 0.3 & 215 & 7 & 22 & $\mathrm{a}$ \\
\hline 3.07 & 0.10 & 15.1 & 0.5 & 231 & 9 & 22 & $\mathrm{a}$ \\
\hline 3.23 & 0.43 & 15.9 & 2.1 & 220 & 11 & 22 & $\mathrm{r}$ \\
\hline 3.58 & 0.22 & 17.7 & 1.1 & 216 & 12 & 22 & $\mathrm{a}$ \\
\hline 4.78 & 0.36 & 23.6 & 1.8 & 157 & 11 & 22 & $\mathrm{a}$ \\
\hline 4.98 & 0.33 & 24.6 & 1.7 & 164 & 9 & 22 & $r$ \\
\hline 5.92 & 0.35 & 29.2 & 1.7 & 128 & 7 & 22 & $\mathrm{a}$ \\
\hline 6.00 & 0.22 & 29.6 & 1.1 & 145 & 7 & 22 & $\mathrm{r}$ \\
\hline 6.78 & 0.18 & 33.5 & 0.9 & 161 & 6 & 22 & $\mathrm{r}$ \\
\hline 7.31 & 0.55 & 36.1 & 2.7 & 142 & 8 & 22 & $\mathrm{a}$ \\
\hline 7.31 & 0.14 & 36.1 & 0.7 & 172 & 3 & 22 & $r$ \\
\hline 7.88 & 0.21 & 38.9 & 1.1 & 178 & 5 & 22 & $\mathrm{r}$ \\
\hline 9.13 & 0.36 & 45.1 & 1.8 & 159 & 6 & 22 & $\mathrm{a}$ \\
\hline 9.33 & 0.71 & 46.0 & 3.5 & 135 & 6 & 15 & $\mathrm{r}$ \\
\hline 10.18 & 0.42 & 50.2 & 2.1 & 170 & 6 & 22 & $\mathrm{a}$ \\
\hline 11.54 & 0.38 & 57.0 & 1.9 & 173 & 5 & 22 & $\mathrm{a}$ \\
\hline 13.23 & 0.53 & 65.3 & 2.6 & 150 & 6 & 22 & $\mathrm{a}$ \\
\hline 15.13 & 1.10 & 74.7 & 5.4 & 144 & 5 & 22 & $\mathrm{a}$ \\
\hline 17.96 & 0.58 & 88.6 & 2.9 & 136 & 3 & 22 & $\mathrm{a}$ \\
\hline 20.34 & 1.03 & 100.4 & 5.1 & 139 & 4 & 22 & $\mathrm{a}$ \\
\hline 22.85 & 0.37 & 112.8 & 1.8 & 142 & 4 & 22 & $\mathrm{a}$ \\
\hline 23.84 & 0.37 & 117.6 & 1.8 & 139 & 3 & 18 & $\mathrm{a}$ \\
\hline
\end{tabular}

Notes. (1), (3) Galactic radius. (2), (4) Dispersion around the galactic radius. (5) Rotation velocity. (6) Dispersion on the rotation velocity. (7) Number of velocity bins. (8) Receding $-\mathrm{r}-$ or approaching $-\mathrm{a}-$ side. 
Table C.14. HCG 2a rotation curve.

\begin{tabular}{|c|c|c|c|c|c|c|c|}
\hline $\begin{array}{c}r \\
(\mathrm{kpc}) \\
(1)\end{array}$ & $\begin{array}{c}\sigma_{r} \\
(\mathrm{kpc}) \\
(2)\end{array}$ & $\begin{array}{c}r \\
\left({ }^{\prime \prime}\right) \\
(3) \\
\end{array}$ & $\begin{array}{l}\sigma_{r} \\
\left({ }^{\prime \prime}\right) \\
(4)\end{array}$ & $\begin{array}{c}v \\
\left(\mathrm{~km} \mathrm{~s}^{-1}\right) \\
(5)\end{array}$ & $\begin{array}{c}\sigma_{v} \\
\left(\mathrm{~km} \mathrm{~s}^{-1}\right) \\
(6)\end{array}$ & $\begin{array}{c}N \\
\text { bins } \\
(7)\end{array}$ & $\begin{array}{l}\text { Side } \\
(8)\end{array}$ \\
\hline 0.18 & 0.01 & 0.6 & 0.0 & -49 & 13 & 3 & $\mathrm{a}$ \\
\hline 0.18 & 0.01 & 0.6 & 0.0 & 62 & 16 & 3 & $\mathrm{r}$ \\
\hline 0.33 & 0.03 & 1.2 & 0.1 & 60 & 10 & 5 & $\mathrm{r}$ \\
\hline 0.33 & 0.03 & 1.2 & 0.1 & -32 & 9 & 5 & $\mathrm{a}$ \\
\hline 0.52 & 0.05 & 1.8 & 0.2 & 55 & 5 & 7 & $\mathrm{r}$ \\
\hline 0.52 & 0.06 & 1.8 & 0.2 & -24 & 4 & 9 & $\mathrm{a}$ \\
\hline 0.70 & 0.06 & 2.5 & 0.2 & 45 & 3 & 11 & $\mathrm{r}$ \\
\hline 0.71 & 0.06 & 2.5 & 0.2 & -20 & 3 & 12 & $\mathrm{a}$ \\
\hline 0.92 & 0.06 & 3.2 & 0.2 & -9 & 2 & 16 & $\mathrm{a}$ \\
\hline 0.92 & 0.06 & 3.3 & 0.2 & 46 & 5 & 14 & $\mathrm{r}$ \\
\hline 1.12 & 0.06 & 3.9 & 0.2 & -3 & 2 & 18 & $\mathrm{a}$ \\
\hline 1.12 & 0.05 & 4.0 & 0.2 & 38 & 6 & 10 & $\mathrm{r}$ \\
\hline 1.30 & 0.05 & 4.6 & 0.2 & 46 & 6 & 12 & $\mathrm{r}$ \\
\hline 1.31 & 0.06 & 4.6 & 0.2 & 5 & 3 & 20 & $\mathrm{a}$ \\
\hline 1.51 & 0.06 & 5.3 & 0.2 & 0 & 4 & 23 & $\mathrm{a}$ \\
\hline 1.51 & 0.06 & 5.4 & 0.2 & 47 & 3 & 18 & $\mathrm{r}$ \\
\hline 1.68 & 0.04 & 5.9 & 0.2 & -3 & 4 & 16 & $\mathrm{a}$ \\
\hline 1.71 & 0.07 & 6.0 & 0.2 & 56 & 3 & 16 & $r$ \\
\hline 1.81 & 0.04 & 6.4 & 0.1 & 0 & 4 & 16 & $\mathrm{a}$ \\
\hline 1.93 & 0.03 & 6.8 & 0.1 & 6 & 5 & 16 & $\mathrm{a}$ \\
\hline 1.96 & 0.06 & 6.9 & 0.2 & 32 & 8 & 16 & $\mathrm{r}$ \\
\hline 2.05 & 0.03 & 7.3 & 0.1 & 1 & 4 & 16 & $\mathrm{a}$ \\
\hline 2.17 & 0.03 & 7.7 & 0.1 & 14 & 6 & 16 & $\mathrm{a}$ \\
\hline 2.17 & 0.06 & 7.7 & 0.2 & 54 & 7 & 16 & $\mathrm{r}$ \\
\hline 2.29 & 0.04 & 8.1 & 0.1 & 15 & 4 & 16 & $\mathrm{a}$ \\
\hline 2.38 & 0.06 & 8.4 & 0.2 & 42 & 5 & 16 & $r$ \\
\hline 2.40 & 0.05 & 8.5 & 0.2 & 19 & 5 & 16 & $\mathrm{a}$ \\
\hline 2.55 & 0.05 & 9.0 & 0.2 & 23 & 6 & 16 & $\mathrm{a}$ \\
\hline 2.60 & 0.09 & 9.2 & 0.3 & 65 & 5 & 16 & $\mathrm{r}$ \\
\hline 2.67 & 0.04 & 9.5 & 0.1 & 28 & 7 & 16 & $\mathrm{a}$ \\
\hline 2.81 & 0.03 & 9.9 & 0.1 & 35 & 7 & 16 & $\mathrm{a}$ \\
\hline 2.84 & 0.06 & 10.0 & 0.2 & 68 & 6 & 16 & $\mathrm{r}$ \\
\hline 2.95 & 0.04 & 10.4 & 0.1 & 41 & 9 & 16 & $\mathrm{a}$ \\
\hline 3.09 & 0.03 & 10.9 & 0.1 & 54 & 6 & 16 & $\mathrm{a}$ \\
\hline 3.09 & 0.06 & 10.9 & 0.2 & 70 & 6 & 16 & $r$ \\
\hline 3.20 & 0.03 & 11.3 & 0.1 & 63 & 3 & 16 & $\mathrm{a}$ \\
\hline 3.31 & 0.06 & 11.7 & 0.2 & 73 & 6 & 16 & $\mathrm{r}$ \\
\hline 3.32 & 0.04 & 11.8 & 0.1 & 57 & 3 & 16 & $\mathrm{a}$ \\
\hline 3.45 & 0.04 & 12.2 & 0.1 & 71 & 4 & 16 & $\mathrm{a}$ \\
\hline 3.56 & 0.07 & 12.6 & 0.2 & 87 & 4 & 16 & $\mathrm{r}$ \\
\hline 3.57 & 0.03 & 12.6 & 0.1 & 75 & 5 & 16 & $\mathrm{a}$ \\
\hline 3.66 & 0.03 & 13.0 & 0.1 & 79 & 7 & 16 & $\mathrm{a}$ \\
\hline 3.75 & 0.05 & 13.3 & 0.2 & 96 & 7 & 16 & $\mathrm{r}$ \\
\hline 3.76 & 0.03 & 13.3 & 0.1 & 81 & 4 & 16 & $\mathrm{a}$ \\
\hline 3.86 & 0.03 & 13.7 & 0.1 & 78 & 3 & 16 & $\mathrm{a}$ \\
\hline 3.93 & 0.05 & 13.9 & 0.2 & 102 & 7 & 16 & $\mathrm{r}$ \\
\hline 3.94 & 0.02 & 14.0 & 0.1 & 89 & 4 & 16 & $\mathrm{a}$ \\
\hline 4.01 & 0.01 & 14.2 & 0.0 & 73 & 5 & 16 & $\mathrm{a}$ \\
\hline 4.08 & 0.02 & 14.5 & 0.1 & 90 & 4 & 16 & $\mathrm{a}$ \\
\hline 4.09 & 0.04 & 14.5 & 0.1 & 114 & 6 & 16 & $r$ \\
\hline 4.17 & 0.02 & 14.7 & 0.1 & 85 & 2 & 16 & $\mathrm{a}$ \\
\hline 4.23 & 0.02 & 15.0 & 0.1 & 102 & 5 & 16 & $\mathrm{a}$ \\
\hline 4.28 & 0.05 & 15.1 & 0.2 & 115 & 5 & 16 & $r$ \\
\hline 4.30 & 0.02 & 15.2 & 0.1 & 98 & 5 & 16 & $\mathrm{a}$ \\
\hline 4.36 & 0.01 & 15.4 & 0.0 & 100 & 3 & 16 & $\mathrm{a}$ \\
\hline 4.42 & 0.02 & 15.6 & 0.1 & 100 & 6 & 16 & $\mathrm{a}$ \\
\hline 4.49 & 0.02 & 15.9 & 0.1 & 97 & 5 & 16 & $\mathrm{a}$ \\
\hline 4.53 & 0.02 & 16.0 & 0.1 & 102 & 4 & 16 & $\mathrm{a}$ \\
\hline
\end{tabular}


Table C.14. continued.

\begin{tabular}{|c|c|c|c|c|c|c|c|}
\hline $\begin{array}{c}r \\
(\mathrm{kpc}) \\
(1)\end{array}$ & $\begin{array}{c}\sigma_{r} \\
(\mathrm{kpc}) \\
(2)\end{array}$ & $\begin{array}{c}r \\
\left({ }^{\prime \prime}\right) \\
(3)\end{array}$ & $\begin{array}{l}\sigma_{r} \\
\left({ }^{\prime \prime}\right) \\
(4)\end{array}$ & $\begin{array}{c}v \\
\left(\mathrm{~km} \mathrm{~s}^{-1}\right) \\
(5)\end{array}$ & $\begin{array}{c}\sigma_{v} \\
\left(\mathrm{~km} \mathrm{~s}^{-1}\right) \\
(6)\end{array}$ & $\begin{array}{c}N \\
\text { bins } \\
(7)\end{array}$ & $\begin{array}{l}\text { Side } \\
\text { (8) }\end{array}$ \\
\hline 4.55 & 0.11 & 16.1 & 0.4 & 109 & 7 & 16 & $r$ \\
\hline 4.61 & 0.02 & 16.3 & 0.1 & 113 & 4 & 16 & $\mathrm{a}$ \\
\hline 4.67 & 0.01 & 16.5 & 0.0 & 104 & 3 & 16 & $\mathrm{a}$ \\
\hline 4.72 & 0.02 & 16.7 & 0.1 & 109 & 6 & 16 & $\mathrm{a}$ \\
\hline 4.78 & 0.02 & 16.9 & 0.1 & 107 & 5 & 16 & $\mathrm{a}$ \\
\hline 4.81 & 0.08 & 17.0 & 0.3 & 123 & 9 & 16 & $\mathrm{r}$ \\
\hline 4.83 & 0.02 & 17.1 & 0.1 & 99 & 3 & 16 & $\mathrm{a}$ \\
\hline 4.88 & 0.02 & 17.3 & 0.1 & 112 & 4 & 16 & $\mathrm{a}$ \\
\hline 4.94 & 0.02 & 17.5 & 0.1 & 109 & 4 & 16 & $\mathrm{a}$ \\
\hline 4.99 & 0.01 & 17.6 & 0.0 & 113 & 5 & 16 & $\mathrm{a}$ \\
\hline 5.03 & 0.05 & 17.8 & 0.2 & 123 & 5 & 16 & $\mathrm{r}$ \\
\hline 5.04 & 0.02 & 17.8 & 0.1 & 104 & 4 & 16 & $\mathrm{a}$ \\
\hline 5.10 & 0.01 & 18.0 & 0.0 & 119 & 6 & 16 & $\mathrm{a}$ \\
\hline 5.14 & 0.02 & 18.2 & 0.1 & 105 & 4 & 16 & $\mathrm{a}$ \\
\hline 5.19 & 0.01 & 18.4 & 0.0 & 115 & 6 & 16 & $\mathrm{a}$ \\
\hline 5.25 & 0.02 & 18.6 & 0.1 & 114 & 5 & 16 & $\mathrm{a}$ \\
\hline 5.27 & 0.08 & 18.6 & 0.3 & 123 & 5 & 16 & $\mathrm{r}$ \\
\hline 5.30 & 0.01 & 18.7 & 0.0 & 116 & 6 & 16 & $\mathrm{a}$ \\
\hline 5.35 & 0.01 & 18.9 & 0.0 & 107 & 5 & 16 & $\mathrm{a}$ \\
\hline 5.40 & 0.02 & 19.1 & 0.1 & 111 & 5 & 16 & $\mathrm{a}$ \\
\hline 5.45 & 0.02 & 19.3 & 0.1 & 112 & 6 & 16 & $\mathrm{a}$ \\
\hline 5.45 & 0.06 & 19.3 & 0.2 & 129 & 5 & 16 & $\mathrm{r}$ \\
\hline 5.51 & 0.02 & 19.5 & 0.1 & 116 & 6 & 16 & $\mathrm{a}$ \\
\hline 5.56 & 0.02 & 19.7 & 0.1 & 112 & 5 & 16 & $\mathrm{a}$ \\
\hline 5.61 & 0.01 & 19.8 & 0.0 & 119 & 7 & 16 & $\mathrm{a}$ \\
\hline 5.66 & 0.02 & 20.0 & 0.1 & 116 & 5 & 16 & $\mathrm{a}$ \\
\hline 5.70 & 0.01 & 20.2 & 0.0 & 121 & 4 & 16 & $\mathrm{a}$ \\
\hline 5.73 & 0.08 & 20.3 & 0.3 & 141 & 5 & 16 & $\mathrm{r}$ \\
\hline 5.75 & 0.01 & 20.4 & 0.0 & 110 & 4 & 16 & $\mathrm{a}$ \\
\hline 5.80 & 0.02 & 20.5 & 0.1 & 120 & 6 & 16 & $\mathrm{a}$ \\
\hline 5.86 & 0.02 & 20.7 & 0.1 & 130 & 5 & 16 & $\mathrm{a}$ \\
\hline 5.92 & 0.02 & 21.0 & 0.1 & 122 & 5 & 16 & $\mathrm{a}$ \\
\hline 5.98 & 0.01 & 21.1 & 0.0 & 126 & 4 & 16 & $\mathrm{a}$ \\
\hline 6.03 & 0.02 & 21.3 & 0.1 & 122 & 5 & 16 & $\mathrm{a}$ \\
\hline 6.04 & 0.06 & 21.4 & 0.2 & 135 & 7 & 16 & $\mathrm{r}$ \\
\hline 6.09 & 0.02 & 21.6 & 0.1 & 124 & 5 & 16 & $\mathrm{a}$ \\
\hline 6.14 & 0.02 & 21.7 & 0.1 & 124 & 5 & 16 & $\mathrm{a}$ \\
\hline 6.20 & 0.01 & 21.9 & 0.1 & 122 & 6 & 16 & $\mathrm{a}$ \\
\hline 6.24 & 0.05 & 22.1 & 0.2 & 121 & 7 & 16 & $\mathrm{r}$ \\
\hline 6.27 & 0.01 & 22.2 & 0.0 & 129 & 3 & 16 & $\mathrm{a}$ \\
\hline 6.33 & 0.02 & 22.4 & 0.1 & 126 & 6 & 16 & $\mathrm{a}$ \\
\hline 6.38 & 0.02 & 22.6 & 0.1 & 128 & 8 & 16 & $\mathrm{a}$ \\
\hline 6.44 & 0.05 & 22.8 & 0.2 & 131 & 5 & 16 & $\mathrm{r}$ \\
\hline 6.45 & 0.02 & 22.8 & 0.1 & 131 & 4 & 16 & $\mathrm{a}$ \\
\hline 6.53 & 0.02 & 23.1 & 0.1 & 128 & 5 & 16 & $\mathrm{a}$ \\
\hline 6.59 & 0.02 & 23.3 & 0.1 & 128 & 3 & 16 & $\mathrm{a}$ \\
\hline 6.65 & 0.02 & 23.5 & 0.1 & 133 & 3 & 16 & $\mathrm{a}$ \\
\hline 6.65 & 0.08 & 23.5 & 0.3 & 137 & 6 & 16 & $\mathrm{r}$ \\
\hline 6.71 & 0.02 & 23.8 & 0.1 & 124 & 5 & 16 & $\mathrm{a}$ \\
\hline 6.79 & 0.03 & 24.0 & 0.1 & 132 & 3 & 16 & $\mathrm{a}$ \\
\hline 6.88 & 0.03 & 24.3 & 0.1 & 124 & 4 & 16 & $\mathrm{a}$ \\
\hline 6.89 & 0.05 & 24.4 & 0.2 & 133 & 9 & 16 & $\mathrm{r}$ \\
\hline 6.96 & 0.02 & 24.6 & 0.1 & 129 & 5 & 16 & $\mathrm{a}$ \\
\hline 7.02 & 0.02 & 24.8 & 0.1 & 128 & 5 & 16 & $\mathrm{a}$ \\
\hline 7.10 & 0.03 & 25.1 & 0.1 & 139 & 4 & 16 & $\mathrm{a}$ \\
\hline 7.14 & 0.06 & 25.3 & 0.2 & 138 & 8 & 16 & $\mathrm{r}$ \\
\hline 7.18 & 0.02 & 25.4 & 0.1 & 136 & 3 & 16 & $\mathrm{a}$ \\
\hline 7.25 & 0.02 & 25.6 & 0.1 & 139 & 5 & 16 & $\mathrm{a}$ \\
\hline 7.30 & 0.02 & 25.8 & 0.1 & 134 & 5 & 16 & $\mathrm{a}$ \\
\hline
\end{tabular}


Table C.14. continued.

\begin{tabular}{|c|c|c|c|c|c|c|c|}
\hline $\begin{array}{c}r \\
(\mathrm{kpc}) \\
(1)\end{array}$ & $\begin{array}{c}\sigma_{r} \\
(\mathrm{kpc}) \\
(2)\end{array}$ & $\begin{array}{c}r \\
\left({ }^{\prime \prime}\right) \\
(3)\end{array}$ & $\begin{array}{l}\sigma_{r} \\
\left({ }^{\prime \prime}\right) \\
(4)\end{array}$ & $\begin{array}{c}v \\
\left(\mathrm{~km} \mathrm{~s}^{-1}\right) \\
(5)\end{array}$ & $\begin{array}{c}\sigma_{v} \\
\left(\mathrm{~km} \mathrm{~s}^{-1}\right) \\
(6)\end{array}$ & $\begin{array}{c}N \\
\text { bins } \\
(7)\end{array}$ & $\begin{array}{r}\text { Side } \\
\text { (8) }\end{array}$ \\
\hline 7.37 & 0.08 & 26.1 & 0.3 & 134 & 7 & 16 & $r$ \\
\hline 7.37 & 0.02 & 26.1 & 0.1 & 141 & 6 & 16 & $a$ \\
\hline 7.44 & 0.01 & 26.3 & 0.0 & 148 & 2 & 16 & $a$ \\
\hline 7.48 & 0.03 & 26.5 & 0.1 & 144 & 5 & 16 & $a$ \\
\hline 7.56 & 0.05 & 26.8 & 0.2 & 128 & 5 & 16 & $r$ \\
\hline 7.57 & 0.03 & 26.8 & 0.1 & 151 & 3 & 16 & $\mathrm{a}$ \\
\hline 7.65 & 0.02 & 27.1 & 0.1 & 150 & 5 & 16 & $\mathrm{a}$ \\
\hline 7.72 & 0.04 & 27.3 & 0.1 & 142 & 7 & 16 & $r$ \\
\hline 7.72 & 0.01 & 27.3 & 0.0 & 152 & 3 & 16 & $\mathrm{a}$ \\
\hline 7.77 & 0.02 & 27.5 & 0.1 & 151 & 6 & 16 & $\mathrm{a}$ \\
\hline 7.85 & 0.02 & 27.8 & 0.1 & 157 & 2 & 16 & $\mathrm{a}$ \\
\hline 7.87 & 0.05 & 27.8 & 0.2 & 152 & 9 & 16 & $r$ \\
\hline 7.91 & 0.02 & 28.0 & 0.1 & 146 & 4 & 16 & $\mathrm{a}$ \\
\hline 8.00 & 0.02 & 28.3 & 0.1 & 151 & 4 & 16 & $\mathrm{a}$ \\
\hline 8.02 & 0.04 & 28.4 & 0.1 & 150 & 8 & 16 & $r$ \\
\hline 8.06 & 0.03 & 28.5 & 0.1 & 151 & 8 & 16 & $\mathrm{a}$ \\
\hline 8.15 & 0.03 & 28.8 & 0.1 & 141 & 5 & 16 & $\mathrm{a}$ \\
\hline 8.19 & 0.05 & 29.0 & 0.2 & 156 & 5 & 16 & $\mathrm{r}$ \\
\hline 8.23 & 0.03 & 29.1 & 0.1 & 162 & 4 & 16 & $\mathrm{a}$ \\
\hline 8.33 & 0.02 & 29.5 & 0.1 & 153 & 5 & 16 & $\mathrm{a}$ \\
\hline 8.36 & 0.05 & 29.6 & 0.2 & 147 & 8 & 16 & $\mathrm{r}$ \\
\hline 8.43 & 0.03 & 29.8 & 0.1 & 166 & 6 & 16 & $\mathrm{a}$ \\
\hline 8.52 & 0.03 & 30.1 & 0.1 & 158 & 7 & 16 & $\mathrm{a}$ \\
\hline 8.57 & 0.05 & 30.3 & 0.2 & 153 & 7 & 16 & $r$ \\
\hline 8.61 & 0.02 & 30.5 & 0.1 & 169 & 5 & 16 & $\mathrm{a}$ \\
\hline 8.69 & 0.03 & 30.7 & 0.1 & 164 & 6 & 16 & $\mathrm{a}$ \\
\hline 8.79 & 0.06 & 31.1 & 0.2 & 149 & 6 & 16 & $\mathrm{r}$ \\
\hline 8.79 & 0.03 & 31.1 & 0.1 & 171 & 8 & 16 & $\mathrm{a}$ \\
\hline 8.89 & 0.03 & 31.5 & 0.1 & 170 & 6 & 16 & $\mathrm{a}$ \\
\hline 8.98 & 0.02 & 31.8 & 0.1 & 166 & 5 & 16 & $\mathrm{a}$ \\
\hline 9.05 & 0.07 & 32.0 & 0.2 & 161 & 7 & 16 & $\mathrm{r}$ \\
\hline 9.08 & 0.04 & 32.1 & 0.1 & 169 & 6 & 16 & $\mathrm{a}$ \\
\hline 9.20 & 0.03 & 32.6 & 0.1 & 187 & 5 & 16 & $\mathrm{a}$ \\
\hline 9.30 & 0.04 & 32.9 & 0.1 & 174 & 8 & 16 & $\mathrm{a}$ \\
\hline 9.31 & 0.10 & 32.9 & 0.4 & 165 & 8 & 16 & $r$ \\
\hline 9.41 & 0.03 & 33.3 & 0.1 & 182 & 8 & 16 & $\mathrm{a}$ \\
\hline 9.51 & 0.03 & 33.6 & 0.1 & 176 & 7 & 16 & $\mathrm{a}$ \\
\hline 9.60 & 0.03 & 34.0 & 0.1 & 177 & 7 & 16 & $\mathrm{a}$ \\
\hline 9.66 & 0.11 & 34.2 & 0.4 & 177 & 8 & 16 & $r$ \\
\hline 9.71 & 0.03 & 34.4 & 0.1 & 187 & 7 & 16 & $\mathrm{a}$ \\
\hline 9.82 & 0.03 & 34.8 & 0.1 & 184 & 4 & 16 & $\mathrm{a}$ \\
\hline 9.90 & 0.03 & 35.0 & 0.1 & 182 & 8 & 16 & $\mathrm{a}$ \\
\hline 10.00 & 0.03 & 35.4 & 0.1 & 181 & 8 & 16 & $\mathrm{a}$ \\
\hline 10.03 & 0.12 & 35.5 & 0.4 & 193 & 7 & 16 & $\mathrm{r}$ \\
\hline 10.09 & 0.03 & 35.7 & 0.1 & 187 & 9 & 16 & $\mathrm{a}$ \\
\hline 10.18 & 0.02 & 36.0 & 0.1 & 184 & 5 & 16 & $\mathrm{a}$ \\
\hline 10.26 & 0.02 & 36.3 & 0.1 & 183 & 9 & 16 & $\mathrm{a}$ \\
\hline 10.36 & 0.03 & 36.6 & 0.1 & 180 & 6 & 16 & $\mathrm{a}$ \\
\hline 10.44 & 0.16 & 36.9 & 0.6 & 201 & 5 & 16 & $\mathrm{r}$ \\
\hline 10.45 & 0.02 & 37.0 & 0.1 & 193 & 7 & 16 & $\mathrm{a}$ \\
\hline 10.53 & 0.03 & 37.3 & 0.1 & 189 & 5 & 16 & $\mathrm{a}$ \\
\hline 10.62 & 0.03 & 37.6 & 0.1 & 198 & 7 & 16 & $\mathrm{a}$ \\
\hline 10.73 & 0.04 & 38.0 & 0.1 & 201 & 4 & 16 & $\mathrm{a}$ \\
\hline 10.86 & 0.03 & 38.4 & 0.1 & 198 & 7 & 16 & $\mathrm{a}$ \\
\hline 10.94 & 0.02 & 38.7 & 0.1 & 208 & 7 & 16 & $\mathrm{a}$ \\
\hline 11.03 & 0.23 & 39.0 & 0.8 & 194 & 10 & 16 & $\mathrm{r}$ \\
\hline 11.03 & 0.03 & 39.0 & 0.1 & 195 & 9 & 16 & $\mathrm{a}$ \\
\hline 11.14 & 0.03 & 39.4 & 0.1 & 202 & 7 & 16 & $\mathrm{a}$ \\
\hline 11.22 & 0.03 & 39.7 & 0.1 & 206 & 8 & 16 & $\mathrm{a}$ \\
\hline
\end{tabular}


Table C.14. continued.

\begin{tabular}{|c|c|c|c|c|c|c|c|}
\hline $\begin{array}{c}r \\
(\mathrm{kpc}) \\
(1)\end{array}$ & $\begin{array}{c}\sigma_{r} \\
(\mathrm{kpc}) \\
(2)\end{array}$ & $\begin{array}{l}r \\
\left({ }^{\prime \prime}\right) \\
(3)\end{array}$ & $\begin{array}{l}\sigma_{r} \\
\left({ }^{\prime \prime}\right) \\
(4)\end{array}$ & $\begin{array}{c}v \\
\left(\mathrm{~km} \mathrm{~s}^{-1}\right) \\
(5)\end{array}$ & $\begin{array}{c}\sigma_{v} \\
\left(\mathrm{~km} \mathrm{~s}^{-1}\right) \\
(6)\end{array}$ & $\begin{array}{c}N \\
\text { bins } \\
(7)\end{array}$ & $\begin{array}{l}\text { Side } \\
(8)\end{array}$ \\
\hline 11.32 & 0.03 & 40.1 & 0.1 & 203 & 7 & 16 & $\mathrm{a}$ \\
\hline 11.46 & 0.03 & 40.5 & 0.1 & 212 & 11 & 16 & $\mathrm{a}$ \\
\hline 11.56 & 0.03 & 40.9 & 0.1 & 197 & 8 & 16 & $\mathrm{a}$ \\
\hline 11.63 & 0.18 & 41.2 & 0.6 & 197 & 10 & 16 & $\mathrm{r}$ \\
\hline 11.74 & 0.06 & 41.5 & 0.2 & 209 & 9 & 16 & $\mathrm{a}$ \\
\hline 11.94 & 0.06 & 42.2 & 0.2 & 214 & 7 & 16 & $\mathrm{a}$ \\
\hline 12.09 & 0.11 & 42.8 & 0.4 & 220 & 9 & 16 & $\mathrm{r}$ \\
\hline 12.21 & 0.08 & 43.2 & 0.3 & 223 & 7 & 16 & $\mathrm{a}$ \\
\hline 12.48 & 0.08 & 44.2 & 0.3 & 227 & 8 & 16 & $\mathrm{a}$ \\
\hline 12.66 & 0.29 & 44.8 & 1.0 & 216 & 10 & 16 & $\mathrm{r}$ \\
\hline 12.74 & 0.06 & 45.1 & 0.2 & 231 & 8 & 16 & $\mathrm{a}$ \\
\hline 13.03 & 0.10 & 46.1 & 0.3 & 243 & 11 & 16 & $\mathrm{a}$ \\
\hline 13.38 & 0.08 & 47.3 & 0.3 & 245 & 7 & 16 & $\mathrm{a}$ \\
\hline 13.41 & 0.15 & 47.5 & 0.5 & 216 & 9 & 16 & $\mathrm{r}$ \\
\hline 13.87 & 0.11 & 49.1 & 0.4 & 226 & 8 & 16 & $\mathrm{r}$ \\
\hline 14.19 & 0.09 & 50.2 & 0.3 & 245 & 7 & 16 & $\mathrm{r}$ \\
\hline 14.36 & 0.49 & 50.8 & 1.7 & 234 & 12 & 16 & $\mathrm{a}$ \\
\hline 14.49 & 0.09 & 51.3 & 0.3 & 236 & 9 & 16 & $\mathrm{r}$ \\
\hline 14.91 & 0.14 & 52.7 & 0.5 & 251 & 6 & 16 & $\mathrm{r}$ \\
\hline 15.59 & 0.21 & 55.1 & 0.7 & 241 & 10 & 16 & $r$ \\
\hline 16.30 & 0.18 & 57.7 & 0.6 & 237 & 10 & 16 & $\mathrm{r}$ \\
\hline 16.50 & 0.76 & 58.4 & 2.7 & 213 & 13 & 16 & $\mathrm{a}$ \\
\hline 16.69 & 0.08 & 59.1 & 0.3 & 248 & 10 & 16 & $\mathrm{r}$ \\
\hline 16.95 & 0.07 & 60.0 & 0.2 & 249 & 7 & 16 & $\mathrm{r}$ \\
\hline 17.18 & 0.06 & 60.8 & 0.2 & 239 & 8 & 16 & $\mathrm{r}$ \\
\hline 17.42 & 0.07 & 61.6 & 0.3 & 232 & 7 & 16 & $\mathrm{r}$ \\
\hline 17.63 & 0.06 & 62.4 & 0.2 & 237 & 11 & 16 & $\mathrm{r}$ \\
\hline 17.85 & 0.07 & 63.2 & 0.2 & 222 & 8 & 16 & $\mathrm{r}$ \\
\hline 18.06 & 0.05 & 63.9 & 0.2 & 226 & 8 & 16 & $r$ \\
\hline 18.25 & 0.06 & 64.6 & 0.2 & 234 & 10 & 16 & $\mathrm{r}$ \\
\hline 18.45 & 0.06 & 65.3 & 0.2 & 229 & 9 & 16 & $\mathrm{r}$ \\
\hline 18.61 & 0.04 & 65.8 & 0.1 & 220 & 11 & 16 & $\mathrm{r}$ \\
\hline 18.77 & 0.06 & 66.4 & 0.2 & 230 & 12 & 16 & $\mathrm{r}$ \\
\hline 18.99 & 0.07 & 67.2 & 0.2 & 243 & 12 & 16 & $\mathrm{r}$ \\
\hline 19.22 & 0.10 & 68.0 & 0.4 & 256 & 11 & 16 & $\mathrm{r}$ \\
\hline 19.73 & 0.23 & 69.8 & 0.8 & 269 & 10 & 16 & $\mathrm{r}$ \\
\hline 20.94 & 0.67 & 74.1 & 2.4 & 274 & 9 & 14 & $\mathrm{r}$ \\
\hline 21.02 & 1.90 & 74.4 & 6.7 & 222 & 10 & 16 & $\mathrm{a}$ \\
\hline
\end{tabular}

Notes. (1), (3) Galactic radius. (2), (4) Dispersion around the galactic radius. (5) Rotation velocity. (6) Dispersion on the rotation velocity. (7) Number of velocity bins. (8) Receding - r - or approaching - a - side. 
Table C.15. HCG 2c rotation curve.

\begin{tabular}{|c|c|c|c|c|c|c|c|}
\hline $\begin{array}{c}r \\
(\mathrm{kpc}) \\
(1)\end{array}$ & $\begin{array}{c}\sigma_{r} \\
(\mathrm{kpc}) \\
(2)\end{array}$ & $\begin{array}{c}r \\
\left({ }^{\prime \prime}\right) \\
(3) \\
\end{array}$ & $\begin{array}{l}\sigma_{r} \\
\left({ }^{\prime \prime}\right) \\
(4)\end{array}$ & $\begin{array}{c}v \\
\left(\mathrm{~km} \mathrm{~s}^{-1}\right) \\
(5)\end{array}$ & $\begin{array}{c}\sigma_{v} \\
\left(\mathrm{~km} \mathrm{~s}^{-1}\right) \\
(6)\end{array}$ & $\begin{array}{c}N \\
\text { bins } \\
(7)\end{array}$ & $\begin{array}{l}\text { Side } \\
(8)\end{array}$ \\
\hline 0.07 & 0.06 & 0.3 & 0.2 & 32 & 4 & 2 & $\mathrm{r}$ \\
\hline 0.12 & 0.00 & 0.4 & 0.0 & 0 & 25 & 1 & $\mathrm{a}$ \\
\hline 0.23 & 0.02 & 0.8 & 0.1 & -11 & 12 & 2 & $\mathrm{a}$ \\
\hline 0.23 & 0.02 & 0.8 & 0.1 & 36 & 3 & 2 & $\mathrm{r}$ \\
\hline 0.42 & 0.05 & 1.5 & 0.2 & 36 & 13 & 3 & $\mathrm{r}$ \\
\hline 0.42 & 0.05 & 1.5 & 0.2 & -30 & 7 & 6 & $\mathrm{a}$ \\
\hline 0.61 & 0.00 & 2.2 & 0.0 & 30 & 25 & 1 & $\mathrm{r}$ \\
\hline 0.67 & 0.03 & 2.4 & 0.1 & 4 & 25 & 3 & $\mathrm{a}$ \\
\hline 0.78 & 0.05 & 2.8 & 0.2 & 25 & 10 & 5 & $\mathrm{a}$ \\
\hline 0.83 & 0.01 & 3.0 & 0.0 & 41 & 8 & 3 & $\mathrm{r}$ \\
\hline 0.91 & 0.01 & 3.3 & 0.0 & 41 & 9 & 2 & $\mathrm{a}$ \\
\hline 0.93 & 0.04 & 3.4 & 0.1 & 32 & 15 & 2 & $\mathrm{r}$ \\
\hline 1.16 & 0.04 & 4.2 & 0.1 & 60 & 8 & 4 & $\mathrm{a}$ \\
\hline 1.19 & 0.03 & 4.3 & 0.1 & 43 & 12 & 4 & $\mathrm{r}$ \\
\hline 1.29 & 0.03 & 4.7 & 0.1 & 39 & 4 & 3 & $\mathrm{a}$ \\
\hline 1.37 & 0.04 & 5.0 & 0.2 & 57 & 4 & 4 & $\mathrm{r}$ \\
\hline 1.48 & 0.07 & 5.4 & 0.2 & 79 & 8 & 4 & $\mathrm{r}$ \\
\hline 1.50 & 0.08 & 5.4 & 0.3 & 74 & 7 & 4 & $\mathrm{a}$ \\
\hline 1.69 & 0.05 & 6.1 & 0.2 & 68 & 6 & 8 & $\mathrm{a}$ \\
\hline 1.70 & 0.04 & 6.1 & 0.2 & 55 & 12 & 5 & $\mathrm{r}$ \\
\hline 1.85 & 0.04 & 6.7 & 0.1 & 55 & 4 & 6 & $\mathrm{a}$ \\
\hline 1.88 & 0.02 & 6.8 & 0.1 & 46 & 5 & 3 & $\mathrm{r}$ \\
\hline 2.01 & 0.10 & 7.3 & 0.4 & 55 & 5 & 18 & $\mathrm{a}$ \\
\hline 2.13 & 0.17 & 7.7 & 0.6 & 45 & 4 & 18 & $\mathrm{r}$ \\
\hline 2.33 & 0.10 & 8.4 & 0.3 & 67 & 4 & 18 & $\mathrm{a}$ \\
\hline 2.58 & 0.06 & 9.3 & 0.2 & 65 & 4 & 18 & $\mathrm{a}$ \\
\hline 2.63 & 0.11 & 9.5 & 0.4 & 56 & 3 & 18 & $\mathrm{r}$ \\
\hline 2.80 & 0.06 & 10.1 & 0.2 & 68 & 3 & 18 & $\mathrm{a}$ \\
\hline 2.97 & 0.05 & 10.7 & 0.2 & 65 & 5 & 18 & $\mathrm{a}$ \\
\hline 3.03 & 0.16 & 10.9 & 0.6 & 55 & 5 & 18 & $\mathrm{r}$ \\
\hline 3.13 & 0.05 & 11.3 & 0.2 & 75 & 3 & 18 & $\mathrm{a}$ \\
\hline 3.27 & 0.04 & 11.8 & 0.1 & 79 & 4 & 18 & $\mathrm{a}$ \\
\hline 3.42 & 0.05 & 12.4 & 0.2 & 72 & 4 & 18 & $\mathrm{a}$ \\
\hline 3.62 & 0.05 & 13.1 & 0.2 & 66 & 4 & 18 & $\mathrm{a}$ \\
\hline 3.77 & 0.06 & 13.6 & 0.2 & 70 & 5 & 18 & $\mathrm{a}$ \\
\hline 3.81 & 0.23 & 13.8 & 0.8 & 74 & 5 & 18 & $\mathrm{r}$ \\
\hline 4.00 & 0.07 & 14.4 & 0.2 & 71 & 4 & 18 & $\mathrm{a}$ \\
\hline 4.19 & 0.05 & 15.2 & 0.2 & 76 & 4 & 18 & $\mathrm{a}$ \\
\hline 4.39 & 0.07 & 15.9 & 0.2 & 74 & 3 & 18 & $\mathrm{a}$ \\
\hline 4.42 & 0.16 & 15.9 & 0.6 & 75 & 5 & 18 & $\mathrm{r}$ \\
\hline 4.71 & 0.11 & 17.0 & 0.4 & 83 & 3 & 18 & $\mathrm{a}$ \\
\hline 5.10 & 0.13 & 18.4 & 0.5 & 81 & 5 & 18 & $\mathrm{a}$ \\
\hline 5.11 & 0.20 & 18.5 & 0.7 & 74 & 3 & 18 & $\mathrm{r}$ \\
\hline 5.48 & 0.10 & 19.8 & 0.4 & 79 & 4 & 18 & $\mathrm{a}$ \\
\hline 5.74 & 0.06 & 20.7 & 0.2 & 84 & 5 & 18 & $\mathrm{a}$ \\
\hline 5.84 & 0.21 & 21.1 & 0.7 & 80 & 4 & 18 & $\mathrm{r}$ \\
\hline 6.00 & 0.12 & 21.7 & 0.4 & 83 & 5 & 18 & $\mathrm{a}$ \\
\hline 6.31 & 0.08 & 22.8 & 0.3 & 92 & 5 & 18 & $\mathrm{a}$ \\
\hline 6.49 & 0.18 & 23.4 & 0.7 & 95 & 5 & 18 & $\mathrm{r}$ \\
\hline 6.58 & 0.07 & 23.8 & 0.3 & 98 & 5 & 18 & $\mathrm{a}$ \\
\hline 6.79 & 0.05 & 24.5 & 0.2 & 87 & 4 & 18 & $\mathrm{a}$ \\
\hline 6.97 & 0.04 & 25.2 & 0.2 & 100 & 4 & 18 & $\mathrm{a}$ \\
\hline 7.14 & 0.07 & 25.8 & 0.2 & 102 & 3 & 18 & $\mathrm{a}$ \\
\hline 7.19 & 0.24 & 26.0 & 0.9 & 85 & 6 & 18 & $\mathrm{r}$ \\
\hline 7.37 & 0.06 & 26.6 & 0.2 & 108 & 3 & 18 & $\mathrm{a}$ \\
\hline 7.52 & 0.06 & 27.2 & 0.2 & 104 & 3 & 18 & $\mathrm{a}$ \\
\hline 7.72 & 0.05 & 27.9 & 0.2 & 109 & 3 & 18 & $\mathrm{a}$ \\
\hline 7.87 & 0.06 & 28.4 & 0.2 & 116 & 2 & 18 & $\mathrm{a}$ \\
\hline
\end{tabular}


Table C.15. continued.

\begin{tabular}{cccccccc}
\hline \hline $\begin{array}{c}r \\
(\mathrm{kpc})\end{array}$ & $\begin{array}{c}\sigma_{r} \\
(\mathrm{kpc})\end{array}$ & $\begin{array}{c}r \\
\left({ }^{\prime \prime}\right)\end{array}$ & $\begin{array}{c}\sigma_{r} \\
\left({ }^{\prime \prime}\right)\end{array}$ & $\begin{array}{c}v \\
\left(\mathrm{~km} \mathrm{~s}^{-1}\right)\end{array}$ & $\begin{array}{c}\sigma_{v} \\
\left(\mathrm{~km} \mathrm{~s}^{-1}\right) \\
(6)\end{array}$ & $\begin{array}{c}N \\
\text { bins } \\
(7)\end{array}$ & Side \\
\hline 8.00 & 0.22 & 28.9 & 0.8 & 90 & 7 & 18 & $\mathrm{r}$ \\
8.07 & 0.05 & 29.2 & 0.2 & 113 & 4 & 18 & $\mathrm{a}$ \\
8.37 & 0.15 & 30.2 & 0.5 & 115 & 5 & 18 & $\mathrm{a}$ \\
8.72 & 0.23 & 31.5 & 0.8 & 106 & 3 & 18 & $\mathrm{r}$ \\
9.03 & 0.25 & 32.6 & 0.9 & 121 & 6 & 18 & $\mathrm{a}$ \\
9.63 & 0.36 & 34.8 & 1.3 & 100 & 5 & 18 & $\mathrm{r}$ \\
10.46 & 0.92 & 37.8 & 3.3 & 131 & 7 & 17 & $\mathrm{a}$ \\
11.16 & 0.55 & 40.3 & 2.0 & 130 & 9 & 14 & $\mathrm{r}$ \\
\hline
\end{tabular}

Notes. (1), (3) Galactic radius. (2), (4) Dispersion around the galactic radius. (5) Rotation velocity. (6) Dispersion on the rotation velocity. (7) Number of velocity bins. (8) Receding $-\mathrm{r}-$ or approaching $-\mathrm{a}-$ side. 
Table C.16. HCG 7a rotation curve.

\begin{tabular}{|c|c|c|c|c|c|c|c|}
\hline $\begin{array}{c}r \\
(\mathrm{kpc}) \\
(1)\end{array}$ & $\begin{array}{c}\sigma_{r} \\
(\mathrm{kpc}) \\
(2)\end{array}$ & $\begin{array}{c}r \\
\left({ }^{\prime \prime}\right) \\
(3)\end{array}$ & $\begin{array}{l}\sigma_{r} \\
\left({ }^{\prime \prime}\right) \\
(4)\end{array}$ & $\begin{array}{c}v \\
\left(\mathrm{~km} \mathrm{~s}^{-1}\right) \\
(5)\end{array}$ & $\begin{array}{c}\sigma_{v} \\
\left(\mathrm{~km} \mathrm{~s}^{-1}\right) \\
(6)\end{array}$ & $\begin{array}{c}N \\
\text { bins } \\
(7)\end{array}$ & $\begin{array}{l}\text { Side } \\
(8)\end{array}$ \\
\hline 0.00 & 0.00 & 0.0 & 0.0 & -12 & 53 & 1 & $\mathrm{a}$ \\
\hline 0.29 & 0.04 & 1.1 & 0.1 & 115 & 5 & 3 & $\mathrm{a}$ \\
\hline 0.30 & 0.03 & 1.1 & 0.1 & 161 & 14 & 4 & $\mathrm{r}$ \\
\hline 0.42 & 0.05 & 1.6 & 0.2 & 191 & 17 & 5 & $\mathrm{r}$ \\
\hline 0.44 & 0.04 & 1.6 & 0.1 & 159 & 6 & 4 & $\mathrm{a}$ \\
\hline 0.58 & 0.05 & 2.2 & 0.2 & 249 & 14 & 10 & $\mathrm{r}$ \\
\hline 0.58 & 0.05 & 2.2 & 0.2 & 203 & 5 & 10 & $\mathrm{a}$ \\
\hline 0.76 & 0.05 & 2.8 & 0.2 & 245 & 9 & 9 & $\mathrm{r}$ \\
\hline 0.77 & 0.05 & 2.9 & 0.2 & 255 & 4 & 14 & $\mathrm{a}$ \\
\hline 0.94 & 0.04 & 3.5 & 0.2 & 262 & 14 & 3 & $\mathrm{r}$ \\
\hline 0.94 & 0.05 & 3.5 & 0.2 & 288 & 2 & 6 & $\mathrm{a}$ \\
\hline 1.01 & 0.00 & 3.8 & 0.0 & 222 & 53 & 1 & $r$ \\
\hline 1.05 & 0.03 & 3.9 & 0.1 & 305 & 8 & 6 & $\mathrm{a}$ \\
\hline 1.22 & 0.02 & 4.5 & 0.1 & 291 & 13 & 2 & $\mathrm{a}$ \\
\hline 1.24 & 0.00 & 4.6 & 0.0 & 282 & 53 & 1 & $\mathrm{r}$ \\
\hline 1.41 & 0.04 & 5.2 & 0.1 & 260 & 7 & 3 & $\mathrm{a}$ \\
\hline 1.47 & 0.05 & 5.4 & 0.2 & 244 & 37 & 3 & $r$ \\
\hline 1.59 & 0.04 & 5.9 & 0.2 & 238 & 29 & 4 & $\mathrm{a}$ \\
\hline 1.72 & 0.04 & 6.4 & 0.1 & 285 & 7 & 2 & $\mathrm{a}$ \\
\hline 1.83 & 0.01 & 6.8 & 0.0 & 233 & 17 & 3 & $\mathrm{r}$ \\
\hline 1.91 & 0.04 & 7.1 & 0.2 & 178 & 11 & 3 & $\mathrm{r}$ \\
\hline 1.92 & 0.03 & 7.1 & 0.1 & 227 & 12 & 3 & $\mathrm{a}$ \\
\hline 2.07 & 0.02 & 7.7 & 0.1 & 254 & 53 & 2 & $\mathrm{a}$ \\
\hline 2.16 & 0.02 & 8.0 & 0.1 & 195 & 0 & 2 & $\mathrm{r}$ \\
\hline 2.25 & 0.02 & 8.3 & 0.1 & 229 & 17 & 3 & $\mathrm{r}$ \\
\hline 2.28 & 0.03 & 8.4 & 0.1 & 210 & 5 & 2 & $\mathrm{a}$ \\
\hline 2.41 & 0.02 & 8.9 & 0.1 & 234 & 23 & 4 & $\mathrm{r}$ \\
\hline 2.45 & 0.03 & 9.1 & 0.1 & 162 & 2 & 2 & $\mathrm{a}$ \\
\hline 2.61 & 0.03 & 9.7 & 0.1 & 214 & 12 & 6 & $\mathrm{r}$ \\
\hline 2.63 & 0.01 & 9.7 & 0.1 & 177 & 10 & 4 & $\mathrm{a}$ \\
\hline 2.76 & 0.03 & 10.2 & 0.1 & 192 & 10 & 3 & $\mathrm{a}$ \\
\hline 2.82 & 0.00 & 10.4 & 0.0 & 196 & 53 & 1 & $r$ \\
\hline 2.92 & 0.03 & 10.8 & 0.1 & 236 & 24 & 3 & $\mathrm{r}$ \\
\hline 2.94 & 0.05 & 10.9 & 0.2 & 177 & 20 & 5 & $\mathrm{a}$ \\
\hline 3.15 & 0.05 & 11.7 & 0.2 & 186 & 6 & 8 & $\mathrm{a}$ \\
\hline 3.17 & 0.02 & 11.7 & 0.1 & 178 & 12 & 3 & $\mathrm{r}$ \\
\hline 3.31 & 0.13 & 12.3 & 0.5 & 191 & 3 & 22 & $\mathrm{a}$ \\
\hline 3.52 & 0.27 & 13.0 & 1.0 & 197 & 6 & 22 & $\mathrm{r}$ \\
\hline 3.83 & 0.18 & 14.2 & 0.7 & 198 & 6 & 22 & $\mathrm{a}$ \\
\hline 4.35 & 0.20 & 16.1 & 0.7 & 216 & 7 & 22 & $\mathrm{r}$ \\
\hline 4.36 & 0.14 & 16.1 & 0.5 & 202 & 5 & 22 & $\mathrm{a}$ \\
\hline 4.78 & 0.13 & 17.7 & 0.5 & 215 & 4 & 22 & a \\
\hline 4.91 & 0.12 & 18.2 & 0.4 & 204 & 4 & 22 & $\mathrm{r}$ \\
\hline 5.13 & 0.08 & 19.0 & 0.3 & 223 & 5 & 22 & $\mathrm{a}$ \\
\hline 5.19 & 0.06 & 19.2 & 0.2 & 202 & 4 & 22 & $\mathrm{r}$ \\
\hline 5.36 & 0.06 & 19.8 & 0.2 & 217 & 6 & 22 & $\mathrm{a}$ \\
\hline 5.41 & 0.07 & 20.0 & 0.2 & 203 & 4 & 22 & $\mathrm{r}$ \\
\hline 5.59 & 0.06 & 20.7 & 0.2 & 229 & 3 & 22 & $\mathrm{a}$ \\
\hline 5.60 & 0.05 & 20.7 & 0.2 & 215 & 6 & 22 & $\mathrm{r}$ \\
\hline 5.79 & 0.06 & 21.4 & 0.2 & 206 & 3 & 22 & $\mathrm{r}$ \\
\hline 5.81 & 0.07 & 21.5 & 0.2 & 223 & 5 & 22 & $\mathrm{a}$ \\
\hline 5.96 & 0.05 & 22.1 & 0.2 & 208 & 3 & 22 & $\mathrm{r}$ \\
\hline 6.03 & 0.07 & 22.3 & 0.3 & 221 & 4 & 22 & $\mathrm{a}$ \\
\hline 6.14 & 0.05 & 22.8 & 0.2 & 219 & 5 & 22 & $\mathrm{r}$ \\
\hline 6.26 & 0.07 & 23.2 & 0.3 & 229 & 5 & 22 & $\mathrm{a}$ \\
\hline 6.38 & 0.07 & 23.6 & 0.2 & 218 & 4 & 22 & $\mathrm{r}$ \\
\hline 6.47 & 0.06 & 24.0 & 0.2 & 230 & 6 & 22 & $\mathrm{a}$ \\
\hline 6.61 & 0.08 & 24.5 & 0.3 & 229 & 5 & 22 & $\mathrm{r}$ \\
\hline
\end{tabular}


Table C.16. continued.

\begin{tabular}{cccccccc}
\hline \hline $\begin{array}{c}r \\
(\mathrm{kpc})\end{array}$ & $\begin{array}{c}\sigma_{r} \\
(\mathrm{kpc})\end{array}$ & $\begin{array}{c}r \\
\left({ }^{\prime \prime}\right)\end{array}$ & $\begin{array}{c}\sigma_{r} \\
\left({ }^{\prime \prime}\right)\end{array}$ & $\begin{array}{c}v \\
\left(\mathrm{~km} \mathrm{~s}^{-1}\right)\end{array}$ & $\begin{array}{c}\sigma_{v} \\
\left(\mathrm{~km} \mathrm{~s}^{-1}\right) \\
(6)\end{array}$ & $\begin{array}{c}N \\
\text { bins } \\
(7)\end{array}$ & Side \\
\hline 6.66 & $(2)$ & $(3)$ & $(4)$ & $(5)$ & 4 & 22 & $\mathrm{a}$ \\
6.83 & 0.05 & 24.6 & 0.2 & 229 & 4 & 22 & $\mathrm{a}$ \\
6.94 & 0.12 & 25.3 & 0.2 & 227 & 4 & 22 & $\mathrm{r}$ \\
7.07 & 0.06 & 26.2 & 0.4 & 219 & 6 & 22 & $\mathrm{a}$ \\
7.27 & 0.08 & 26.9 & 0.3 & 223 & 4 & 22 & $\mathrm{r}$ \\
7.30 & 0.06 & 27.0 & 0.2 & 236 & 7 & 22 & $\mathrm{a}$ \\
7.53 & 0.08 & 27.9 & 0.3 & 233 & 5 & 22 & $\mathrm{r}$ \\
7.54 & 0.08 & 27.9 & 0.3 & 236 & 6 & 22 & $\mathrm{a}$ \\
7.79 & 0.07 & 28.9 & 0.3 & 240 & 6 & 22 & $\mathrm{a}$ \\
7.87 & 0.11 & 29.1 & 0.4 & 246 & 4 & 22 & $\mathrm{r}$ \\
8.07 & 0.10 & 29.9 & 0.4 & 236 & 8 & 22 & $\mathrm{a}$ \\
8.35 & 0.15 & 30.9 & 0.5 & 247 & 5 & 22 & $\mathrm{r}$ \\
8.49 & 0.13 & 31.4 & 0.5 & 236 & 9 & 22 & $\mathrm{a}$ \\
8.94 & 0.20 & 33.1 & 0.7 & 236 & 8 & 22 & $\mathrm{r}$ \\
8.97 & 0.17 & 33.2 & 0.6 & 219 & 7 & 22 & $\mathrm{a}$ \\
9.74 & 0.25 & 36.1 & 0.9 & 251 & 7 & 22 & $\mathrm{r}$ \\
9.88 & 0.44 & 36.6 & 1.6 & 237 & 8 & 22 & $\mathrm{a}$ \\
10.50 & 0.19 & 38.9 & 0.7 & 205 & 7 & 22 & $\mathrm{r}$ \\
11.24 & 0.26 & 41.6 & 1.0 & 203 & 11 & 22 & $\mathrm{r}$ \\
12.04 & 1.01 & 44.6 & 3.7 & 202 & 14 & 13 & $\mathrm{a}$ \\
12.70 & 1.39 & 47.0 & 5.2 & 237 & 12 & 22 & $\mathrm{r}$ \\
\hline
\end{tabular}

Notes. (1), (3) Galactic radius. (2), (4) Dispersion around the galactic radius. (5) Rotation velocity. (6) Dispersion on the rotation velocity. (7) Number of velocity bins. (8) Receding $-\mathrm{r}-$ or approaching $-\mathrm{a}-$ side. 
Table C.17. HCG 68c rotation curve.

\begin{tabular}{|c|c|c|c|c|c|c|c|}
\hline $\begin{array}{c}r \\
(\mathrm{kpc}) \\
(1)\end{array}$ & $\begin{array}{c}\sigma_{r} \\
(\mathrm{kpc}) \\
(2)\end{array}$ & $\begin{array}{c}r \\
\left({ }^{\prime \prime}\right) \\
(3)\end{array}$ & $\begin{array}{l}\sigma_{r} \\
\left({ }^{\prime \prime}\right) \\
(4)\end{array}$ & $\begin{array}{c}v \\
\left(\mathrm{~km} \mathrm{~s}^{-1}\right) \\
(5)\end{array}$ & $\begin{array}{c}\sigma_{v} \\
\left(\mathrm{~km} \mathrm{~s}^{-1}\right) \\
(6)\end{array}$ & $\begin{array}{c}N \\
\text { bins } \\
(7)\end{array}$ & $\begin{array}{l}\text { Side } \\
\text { (8) }\end{array}$ \\
\hline 0.90 & 0.00 & 5.5 & 0.0 & 235 & 20 & 1 & $a$ \\
\hline 1.28 & 0.00 & 7.8 & 0.0 & 156 & 20 & 1 & $\mathrm{a}$ \\
\hline 1.57 & 0.00 & 9.5 & 0.0 & 192 & 2 & 2 & $\mathrm{r}$ \\
\hline 1.58 & 0.00 & 9.6 & 0.0 & 215 & 20 & 1 & $\mathrm{a}$ \\
\hline 1.68 & 0.00 & 10.2 & 0.0 & 162 & 20 & 1 & $\mathrm{r}$ \\
\hline 1.77 & 0.02 & 10.7 & 0.1 & 203 & 11 & 2 & $\mathrm{r}$ \\
\hline 1.97 & 0.00 & 12.0 & 0.0 & 206 & 19 & 2 & $\mathrm{a}$ \\
\hline 2.08 & 0.01 & 12.6 & 0.1 & 223 & 20 & 3 & $\mathrm{r}$ \\
\hline 2.17 & 0.04 & 13.2 & 0.2 & 234 & 6 & 2 & $\mathrm{a}$ \\
\hline 2.19 & 0.00 & 13.3 & 0.0 & 274 & 20 & 1 & $\mathrm{r}$ \\
\hline 2.26 & 0.03 & 13.7 & 0.2 & 190 & 4 & 4 & $\mathrm{r}$ \\
\hline 2.28 & 0.00 & 13.8 & 0.0 & 191 & 20 & 1 & $\mathrm{a}$ \\
\hline 2.40 & 0.00 & 14.6 & 0.0 & 207 & 13 & 2 & $\mathrm{r}$ \\
\hline 2.41 & 0.04 & 14.6 & 0.3 & 193 & 19 & 2 & $\mathrm{a}$ \\
\hline 2.50 & 0.02 & 15.2 & 0.1 & 218 & 11 & 4 & $\mathrm{r}$ \\
\hline 2.54 & 0.02 & 15.4 & 0.1 & 249 & 4 & 2 & $\mathrm{a}$ \\
\hline 2.69 & 0.06 & 16.3 & 0.4 & 222 & 5 & 19 & $\mathrm{r}$ \\
\hline 2.87 & 0.06 & 17.4 & 0.4 & 223 & 3 & 19 & $\mathrm{r}$ \\
\hline 2.93 & 0.15 & 17.8 & 0.9 & 210 & 7 & 19 & $\mathrm{a}$ \\
\hline 3.04 & 0.04 & 18.5 & 0.3 & 217 & 4 & 19 & $\mathrm{r}$ \\
\hline 3.22 & 0.06 & 19.6 & 0.3 & 216 & 6 & 19 & $\mathrm{a}$ \\
\hline 3.23 & 0.05 & 19.6 & 0.3 & 223 & 3 & 19 & $\mathrm{r}$ \\
\hline 3.36 & 0.03 & 20.4 & 0.2 & 213 & 5 & 19 & $\mathrm{a}$ \\
\hline 3.39 & 0.04 & 20.6 & 0.2 & 222 & 4 & 19 & $\mathrm{r}$ \\
\hline 3.48 & 0.04 & 21.1 & 0.2 & 207 & 4 & 19 & $\mathrm{a}$ \\
\hline 3.52 & 0.03 & 21.4 & 0.2 & 224 & 4 & 19 & $\mathrm{r}$ \\
\hline 3.60 & 0.03 & 21.8 & 0.2 & 217 & 5 & 19 & $\mathrm{a}$ \\
\hline 3.64 & 0.03 & 22.1 & 0.2 & 234 & 3 & 19 & $\mathrm{r}$ \\
\hline 3.70 & 0.03 & 22.4 & 0.2 & 214 & 6 & 19 & $\mathrm{a}$ \\
\hline 3.74 & 0.03 & 22.7 & 0.2 & 226 & 5 & 19 & $\mathrm{r}$ \\
\hline 3.80 & 0.02 & 23.1 & 0.1 & 217 & 3 & 19 & $\mathrm{a}$ \\
\hline 3.85 & 0.03 & 23.3 & 0.2 & 225 & 4 & 19 & $\mathrm{r}$ \\
\hline 3.88 & 0.03 & 23.5 & 0.2 & 215 & 5 & 19 & $\mathrm{a}$ \\
\hline 3.96 & 0.03 & 24.0 & 0.2 & 223 & 4 & 19 & $\mathrm{r}$ \\
\hline 3.98 & 0.03 & 24.2 & 0.2 & 211 & 5 & 19 & $\mathrm{a}$ \\
\hline 4.06 & 0.03 & 24.7 & 0.2 & 233 & 5 & 19 & $\mathrm{r}$ \\
\hline 4.10 & 0.04 & 24.9 & 0.2 & 214 & 4 & 19 & $\mathrm{a}$ \\
\hline 4.17 & 0.03 & 25.3 & 0.2 & 225 & 4 & 19 & $\mathrm{r}$ \\
\hline 4.19 & 0.03 & 25.4 & 0.2 & 216 & 5 & 19 & $\mathrm{a}$ \\
\hline 4.26 & 0.02 & 25.8 & 0.1 & 229 & 5 & 19 & $\mathrm{r}$ \\
\hline 4.27 & 0.02 & 25.9 & 0.1 & 214 & 5 & 19 & $\mathrm{a}$ \\
\hline 4.35 & 0.02 & 26.4 & 0.2 & 220 & 4 & 19 & $\mathrm{a}$ \\
\hline 4.37 & 0.04 & 26.5 & 0.3 & 224 & 2 & 19 & $\mathrm{r}$ \\
\hline 4.42 & 0.02 & 26.8 & 0.1 & 220 & 4 & 19 & $\mathrm{a}$ \\
\hline 4.48 & 0.02 & 27.2 & 0.1 & 217 & 3 & 19 & $\mathrm{a}$ \\
\hline 4.51 & 0.03 & 27.4 & 0.2 & 231 & 4 & 19 & $\mathrm{r}$ \\
\hline 4.55 & 0.01 & 27.6 & 0.1 & 222 & 2 & 19 & $\mathrm{a}$ \\
\hline 4.60 & 0.03 & 27.9 & 0.2 & 229 & 3 & 19 & $\mathrm{r}$ \\
\hline 4.61 & 0.02 & 27.9 & 0.1 & 219 & 3 & 19 & $\mathrm{a}$ \\
\hline 4.69 & 0.02 & 28.4 & 0.1 & 224 & 4 & 19 & $\mathrm{r}$ \\
\hline 4.69 & 0.02 & 28.5 & 0.1 & 219 & 4 & 19 & $\mathrm{a}$ \\
\hline 4.75 & 0.02 & 28.8 & 0.1 & 225 & 4 & 19 & $\mathrm{r}$ \\
\hline 4.76 & 0.02 & 28.9 & 0.1 & 223 & 3 & 19 & $\mathrm{a}$ \\
\hline 4.83 & 0.03 & 29.3 & 0.2 & 215 & 4 & 19 & $\mathrm{a}$ \\
\hline 4.85 & 0.03 & 29.4 & 0.2 & 222 & 3 & 19 & $\mathrm{r}$ \\
\hline 4.89 & 0.02 & 29.7 & 0.1 & 223 & 4 & 19 & $\mathrm{a}$ \\
\hline 4.94 & 0.04 & 30.0 & 0.2 & 221 & 4 & 19 & $\mathrm{r}$ \\
\hline 4.95 & 0.02 & 30.0 & 0.1 & 228 & 3 & 19 & $\mathrm{a}$ \\
\hline
\end{tabular}


Table C.17. continued.

\begin{tabular}{|c|c|c|c|c|c|c|c|}
\hline $\begin{array}{c}r \\
(\mathrm{kpc}) \\
(1)\end{array}$ & $\begin{array}{c}\sigma_{r} \\
(\mathrm{kpc}) \\
(2)\end{array}$ & $\begin{array}{c}r \\
\left({ }^{\prime \prime}\right) \\
(3)\end{array}$ & $\begin{array}{l}\sigma_{r} \\
\left({ }^{\prime \prime}\right) \\
(4)\end{array}$ & $\begin{array}{c}v \\
\left(\mathrm{~km} \mathrm{~s}^{-1}\right) \\
(5)\end{array}$ & $\begin{array}{c}\sigma_{v} \\
\left(\mathrm{~km} \mathrm{~s}^{-1}\right) \\
(6)\end{array}$ & $\begin{array}{c}N \\
\text { bins } \\
(7)\end{array}$ & $\begin{array}{r}\text { Side } \\
(8)\end{array}$ \\
\hline 5.02 & 0.02 & 30.5 & 0.1 & 230 & 4 & 19 & $\mathrm{r}$ \\
\hline 5.02 & 0.02 & 30.5 & 0.1 & 211 & 2 & 19 & $\mathrm{a}$ \\
\hline 5.08 & 0.02 & 30.8 & 0.1 & 223 & 3 & 19 & $\mathrm{a}$ \\
\hline 5.09 & 0.03 & 30.9 & 0.2 & 223 & 3 & 19 & $\mathrm{r}$ \\
\hline 5.16 & 0.02 & 31.3 & 0.1 & 218 & 3 & 19 & $\mathrm{a}$ \\
\hline 5.19 & 0.02 & 31.5 & 0.1 & 226 & 3 & 19 & $\mathrm{r}$ \\
\hline 5.23 & 0.02 & 31.7 & 0.1 & 218 & 3 & 19 & $\mathrm{a}$ \\
\hline 5.26 & 0.02 & 31.9 & 0.1 & 226 & 4 & 19 & $\mathrm{r}$ \\
\hline 5.30 & 0.02 & 32.2 & 0.1 & 221 & 2 & 19 & $\mathrm{a}$ \\
\hline 5.33 & 0.02 & 32.4 & 0.1 & 226 & 3 & 19 & $\mathrm{r}$ \\
\hline 5.36 & 0.02 & 32.5 & 0.1 & 225 & 2 & 19 & $\mathrm{a}$ \\
\hline 5.40 & 0.02 & 32.7 & 0.1 & 225 & 3 & 19 & $\mathrm{r}$ \\
\hline 5.43 & 0.03 & 32.9 & 0.2 & 228 & 3 & 19 & $\mathrm{a}$ \\
\hline 5.48 & 0.02 & 33.2 & 0.1 & 225 & 3 & 19 & $\mathrm{r}$ \\
\hline 5.49 & 0.01 & 33.3 & 0.1 & 223 & 2 & 19 & $\mathrm{a}$ \\
\hline 5.54 & 0.02 & 33.6 & 0.1 & 221 & 3 & 19 & $r$ \\
\hline 5.57 & 0.03 & 33.8 & 0.2 & 230 & 3 & 19 & $\mathrm{a}$ \\
\hline 5.61 & 0.02 & 34.0 & 0.1 & 222 & 3 & 19 & $\mathrm{r}$ \\
\hline 5.64 & 0.02 & 34.2 & 0.1 & 217 & 2 & 19 & $\mathrm{a}$ \\
\hline 5.68 & 0.02 & 34.4 & 0.1 & 219 & 2 & 19 & $\mathrm{r}$ \\
\hline 5.71 & 0.02 & 34.6 & 0.1 & 226 & 2 & 19 & $\mathrm{a}$ \\
\hline 5.74 & 0.02 & 34.8 & 0.1 & 218 & 2 & 19 & $\mathrm{r}$ \\
\hline 5.78 & 0.02 & 35.1 & 0.1 & 225 & 3 & 19 & $\mathrm{a}$ \\
\hline 5.80 & 0.02 & 35.2 & 0.1 & 223 & 3 & 19 & $\mathrm{r}$ \\
\hline 5.85 & 0.02 & 35.5 & 0.1 & 224 & 3 & 19 & $\mathrm{a}$ \\
\hline 5.85 & 0.02 & 35.5 & 0.1 & 224 & 3 & 19 & $\mathrm{r}$ \\
\hline 5.91 & 0.01 & 35.9 & 0.1 & 224 & 2 & 19 & $\mathrm{a}$ \\
\hline 5.92 & 0.01 & 35.9 & 0.1 & 219 & 2 & 19 & $\mathrm{r}$ \\
\hline 5.96 & 0.02 & 36.2 & 0.1 & 225 & 3 & 19 & $\mathrm{a}$ \\
\hline 5.99 & 0.02 & 36.3 & 0.1 & 223 & 1 & 19 & $\mathrm{r}$ \\
\hline 6.03 & 0.02 & 36.6 & 0.2 & 226 & 2 & 19 & $\mathrm{a}$ \\
\hline 6.05 & 0.02 & 36.7 & 0.1 & 217 & 2 & 19 & $\mathrm{r}$ \\
\hline 6.11 & 0.02 & 37.0 & 0.1 & 227 & 2 & 19 & $\mathrm{a}$ \\
\hline 6.11 & 0.02 & 37.1 & 0.1 & 219 & 3 & 19 & $r$ \\
\hline 6.18 & 0.02 & 37.5 & 0.1 & 233 & 3 & 19 & $\mathrm{a}$ \\
\hline 6.18 & 0.02 & 37.5 & 0.2 & 214 & 3 & 19 & $\mathrm{r}$ \\
\hline 6.24 & 0.01 & 37.8 & 0.1 & 220 & 3 & 19 & $\mathrm{r}$ \\
\hline 6.25 & 0.02 & 37.9 & 0.1 & 230 & 3 & 19 & $\mathrm{a}$ \\
\hline 6.30 & 0.02 & 38.2 & 0.1 & 218 & 2 & 19 & $\mathrm{r}$ \\
\hline 6.31 & 0.02 & 38.3 & 0.1 & 229 & 3 & 19 & $\mathrm{a}$ \\
\hline 6.37 & 0.02 & 38.6 & 0.1 & 218 & 3 & 19 & $\mathrm{r}$ \\
\hline 6.39 & 0.02 & 38.8 & 0.1 & 230 & 3 & 19 & $\mathrm{a}$ \\
\hline 6.44 & 0.02 & 39.0 & 0.1 & 223 & 4 & 19 & $\mathrm{r}$ \\
\hline 6.45 & 0.02 & 39.2 & 0.1 & 232 & 2 & 19 & $\mathrm{a}$ \\
\hline 6.51 & 0.02 & 39.5 & 0.1 & 225 & 3 & 19 & $\mathrm{r}$ \\
\hline 6.54 & 0.02 & 39.7 & 0.1 & 234 & 3 & 19 & $\mathrm{a}$ \\
\hline 6.59 & 0.02 & 40.0 & 0.1 & 227 & 3 & 19 & $\mathrm{r}$ \\
\hline 6.63 & 0.03 & 40.2 & 0.2 & 239 & 3 & 19 & $\mathrm{a}$ \\
\hline 6.68 & 0.03 & 40.5 & 0.2 & 231 & 3 & 19 & $\mathrm{r}$ \\
\hline 6.73 & 0.03 & 40.8 & 0.2 & 245 & 2 & 19 & $\mathrm{a}$ \\
\hline 6.78 & 0.04 & 41.1 & 0.2 & 234 & 6 & 19 & $\mathrm{r}$ \\
\hline 6.83 & 0.03 & 41.5 & 0.2 & 242 & 3 & 19 & $\mathrm{a}$ \\
\hline 6.89 & 0.02 & 41.8 & 0.1 & 224 & 4 & 19 & $\mathrm{r}$ \\
\hline 6.94 & 0.03 & 42.1 & 0.2 & 234 & 5 & 19 & $\mathrm{a}$ \\
\hline 6.97 & 0.03 & 42.3 & 0.2 & 230 & 4 & 19 & $\mathrm{r}$ \\
\hline 7.04 & 0.03 & 42.7 & 0.2 & 245 & 2 & 19 & a \\
\hline 7.09 & 0.04 & 43.0 & 0.3 & 225 & 5 & 19 & $\mathrm{r}$ \\
\hline 7.16 & 0.03 & 43.4 & 0.2 & 241 & 2 & 19 & $\mathrm{a}$ \\
\hline 7.19 & 0.02 & 43.6 & 0.1 & 230 & 5 & 19 & $\mathrm{r}$ \\
\hline
\end{tabular}


Table C.17. continued.

\begin{tabular}{|c|c|c|c|c|c|c|c|}
\hline $\begin{array}{c}r \\
(\mathrm{kpc}) \\
(1)\end{array}$ & $\begin{array}{c}\sigma_{r} \\
(\mathrm{kpc}) \\
(2)\end{array}$ & $\begin{array}{c}r \\
\left({ }^{\prime \prime}\right) \\
(3)\end{array}$ & $\begin{array}{l}\sigma_{r} \\
\left({ }^{\prime \prime}\right) \\
(4)\end{array}$ & $\begin{array}{c}v \\
\left(\mathrm{~km} \mathrm{~s}^{-1}\right) \\
(5)\end{array}$ & $\begin{array}{c}\sigma_{v} \\
\left(\mathrm{~km} \mathrm{~s}^{-1}\right) \\
(6)\end{array}$ & $\begin{array}{c}N \\
\text { bins } \\
(7)\end{array}$ & $\begin{array}{l}\text { Side } \\
\text { (8) }\end{array}$ \\
\hline 7.27 & 0.03 & 44.1 & 0.2 & 236 & 4 & 19 & $\mathrm{a}$ \\
\hline 7.28 & 0.03 & 44.2 & 0.2 & 229 & 3 & 19 & $\mathrm{r}$ \\
\hline 7.37 & 0.03 & 44.7 & 0.2 & 243 & 3 & 19 & $\mathrm{a}$ \\
\hline 7.38 & 0.03 & 44.8 & 0.2 & 217 & 3 & 19 & $\mathrm{r}$ \\
\hline 7.46 & 0.03 & 45.3 & 0.2 & 239 & 4 & 19 & $\mathrm{a}$ \\
\hline 7.47 & 0.02 & 45.3 & 0.1 & 226 & 3 & 19 & $\mathrm{r}$ \\
\hline 7.56 & 0.03 & 45.9 & 0.2 & 228 & 4 & 19 & $\mathrm{r}$ \\
\hline 7.57 & 0.03 & 45.9 & 0.2 & 241 & 4 & 19 & $\mathrm{a}$ \\
\hline 7.68 & 0.04 & 46.6 & 0.2 & 237 & 4 & 19 & $\mathrm{a}$ \\
\hline 7.68 & 0.04 & 46.6 & 0.3 & 223 & 3 & 19 & $\mathrm{r}$ \\
\hline 7.79 & 0.03 & 47.3 & 0.2 & 227 & 3 & 19 & $\mathrm{r}$ \\
\hline 7.80 & 0.03 & 47.3 & 0.2 & 231 & 4 & 19 & $\mathrm{a}$ \\
\hline 7.89 & 0.02 & 47.9 & 0.1 & 226 & 4 & 19 & $\mathrm{r}$ \\
\hline 7.89 & 0.03 & 47.9 & 0.2 & 230 & 3 & 19 & $\mathrm{a}$ \\
\hline 7.99 & 0.02 & 48.5 & 0.1 & 233 & 4 & 19 & $\mathrm{a}$ \\
\hline 7.99 & 0.04 & 48.5 & 0.3 & 225 & 3 & 19 & $\mathrm{r}$ \\
\hline 8.07 & 0.02 & 49.0 & 0.1 & 228 & 3 & 19 & $\mathrm{a}$ \\
\hline 8.13 & 0.04 & 49.3 & 0.2 & 233 & 3 & 19 & $\mathrm{r}$ \\
\hline 8.15 & 0.02 & 49.4 & 0.1 & 235 & 3 & 19 & $\mathrm{a}$ \\
\hline 8.22 & 0.02 & 49.9 & 0.1 & 227 & 5 & 19 & $\mathrm{a}$ \\
\hline 8.26 & 0.04 & 50.1 & 0.2 & 220 & 4 & 19 & $\mathrm{r}$ \\
\hline 8.30 & 0.03 & 50.4 & 0.2 & 229 & 2 & 19 & $\mathrm{a}$ \\
\hline 8.38 & 0.02 & 50.9 & 0.1 & 229 & 5 & 19 & $\mathrm{a}$ \\
\hline 8.38 & 0.04 & 50.9 & 0.2 & 220 & 4 & 19 & $\mathrm{r}$ \\
\hline 8.46 & 0.03 & 51.3 & 0.2 & 230 & 3 & 19 & $\mathrm{a}$ \\
\hline 8.52 & 0.03 & 51.7 & 0.2 & 227 & 3 & 19 & $\mathrm{r}$ \\
\hline 8.55 & 0.02 & 51.9 & 0.1 & 225 & 5 & 19 & $\mathrm{a}$ \\
\hline 8.62 & 0.02 & 52.3 & 0.1 & 235 & 3 & 19 & $\mathrm{a}$ \\
\hline 8.65 & 0.04 & 52.5 & 0.3 & 220 & 3 & 19 & $\mathrm{r}$ \\
\hline 8.71 & 0.02 & 52.8 & 0.2 & 234 & 4 & 19 & $\mathrm{a}$ \\
\hline 8.78 & 0.03 & 53.3 & 0.2 & 231 & 5 & 19 & $\mathrm{a}$ \\
\hline 8.84 & 0.06 & 53.6 & 0.4 & 226 & 2 & 19 & $\mathrm{r}$ \\
\hline 8.89 & 0.03 & 53.9 & 0.2 & 229 & 5 & 19 & $\mathrm{a}$ \\
\hline 8.99 & 0.03 & 54.5 & 0.2 & 224 & 4 & 19 & $r$ \\
\hline 9.00 & 0.03 & 54.6 & 0.2 & 238 & 5 & 19 & $\mathrm{a}$ \\
\hline 9.10 & 0.03 & 55.2 & 0.2 & 231 & 5 & 19 & $\mathrm{a}$ \\
\hline 9.18 & 0.06 & 55.7 & 0.4 & 226 & 5 & 19 & $\mathrm{r}$ \\
\hline 9.21 & 0.03 & 55.8 & 0.2 & 244 & 5 & 19 & $\mathrm{a}$ \\
\hline 9.28 & 0.02 & 56.3 & 0.1 & 229 & 7 & 19 & $\mathrm{a}$ \\
\hline 9.39 & 0.07 & 56.9 & 0.4 & 227 & 3 & 19 & $\mathrm{r}$ \\
\hline 9.39 & 0.04 & 57.0 & 0.2 & 234 & 6 & 19 & $\mathrm{a}$ \\
\hline 9.52 & 0.04 & 57.7 & 0.2 & 243 & 3 & 19 & $\mathrm{a}$ \\
\hline 9.60 & 0.07 & 58.2 & 0.4 & 230 & 4 & 19 & $\mathrm{r}$ \\
\hline 9.64 & 0.03 & 58.5 & 0.2 & 241 & 5 & 19 & $\mathrm{a}$ \\
\hline 9.78 & 0.04 & 59.4 & 0.2 & 244 & 3 & 19 & $\mathrm{a}$ \\
\hline 9.82 & 0.09 & 59.5 & 0.5 & 229 & 7 & 19 & $\mathrm{r}$ \\
\hline 10.01 & 0.09 & 60.7 & 0.5 & 245 & 2 & 19 & $\mathrm{a}$ \\
\hline 10.09 & 0.07 & 61.2 & 0.4 & 233 & 4 & 19 & $\mathrm{r}$ \\
\hline 10.28 & 0.07 & 62.3 & 0.5 & 249 & 4 & 19 & $\mathrm{a}$ \\
\hline 10.28 & 0.05 & 62.4 & 0.3 & 241 & 4 & 19 & $\mathrm{r}$ \\
\hline 10.49 & 0.08 & 63.6 & 0.5 & 234 & 4 & 19 & $\mathrm{r}$ \\
\hline 10.56 & 0.07 & 64.1 & 0.4 & 238 & 4 & 19 & $\mathrm{a}$ \\
\hline 10.76 & 0.04 & 65.3 & 0.3 & 225 & 5 & 19 & $\mathrm{a}$ \\
\hline 10.79 & 0.10 & 65.5 & 0.6 & 242 & 3 & 19 & $\mathrm{r}$ \\
\hline 10.96 & 0.05 & 66.5 & 0.3 & 234 & 4 & 19 & $\mathrm{a}$ \\
\hline 11.16 & 0.08 & 67.7 & 0.5 & 236 & 5 & 19 & $\mathrm{r}$ \\
\hline 11.17 & 0.08 & 67.8 & 0.5 & 241 & 5 & 19 & $\mathrm{a}$ \\
\hline 11.36 & 0.07 & 68.9 & 0.4 & 242 & 4 & 19 & $\mathrm{r}$ \\
\hline 11.47 & 0.10 & 69.6 & 0.6 & 221 & 4 & 19 & $\mathrm{a}$ \\
\hline
\end{tabular}


Table C.17. continued.

\begin{tabular}{|c|c|c|c|c|c|c|c|}
\hline $\begin{array}{c}r \\
(\mathrm{kpc}) \\
(1)\end{array}$ & $\begin{array}{c}\sigma_{r} \\
(\mathrm{kpc}) \\
(2)\end{array}$ & $\begin{array}{c}r \\
\left({ }^{\prime \prime}\right) \\
(3)\end{array}$ & $\begin{array}{l}\sigma_{r} \\
\left({ }^{\prime \prime}\right) \\
(4)\end{array}$ & $\begin{array}{c}v \\
\left(\mathrm{~km} \mathrm{~s}^{-1}\right) \\
(5)\end{array}$ & $\begin{array}{c}\sigma_{v} \\
\left(\mathrm{~km} \mathrm{~s}^{-1}\right) \\
(6)\end{array}$ & $\begin{array}{c}N \\
\text { bins } \\
(7)\end{array}$ & $\begin{array}{l}\text { Side } \\
(8)\end{array}$ \\
\hline 11.57 & 0.05 & 70.2 & 0.3 & 245 & 5 & 19 & $r$ \\
\hline 11.72 & 0.05 & 71.1 & 0.3 & 245 & 6 & 19 & $\mathrm{r}$ \\
\hline 11.81 & 0.09 & 71.6 & 0.5 & 226 & 5 & 19 & $\mathrm{a}$ \\
\hline 12.00 & 0.08 & 72.8 & 0.5 & 224 & 5 & 19 & $\mathrm{a}$ \\
\hline 12.01 & 0.14 & 72.8 & 0.9 & 233 & 6 & 19 & $\mathrm{r}$ \\
\hline 12.20 & 0.04 & 74.0 & 0.3 & 224 & 5 & 19 & $\mathrm{a}$ \\
\hline 12.32 & 0.04 & 74.7 & 0.2 & 225 & 5 & 19 & $\mathrm{a}$ \\
\hline 12.47 & 0.03 & 75.7 & 0.2 & 227 & 3 & 19 & $\mathrm{a}$ \\
\hline 12.52 & 0.11 & 76.0 & 0.6 & 239 & 6 & 19 & $\mathrm{r}$ \\
\hline 12.61 & 0.05 & 76.5 & 0.3 & 246 & 3 & 19 & $\mathrm{a}$ \\
\hline 12.78 & 0.04 & 77.5 & 0.2 & 237 & 3 & 19 & $\mathrm{a}$ \\
\hline 12.92 & 0.06 & 78.4 & 0.4 & 244 & 2 & 19 & $\mathrm{a}$ \\
\hline 13.02 & 0.17 & 79.0 & 1.0 & 242 & 6 & 19 & $\mathrm{r}$ \\
\hline 13.08 & 0.03 & 79.3 & 0.2 & 243 & 3 & 19 & $\mathrm{a}$ \\
\hline 13.21 & 0.06 & 80.2 & 0.4 & 239 & 3 & 19 & $\mathrm{a}$ \\
\hline 13.43 & 0.07 & 81.5 & 0.4 & 245 & 3 & 19 & $\mathrm{a}$ \\
\hline 13.66 & 0.09 & 82.9 & 0.5 & 250 & 2 & 19 & $\mathrm{a}$ \\
\hline 13.95 & 0.08 & 84.6 & 0.5 & 242 & 4 & 19 & $\mathrm{a}$ \\
\hline 13.99 & 0.38 & 84.9 & 2.3 & 228 & 7 & 19 & $\mathrm{r}$ \\
\hline 14.23 & 0.09 & 86.3 & 0.6 & 244 & 4 & 19 & $\mathrm{a}$ \\
\hline 14.58 & 0.11 & 88.5 & 0.7 & 249 & 5 & 19 & $\mathrm{a}$ \\
\hline 14.84 & 0.13 & 90.0 & 0.8 & 232 & 7 & 19 & $\mathrm{r}$ \\
\hline 15.05 & 0.14 & 91.3 & 0.8 & 237 & 5 & 19 & $\mathrm{a}$ \\
\hline 15.42 & 0.12 & 93.5 & 0.7 & 226 & 2 & 19 & $\mathrm{a}$ \\
\hline 15.59 & 0.18 & 94.6 & 1.1 & 241 & 6 & 19 & $\mathrm{r}$ \\
\hline 15.70 & 0.07 & 95.3 & 0.4 & 227 & 3 & 19 & $\mathrm{a}$ \\
\hline 16.01 & 0.09 & 97.2 & 0.5 & 245 & 3 & 19 & $\mathrm{a}$ \\
\hline 16.34 & 0.30 & 99.2 & 1.9 & 244 & 7 & 19 & $\mathrm{r}$ \\
\hline 16.45 & 0.21 & 99.8 & 1.3 & 246 & 4 & 19 & $\mathrm{a}$ \\
\hline 17.43 & 0.36 & 105.8 & 2.2 & 243 & 6 & 19 & $\mathrm{r}$ \\
\hline 17.47 & 0.29 & 106.0 & 1.7 & 249 & 4 & 19 & $\mathrm{a}$ \\
\hline 18.10 & 0.13 & 109.8 & 0.8 & 228 & 3 & 19 & $\mathrm{a}$ \\
\hline 18.44 & 0.08 & 111.9 & 0.5 & 229 & 3 & 19 & $\mathrm{a}$ \\
\hline 18.92 & 0.24 & 114.8 & 1.5 & 239 & 3 & 17 & $\mathrm{a}$ \\
\hline
\end{tabular}

Notes. (1), (3) Galactic radius. (2), (4) Dispersion around the galactic radius. (5) Rotation velocity. (6) Dispersion on the rotation velocity. (7) Number of velocity bins. (8) Receding $-\mathrm{r}$ - or approaching - a - side. 